ENERGY LABORATORY

IN ASSOCIATION WITH

HEAT TRANSFER LABORATORY, DEPARTMENT OF

MECHANICAL ENGINEERING
MASSACHUSETTS INSTITUTE OF TECHNOLOGY

\title{
ADVANCED DRY COOLING TOWER CONCEPT
}

by

John Curcio

Martin Giebler

Leon R. Glicksman

Warren M. Rohsenow

Sponsored by:

REACTOR RESEARCH AND DEVELOPMENT DIVISION

ENERGY RESEARCH AND DEVELOPMENT ADMINISTRATION
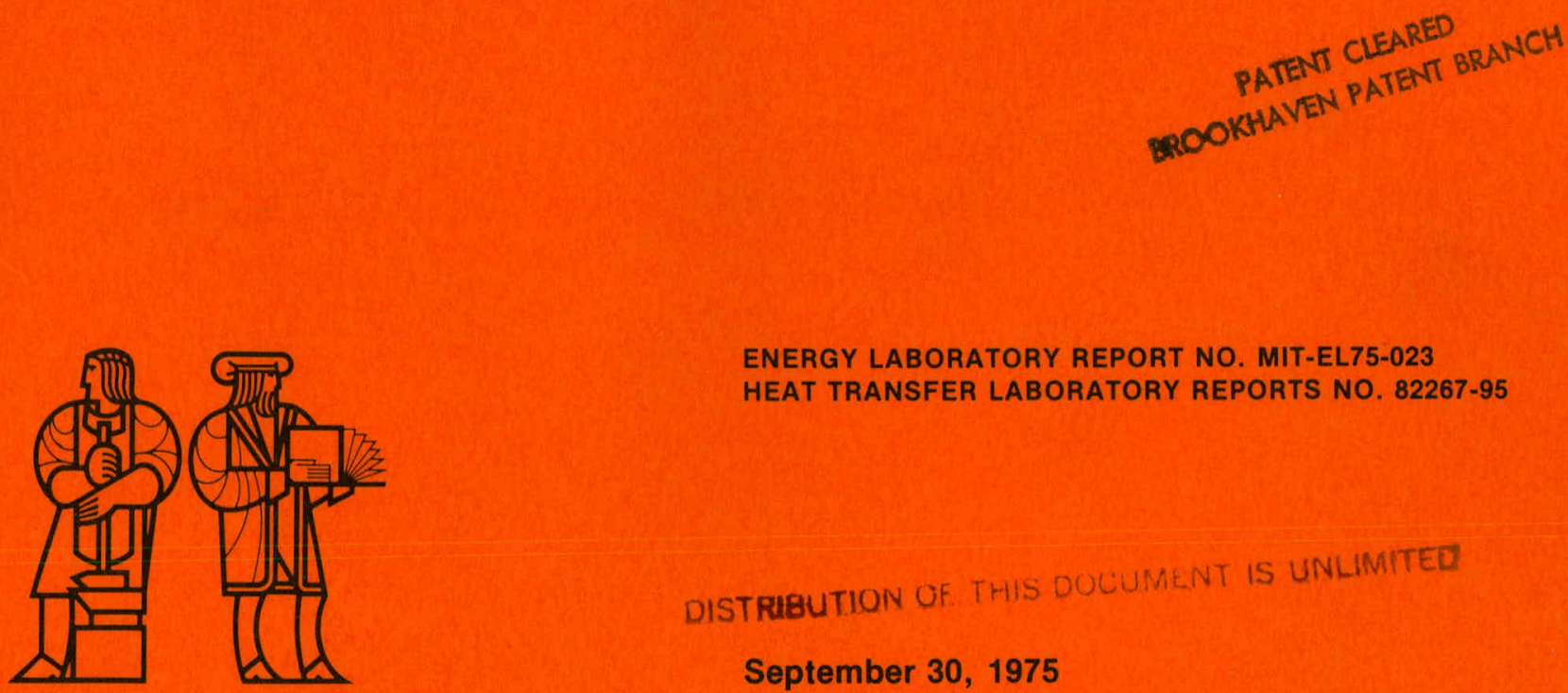

ENERGY LABORATORY REPORT NO. MIT-EL75-023

HEAT TRANSFER LABORATORY REPORTS NO. 82267-95

DISTRIEUTION OF. THIS DOCUMENT IS UNLIMITED

September 30,1975 


\section{DISCLAIMER}

This report was prepared as an account of work sponsored by an agency of the United States Government. Neither the United States Government nor any agency Thereof, nor any of their employees, makes any warranty, express or implied, or assumes any legal liability or responsibility for the accuracy, completeness, or usefulness of any information, apparatus, product, or process disclosed, or represents that its use would not infringe privately owned rights. Reference herein to any specific commercial product, process, or service by trade name, trademark, manufacturer, or otherwise does not necessarily constitute or imply its endorsement, recommendation, or favoring by the United States Government or any agency thereof. The views and opinions of authors expressed herein do not necessarily state or reflect those of the United States Government or any agency thereof. 


\section{DISCLAIMER}

Portions of this document may be illegible in electronic image products. Images are produced from the best available original document. 
Advanced Dry Cooling Tower Concept

\author{
by \\ John Curcio \\ Martin Giebler \\ Leon R. Glicksman \\ Warren M. Rohsenow
}

\begin{abstract}
Energy Laboratory
In Association With

Heat Transfer Laboratory

Department of Mechanical Engineering

Massachusetts Institute of Technology
\end{abstract}

This report was prepared as an account of work
sponsored by the United States Govemment. Neither the

United States nor the United States Department of

Energy, nor any of their employees, nor any of their

contractors, subcontractors, or their employees, makes

any warranty, express or implied, or assumes any lega! liability or responsibility for the accuracy, completeness or usefulness of any information, apparatus, product or process disclosed, or represents that its use would no infringe privately owned rights.

\title{
Sponsored by:
}

Reactor Research and Development Division Energy Research and Development Administration

September 30, 1975

ENERGY LABORATORY REPORT NO. MIT-EL75-023

HEAT TRANSFER LABORATORY REPORTS NO. 82267-95 
This report was prepared as an account of work sponsored by the United States Government. Neither the United States nor the United States Energy Research and Development Administration, nor any of their employees, nor any of their contractors, subcontractors, or their employees, makes any warranty, express or implied, or assumes any legal liability or responsibility for the accuracy, completeness or usefullness of any information, apparatus, product or process disclosed, or represents that its use would not infringe privately owned rights. 
ACKNOWLEDGEMENTS

The Reactor Research and Development Division of the Energy Research and Development Administration sponsored this study under ERDA Contract E(11-1)-2500. Their support is gratefully acknowledged. Special thanks are due to Mr. William F. Savage. His active interest and suggestions were a great benefit to the program. 


\begin{abstract}
The purpose of this year's work has been to develop a new dry cooling tower surface. The new surface utilizes a modification of film type packing in wet cooling towers. It is a concept which may eliminate excessive water loss. Cost of fabrication, and effectiveness of heat transfer surface were among the major design considerations.

Based on preliminary. water wetting investigations over simple geometric surfaces, a conductive plate was shaped to form a series of V-troughs. It provided open chennelled water flow separated by fin-1ike dry surfaces, and simultaneously self distributed random spraying water. The design not only channels the water flow, but also provides a convenient means to vary the air-water interfacial area to the water-plate and dry plate contact area. Varying these ratios will become necessary as optimization studies are completed.

To investigate the effectiveness of this design and of future advanced wet-dry concepts, a model heat transfer test apparatus was constructed. It provided operating conditions (water temperature, water flow rates and air flow rates) similar to those of existing wet cooling tower packing sections. All of the design requirements have been satisfied: hot water flow recirculation and counter flow air stream.

A computer simulation of the proposed surface was made. The simulation modeled heat and mass transfer from the air-water interface as well as heat transfer from the dry surface area. Initial parametric runs were made using the program. They indicate that when the ratio of wet surface area to total surface area is five percent, approximately seventy-five percent of the energy transfer takes place as sensible heat transfer; whereas, for a wet tower at similar conditions approximately eighty-five percent of the total energy transfer takes place by evaporation.
\end{abstract}


TABLE OF CONTENTS

\section{Title Page}

Abstract.................................... 1

Table of Contents............................. 3

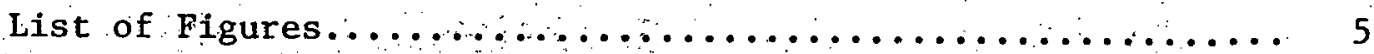

List of Tables........................... 7

List of Principal Symbols...................... 8

Chapter One: InTRoduction....................... 10

1.1 Introduction. ...................... 10

1.2 Scope of This Project.................... 13

Chapter Two: DESIGN OF A WATER DISTRIBUTION TEST APPARATUS.. 14

2.1 Design Consideration.................... 14

2.2. Method of Distribution................. 15

2.3 Design of the Distribution Pipe............. 20

2.4 Selection and Manufacture of the Spray Tube...... 22

2.5 Test Apparatus....................... 23

2.6 Distribution Pipe Calbiration.............. 23

Chapter Three: DESIGN OF A PACKIng TEST PLATE............ 28

3.1 Conceptual Design of the New Wet-Dry Plate....... 28

3.2 Discussion of Visual Observations............ 31

3.3 Geometric Constraints.................... 34

3.4 Summary of Flow Visualization Tests............ 43 
Chapter Four: DESIGN OF AN ADVANCED DRY MODEL TOWER:

HEAT TRANSFER TEST APPARATUS........... 46

4.1 Heat Transfer Test Requirements............. 46

4.2 Design Criteria for the Actual Scale Mode1...... 47

4.3 Model Tower in Operation................ 65

Chapter Five: COMPUTER PROGRAM....................... 69

5.1 Analysis................................ 69

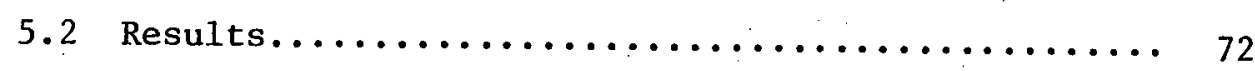

Chapter Six: RESULTS AND CONCLUSIONS.............. 82

6.1 Results........................... 82

6.2 Recommendations..................... 84

6.3 Conclusions.......................... 85

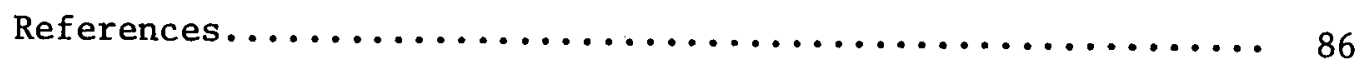

Appendix 1: DISTRIBUTION PIPE DESIGN ANALYSIS.......... 87

Appendix 2: PRESSURE DROP IN THE DISTRIBUTION PIPE....... 89

Appendix 3: FIN EFFICIENCY CALCULATION FOR V-TROUGH PLATES. 91

Appendix 4: CALCULATIONS OF THE TOTAL AIR PRESSURE DROP

THROUGH THE HEAT TRANSFER TEST APPARATUS..... 92

Appendix 5: PLUMBING SYSTEM COMPONENTS FOR THE

HEAT TRANSFER TEST APPARATUS.............. 102

Appendix 6: COMPUTER LISTING.................... 104 
LIST OF FIGURES

1. Conceptual Design of the New Wet-Dry Surface 12

2 Small Hole Spray on a Flat Plate 19

3 Water Flow from a Pipe with a Thin Slot 19

4 Idealization of the Water Spray Tube Configuration 21

5 Schematic of Flow Visualization Test Apparatus 24

6 Flow Visualization Test Apparatus 27

7 Water Channelling Concept $\quad 29$

8 Rivulet Water Flow on a Flat Smooth Plate 35

9 Complete Wetting on a Rough Flat Plate 35

10 Multiple V-Troughs 37

11. Cyclic Variation of V-Trough Flow (smooth surface) 37

12 Spaced Channels 39

13 Flow Diverters on a Spaced Channel Plate 39

14 Large Holes Used to Aid Channelled Flow 41

15 Flat Plate Inlet with Raised Flow Guides 41

16. Repeated Raised Flow Guides $\quad 42$

17 V-Troughs Test Plate Channelling Water Flow 45

18 Heat Transfer Test Apparatus Assembly 48

19 Water Collecting Box 50

20 V-Trough Packing Plate 52

21 Top View of V-Trough Packing Section 54 
22 Model of Packing Section as a Fin

23 Alternate Water Distribution Design

24 Water Distribution Pipes Seen from Below

25 Distribution Pipes and V-Trough Packing Section

26 Juxtaposition of Spráy Pipes, Frame, Spacers, and V-Troughs Plates

27 Air-Flow Pressure Drop Through the Model Tower 64

28 Heat Transfer Test Apparatus $\quad 67$

29 Heat Transfer Test Apparatus 68

30 Basic Equations $\quad 74$

31 Wet to Total Area vs. Various Parameters 77

32 Approximate Air Velocities vs. Various Parameters 78

33 Water Flow Rate vs. Various Parameters 79

34 Drain off Channe1 Configuration for 97

Pressure Drop Analysis

35 Partial End View of Pack Section 98

for Pressure Drop Analysis

36 Elbow Air Exhaust Duct Detail 100

37 Plumbing Schematic for the Heat Transfer 103

Test Apparatus 
LIST OF TABLES

TABLE

PAGE

1 Local Flow Rates Through Pipe

26

2 Nomenclature for Figure 30

75

3 Standard Inputs

76

4 Parametric Study of a Dry Cooling Tower

80

5 Parametric Study of a 5\% Wet Tower

80

6 Parametric Study of a Wet Tower

80

7 The Effect on Performance of Multiplying

81

the Heat Transfer Coefficient by Various

Parameters

8 The Effect of Different Step Sizes on Program Results 
LIST OF PRINCIPAL SYMBOLS

\begin{tabular}{|c|c|}
\hline A & area \\
\hline $\mathrm{C}_{\mathrm{c}}$ & contraction coefficient \\
\hline $\mathrm{C}_{\mathrm{c}}$ & loss coeffictent \\
\hline $\mathrm{C}_{\mathrm{v}}$ & veloctty coefficient \\
\hline $\operatorname{cfm}$ & cubic feet per min \\
\hline $\mathrm{D}$ & diameter \\
\hline $\mathrm{d}$ & diameter \\
\hline $\mathrm{f}$ & friction factor \\
\hline Ft., ft & feet \\
\hline $\mathrm{g}$ & acceleration of gravity \\
\hline gpm & gallons per min \\
\hline $\mathbf{H}$ & helght \\
\hline $\mathbf{h}$ & convective heat transfer coefficient \\
\hline $\mathrm{h}_{\mathrm{f}}$ & head loss due to friction \\
\hline hr & hour \\
\hline IN., in. & Inches \\
\hline $\mathrm{K}_{\mathrm{c}}$ & contraction coefficient \\
\hline k & thermal conductivity \\
\hline $\mathbf{L} \quad \cdots$ & length \\
\hline$\ell$ & length \\
\hline $1 \mathrm{bf}$ & pounds force \\
\hline $1 \mathrm{bm}$ & pounds mass \\
\hline m & defined by Appendix 3 \\
\hline $\mathrm{Nu}$ & Nusse1t Number \\
\hline
\end{tabular}




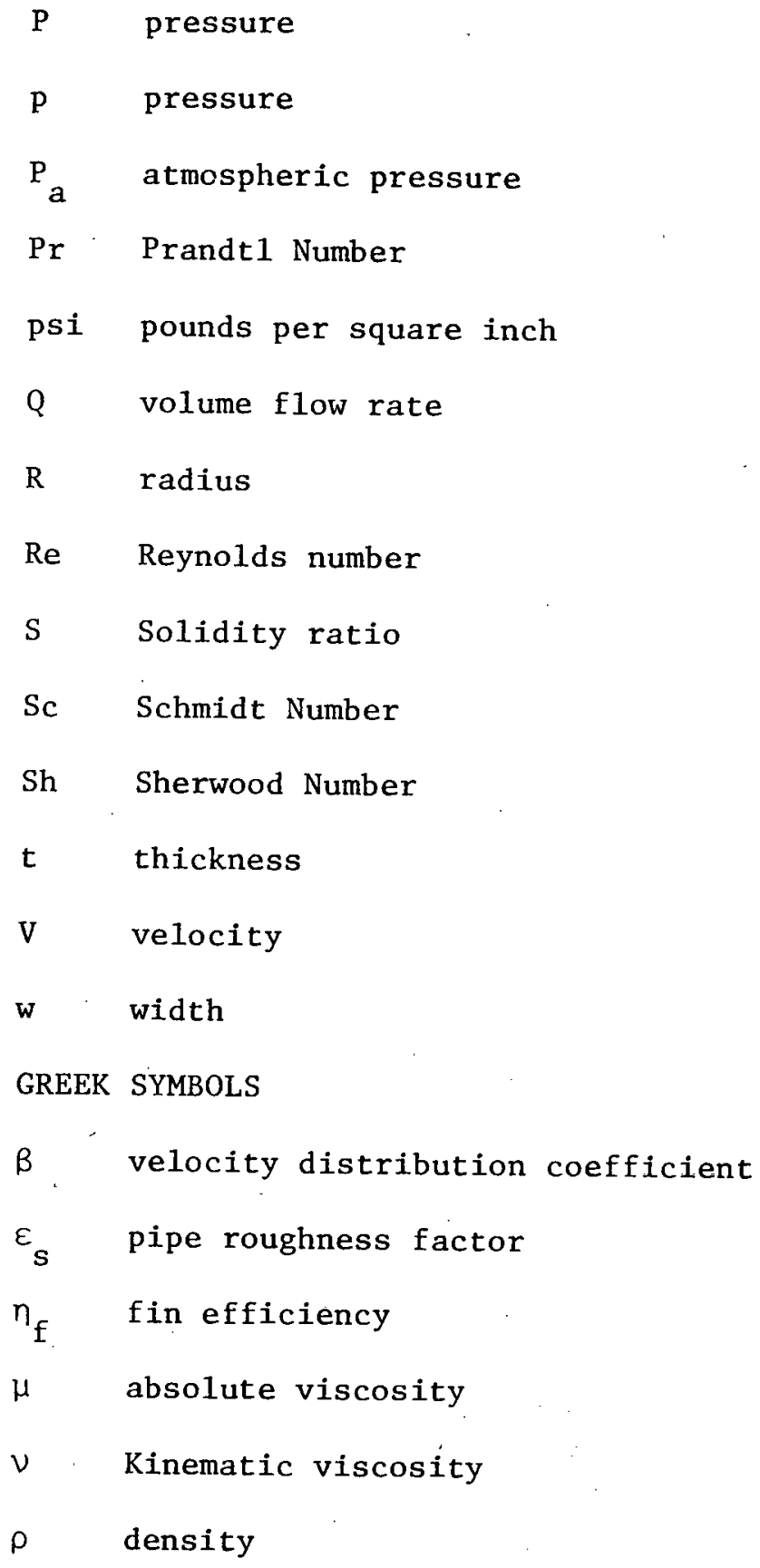


CHAPTER ONE

INTRODUCTION

\subsection{INTRODUCTION}

As the power industries' capacity expands the manner in which the waste heat is dissipated becomes increasingly important. The usual heat sinks are rivers, lakes; large bodies of water and cooling towers. A cooling tower transfers all of the waste heat to the atmosphere; the other sinks discharge the heat to neighboring water bodies. The addition of heat to natural bodies of water causes a rise in temperature. A sudden change in temperature may upset the ecological balance of the water body. Where the water body is too small to accomodate this change, or where no suitable water source is available, a cooling tower is necessary. Both wet and, on a very limited basis, dry cooling towers are presently utilized.

Dry cooling towers transfer heat from a closed system of recirculating water to air without evaporation. The thermal efficiency is dependent on the ambient dry bulb temperature. When the dry bulb temperature is high large conventional heat transfer surfaces are required to provide adequate cooling. The material and manufacturing expense of the fabrication in forming fin tubes or a similar heat transfer surface substantially raises the cost of a dry tower over a wet tower.

Wet towers transfer the heat to the atmosphere predominately by evaporation ( $85 \%$ evaporation, and $15 \%$ convection for typical operating conditions), require less space and are considerably lower in capital cost. However they exhaust moist air, which (depending on existing atmospheric conditions) may take the form of an undesirable fog plume, a 
visibility hazard to highways and airports. These fog plumes are eyesores and may induce precipitation downwind of the tower. The loss of cooling water is also a problem involved with using wet towers.

The purpose of the work for the period from September 1974 to September 1975 has been to develop a new dry heat transfer surface which is similar in design to wet tower packing; and to compare its effectiveness to existing wet and/or dry tower performance data. This entailed fabricating many sample plates and the construction of a model heat transfer test facility. The major design feature of the new dry surface was the use of low cost modifications of typical film type packing plates which have a reduced evaporative water consumption. The primary concern was to reduce water consumption by minimizing the air-water evaporative area while the manufacturing constraint of a closed conventional dry system is overcome; and, at the same time the capacity to function at elevated dry bulb temperatures is maintained.

The design concept is to use a metal plate which has concave channels in which the hot water flows. The rest of the plate is kept dry, and is heated by conduction from the water channels. The dry surface is cooled by convective heat transfer while evaporation takes place only at the exposed air-water interface (see Figure 1). 

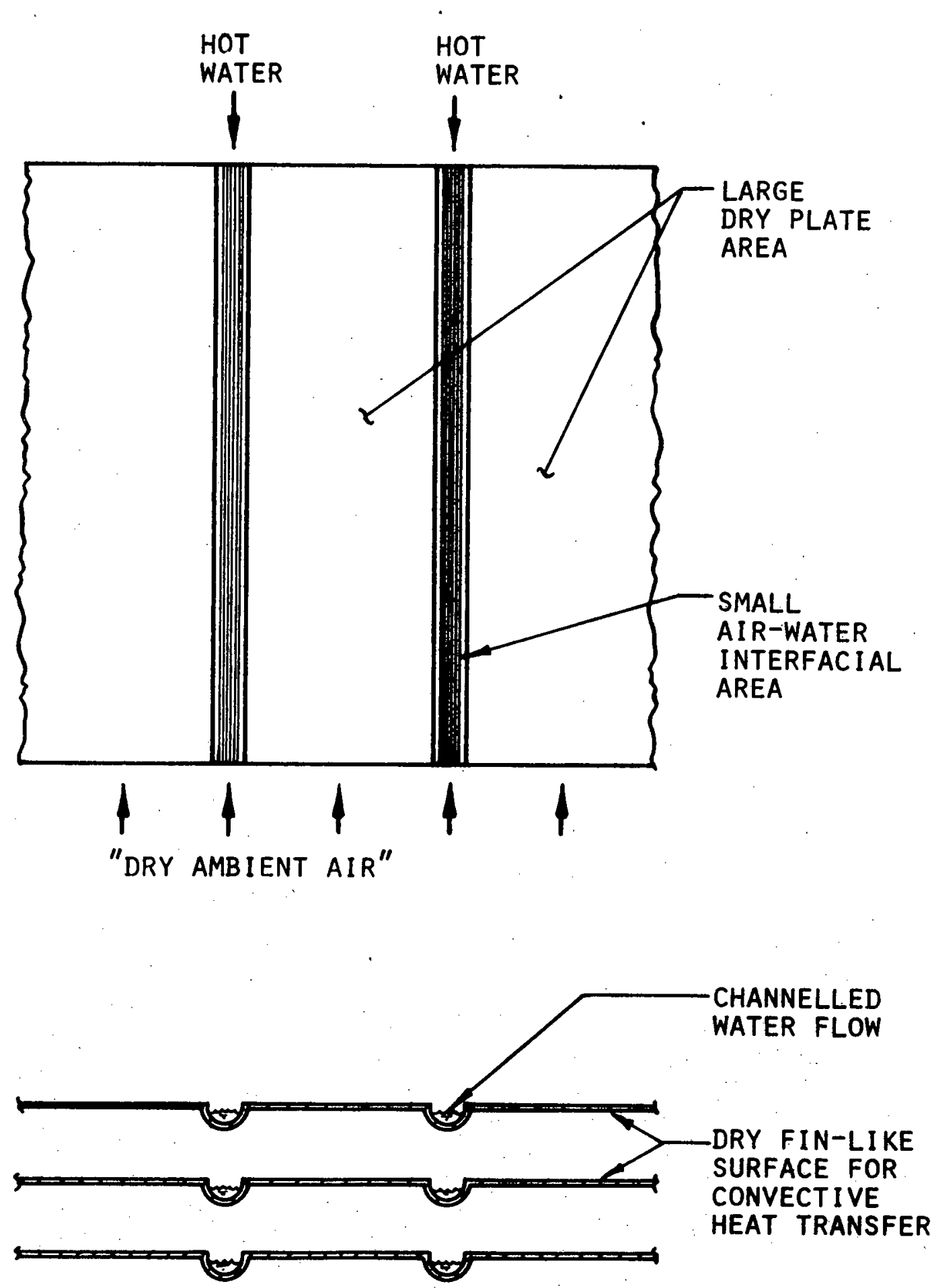

FIGURE 1. CONCEPTUAL DESIGN OF THE NEW WET-DRY SURFACE 


\subsection{SCOPE OF THIS PROJECT}

Film type packing in conventional wet towers is used to provide a surface over which the water will spread in thin film and stay in contact with the air stream long enough to effect evaporation. The primary goal of the first phase of this project was to find a method to shield some of the water from the air stream and in place of evaporation substitute convective heat transfer.

Eight sample packing sections which were based on the above design criteria were fabricated. Two model test apparatuses were constructed. The first was a water spray system. It provided uniform water distribution across the top of teach test plate. This allowed the observation of water wetting characteristics which were unique to individual plate designs.

Chaper 2 discusses the development of a water distrbution test apparatus to spread the water uniformly over any packing surface. Chapter 3 relates the results of various flow visualization tests on sample surfaces and the design of a modified film type packing surface to be tested in a heat transfer device. Chapter 4 shows the design and construction of a heat transfer test apparatus resembling a small scale cooling tower which is used to collect data on design concepts for modified film type packing surfaces. Chapter 5 described the computer simulation of the new concept and gives initial results of a parametric study using the simulation. Chapter 6 summarizes the progress made on the advanced wet-dry concept to date, and offers conclusions and projections based upon the past year's work. 
CHAPTER TWO

DESIGN OF A WATER DISTRIBUTION TEST APPARATUS

\subsection{DESIGN CONSIDERATION}

The development of the wet-dry concept stems from the need to overcome the problems of cost with the dry towers and maintenance of . a high dry surface to wetted surface area ratio. This was accomplished by modifying a film type plate in a manner that prevents water from wetting some of the surface which is in contact with the air stream. Intentionally some of the water sprayed surface is kept dry. Keeping the surface partially dry depends on the surface characteristics of each plate, and on the ability of the plate design to confine the random spray to desired channels. The modified film type plate must direct the spraying water to designated channelled areas and maintain this flow pattern for the entire length of the packing section when placed in a conventional wet tower environment. To determine whether or not such a design was practical, water flow patterns were observed for nominal flow rates on discrete and combined configurations of flat, convex, and concave plate designs with adverse operating conditions simulated by roughening the surface.

Visually examining predominant water wetting characteristics on a test section requires an adequate method of evenly distributing the water to the top of each plate. To design a practical device which could be easily fabricated the existing cooling tower specifications 
were compared with the following requirements for a test system apparatus:

1. Distribution of an even sheet of water across the top of each plate

2. Steady state operation at different water flow rates

3. Variability of test plates' angular orlentation and distance relative to water distribution

4. Collection and recycling of water

5. Visual observation of flow

\subsection{METHOD OF DISTRIBUTION}

One goal of this project was to consider the effectiveness of the advanced wet-dry concept. By using water and air flow rates, as well as inlet temperatures and humidities similar to those in industrial use, direct comparison between the heat transfer data collected from the test apparatus and that already documented would be possible. Creating cooling tower conditions required conventional wet tower flow rates be maintained.

A water flow rate between two and eighteen gallons per minute per square foot of packing section plan area was chosen as the operating range for the sample test system based on the upper and lower flow rate limits currently used in splash and film type cooling towers. This quantity will be referred to throughout the paper and will be defined as shown in equation (I). 


$$
\begin{aligned}
& \frac{\mathrm{gpm}}{\mathrm{ft}^{2}}= \frac{\text { Total water flow rate through the tower }}{\text { Interior cross-sectional area (perpendicular }} \\
& \text { to water flow) of the tower packing section }
\end{aligned}
$$

Consldering wet tower water flow rates where the water is cooled largely by evaporative heat transfer, the conventional packing section holds the water in thin sheets over large areas in contact with the air flow as long as possible. A system which could provide a continuous thin sheet of water at the aforementioned flow rates to the top of each test plate had to be constructed to allow visual inspection of the surface condition and geometric effects on the water sheet as it progressed down the plate, 1.e.,for dry spots, irregular channelling, ripples, and fluctuations in water sheet thickness.

After calculating the water flow rate per linear foot of film type packing plate ( 0.25 to $2.5 \mathrm{gpm} / \mathrm{ft}$ of plate), it became apparent, if the water covered the plate uniformily, the thickness of water would be very small. Based on this hypothetical case of complete wetting, a test section area was chosen to be approximately one foot square, 1.e. large enough to prevent end effects from reaching the center of test plate. Since each channel design would repeat itself at least once every 3 inches, the one foot wide test section would also allow observation of four or more channels and the effect of their presence on each other. Providing such low flow rates spread evenly over a 
one square foot area meant restricting the thickness of the water sheet, 1.e., the water sheet can have only one thickness given a constant flow over the above area. Three methods of water flow rate control were considered: a weir, a tank with a long slot in the bottom, and a pipe with a series of small holes.

To design a small weir tank for such low flows presented a number of manufacturing problems; e.g., machining a kntfe edge which would be mounted, sealed, straight, and level to the tank. In addition there would have been later design problems: It could only feed one plate at a time, and it does not allow for free air passage above the top of the sample plate. It was too sophisticated for the preliminary tests.

The "large tank with a slot in the bottom" would allow a constant and unfform flow, but design and fabrication of the slot (cross-section, nozzle) would be required. Changing the flow rate while maintaining optimum exit fet meant either having an adjustable slot or a number of replacement slots; either alternative entalled designing a nozzle milling tool.

Holes in pipes are easily machined; different flow rates can be easily obtained by adding to the number of holes or by changing the hole size. The pipe can be connected readily to the other components of the system by conventional plumbing units. The only problem foreseen would be clogging. 
Three small experiments were conducted to confirm the decision to use the distribution pipe with a series of holes. The manner in which water runs off a flat plate fed by a round stream was examined. First a flat aluminum plate held at different angles under a running water faucet was observed. Then to compare the pipe with holes to a thin slot, a $11 / 4$ inch copper pipe was drilled radially with small holes (along the length of one side), capped on one end, fed by a hose from the other end, and tested for jet uniformity; plate drain-off was also observed. (See Figure 2). Another pipe of the same diameter was used for the third experiment. It was 12 inches in length with an 0.018 inch width slot and was subjected to the same test.

The results of these preliminary tests revealed conclustvely that the series of holes were more uniform in exit velocity and as a means to wet the entire plate. It was found that a high flow rate within the pipe was required to malntaln a thin sheet of water along the slotted pipe. The pipe velocity was of the same order of magnitude as that of the exiting sheet velocity at the capped end. The addition of the pipe velocity to an otherwise perpendicular jet velocity resulted in an oblique exit at the inlet end of the slot, favoring the down stream direction. At the capped end of the pipe (where the axial velocity of the water in the pipe was close to zero) the sheet exit was perpendicular to the pipe (see Figure 3). Another 


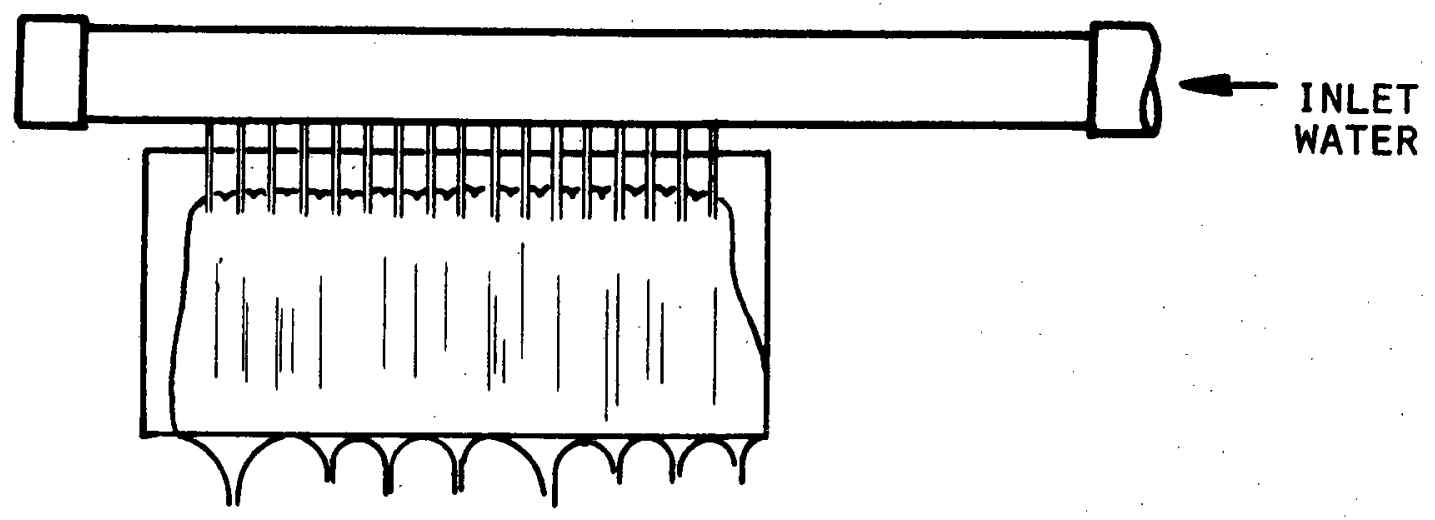

FIGURE 2. SMALL HOLE SPRAY ON A FLAT PLATE

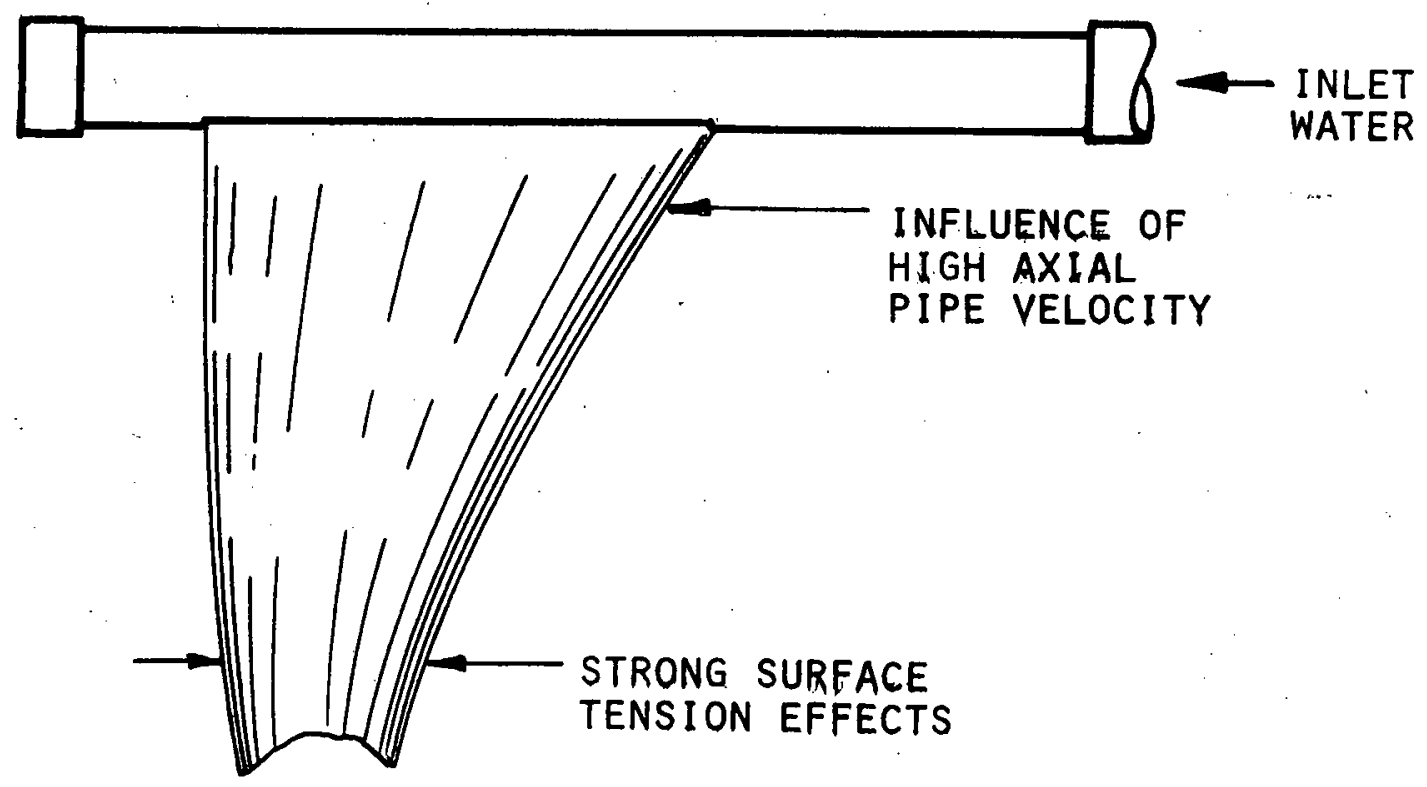

FIGURE 3. WATER FLOW FROM A PIPE WITH A THIN SLOT 
observation which simultaneously ruled out the weir mixing plate was that the drain-off water was highly irregular and not one thin sheet.

To develop the proper size pipe distributor for a one square foot packing plate, necessitated a closer look at three critical design details:

1. Minimum head for uniform flow from each hole

2. Distance between holes to maintain an even mixing on the plate to approximate a thin sheet of water

3. Number of holes per foot to provide the necessary flow rates A short experiment was done using the drilled pipe to determine the minimim head of water required to maintain parallel and coherent exiting from each individual jet for at least one inch after it leaves the pipe. Six inches was measured to be the minimum head for all holes but some still did function well as low as 4 inches. This may be a result of the machining process of the individual holes as well as surface properties of the pipe for the 1/32 inch diameter holes. The copper pipe wall thickness was less than $1 / 16$ inch where the holes were drilled. It was assumed that a thick walled orifice would provide lower operating heads, and, as seen later, it did.

\subsection{DESIGN OF THE DISTRIBUTION PIPE}

The spray pipe design was idealized as shown in Figure 4. A 14 inch length of the pipe was drilled with $1 / 32$ inch diameter holes, 


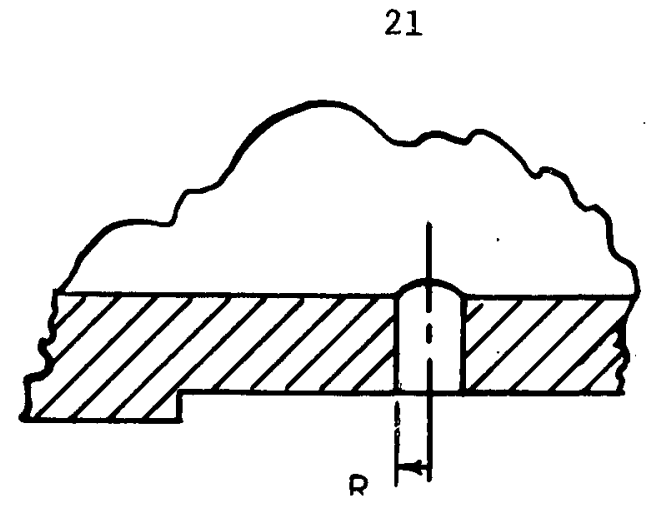

DETAIL

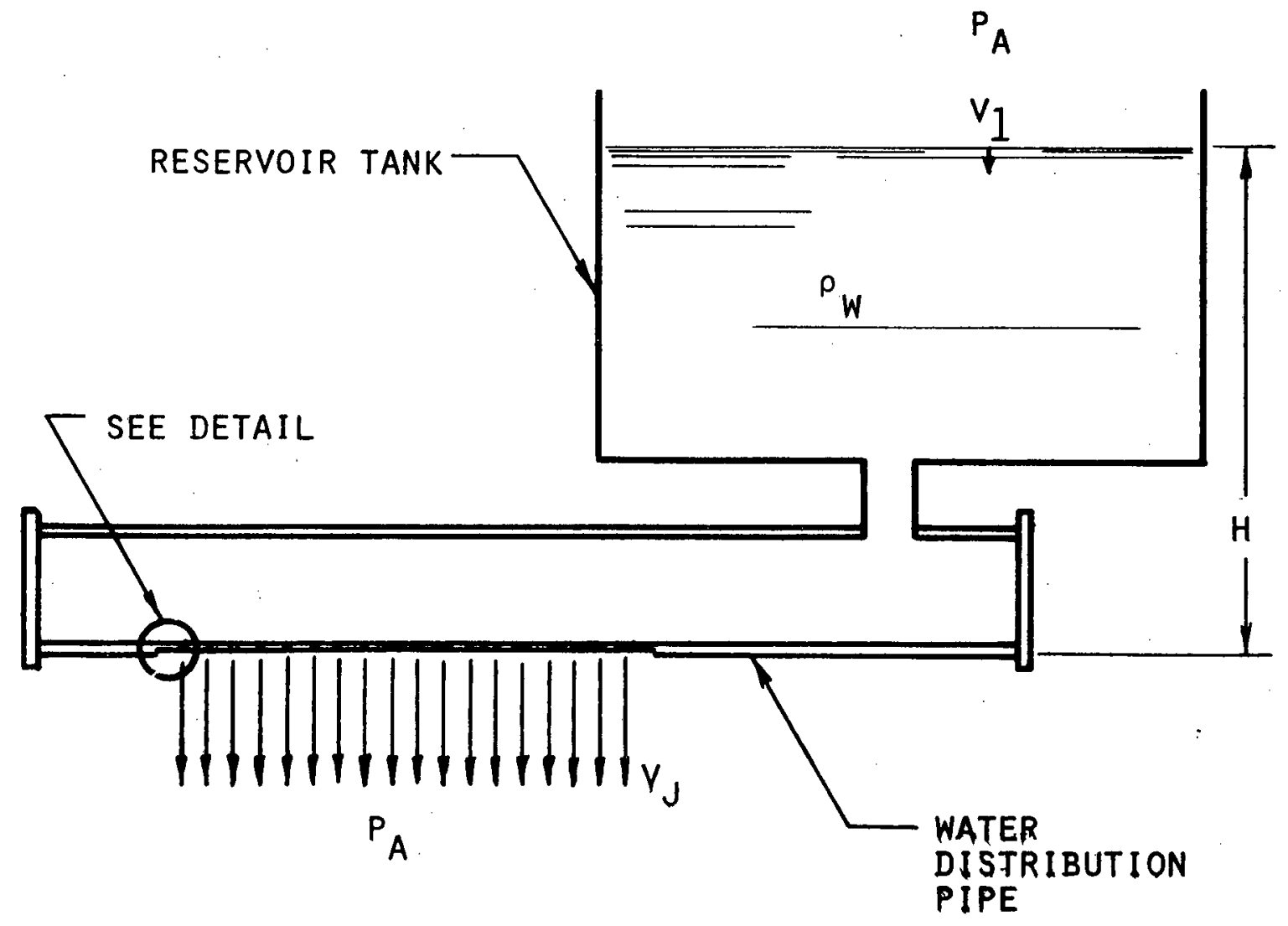

FIGURE 4, IDEALIZATION OF THE WATER SPRAY TUBE CONFIGURATION 
enough to completely overlap the one foot test section, which would be located two or three pipe diameter away from the pipe inlet and fed by a constant reservolr pressure head. Stipulating that holes would not be placed closer than two hole dlameters on center in order to maintain structural stability of the wall while machining, and not closer than six diameters to prevent merging of starting streams, volume flow rate calculations for different size jet holes and water pressure heads were made. The analysis has shown a $1 / 32$ inch diameter is the largest usable hole to provide the 0.25 to 2.5 (gpm/test plate) flow range; and 75 holes per foot are required. A comparison of the pressure drop along the 3 inch diameter pipe to that across any individual jet orffice shows the relative magnitude of the first is considerably smaller. Consequent1y, the friction losses and momentum change in the pipe length is negligible, and the flow rates for all 75 holes are Identical within $3.5 \%$.

2.4 SELECTION AND MANUFACTURE OF THE SPRAY TUBE The spray tube was made from a 3 inch inside diameter plexiglass pipe. The machining was done on a milling machine. First a $1 / 4$ inch flat surface was milled along the axis of the plexi-glass pipe to provide a true circular orffice on this side of the drilled hole. Each of the $96,1 / 32$ inch diameter holes were drilled 0.190 inches on center. Burrs were removed from the inside with fine emery paper and the square flat plexi-glass ends cemented in place. 


\subsection{TEST APPARATUS}

The remaining parts of the system were easily obtained. A twenty-two gallon reservolr tank was mounted over the pipe, and was chosen so the water level could be varied to maintaln different flow

rates. It was necessary to choose a tank large enough that pulsations produced by the pump would be negligible. The collection system consisted of a large V-shaped gutter draining into a five gallon cyclindrical can which was connected to a $10 \mathrm{gpm}$ pump (at 10 foot head of water). Valves and plumbing are shown in Figure 5. Each of the components were held in position by a dexion skeletal frame structure. A similar scheme was used to hold the permanent magnet-hold-down clamp for mounting each test plate quickly, so that they could be rotated and lowered relative to the distribution pipe.

\subsection{DISTRIBUTION PIPE CALIBRATION}

Initially the system employed used valves, fittings, pipes, etc., so that holes clogged from residual debris of the corroded parts. It became necessary to add number 40 guage strainers at the reservoir inlet and outlet, and at the inlet to the collecting tank. These additions allowed for improved flow through all jet holes, eliminated the need to clean the inside of the distribution pipe before each run, and enabled the test apparatus to serve its designated function: uniform flow through all 96 holes.

To measure the mass flow rate across the distribution pipe, the 


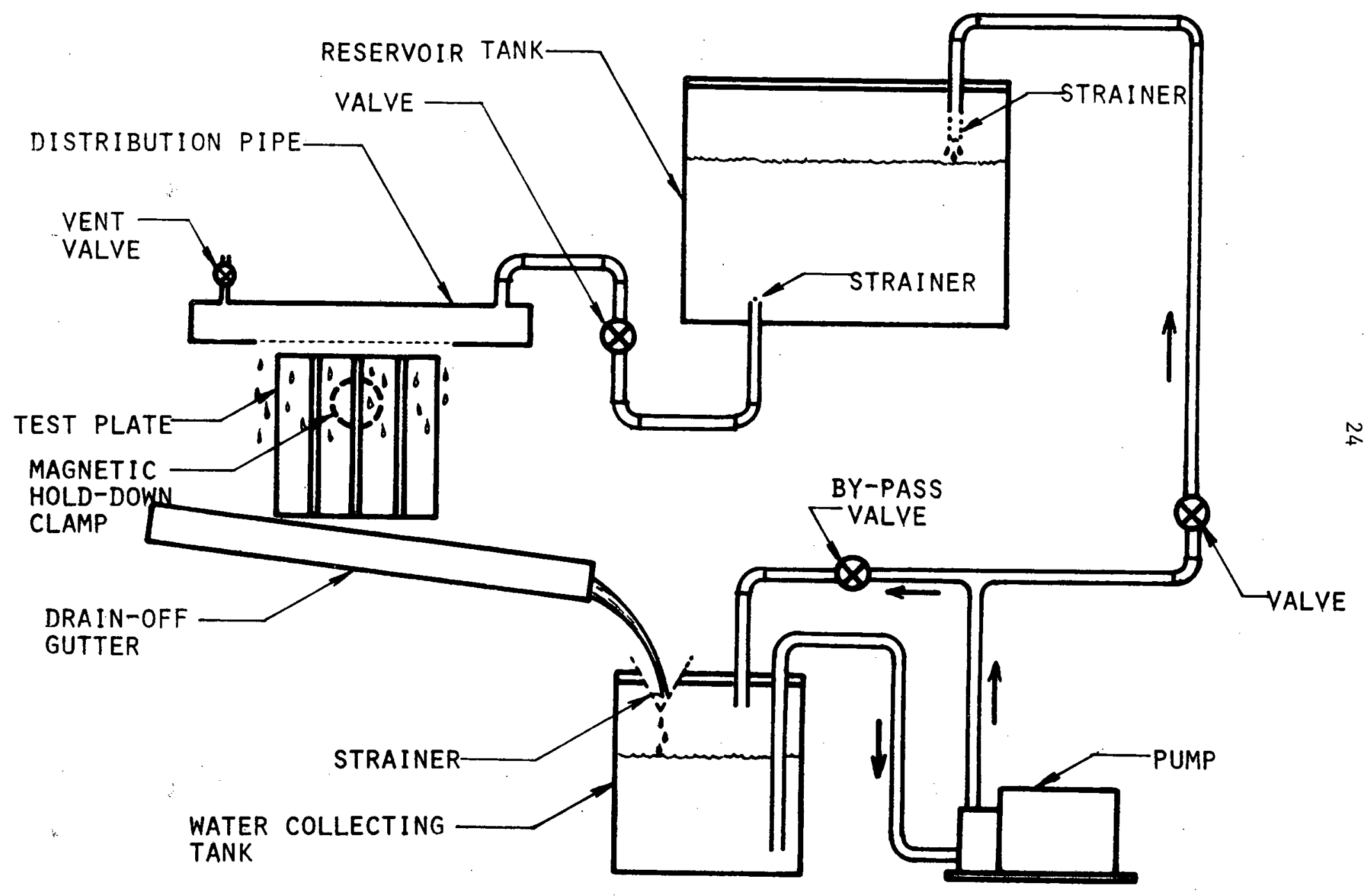

FIGURE 5, SCHEMATIC OF FLOW VISUALIZATION TEST APPARATUS 
water was diverted to a graduated beaker through a V-trough spanning exactly 10 holes, allowing no spillage from adjacent holes. The data is shown in Table 1 , (below) and reveals the following;

1. Flow rate for each hole across the distribution pipe shows less than a $3.5 \%$ deviation.

2. Flow rates for 12 inches of holes could be varied within the design limits of 0.25 to $2.5 \mathrm{gpm} /$ test plate.

NOTE: It was observed at this point that the amount of area wetted within the $V$-trough was dependent on the angle between the length of the trough and gravity, but that all water was channelled uniformly in the vertex of the trough. 
TABLE I.

LOCAL FLOW RATES THROUGH THE DISTRIBUTION PIPE

\begin{tabular}{cc}
$\begin{array}{c}\text { HOLES } \\
\text { OBSERVED }\end{array}$ & $\begin{array}{c}\text { FLOW RATE } \\
\text { (m1/sec) }\end{array}$ \\
\hline $1-10$ & 8.22 \\
$11-20$ & 8.48 \\
$21-30$ & 8.61 \\
$31-40$ & 8.51 \\
$41-50$ & 8.44 \\
$51-60$ & 8.53 \\
$61-70$ & 8.47 \\
$71-80$ & 8.31 \\
$81-90$ & 8.36
\end{tabular}

* Flow rates based on the time required to collect $500 \mathrm{ml}$ of water. 


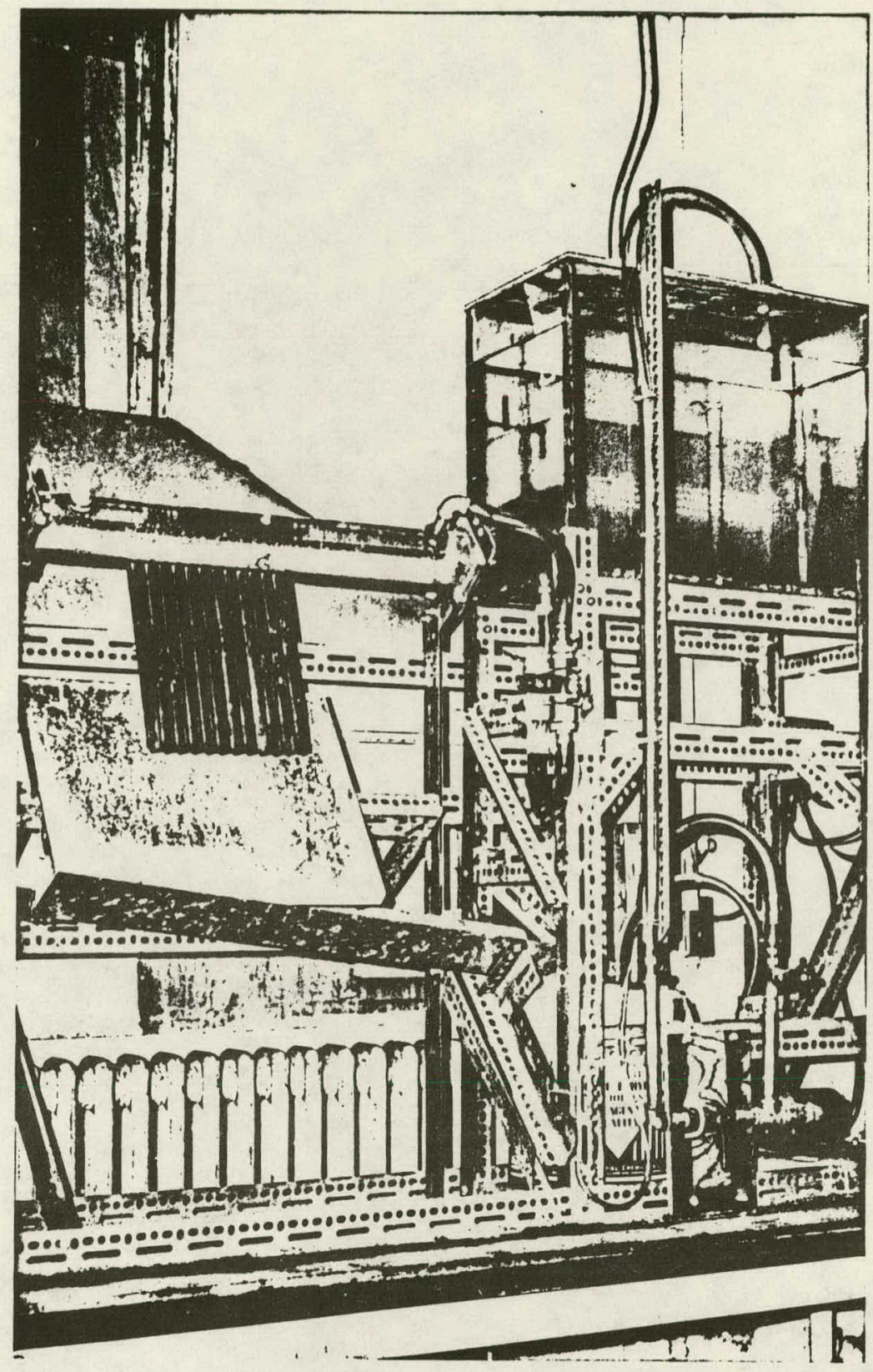

FIGURE 6. FLOW VISUALIZATION TEST APPARATUS 
CHAPTER THREE

DESIGN OF A PACKING TEST PLATE

\subsection{CONCEPTUAL DESIGN OF THE NEW WET-DRY PLATE}

Designs were sought which minimized the ratio of the air-water interface area to the total plate area to reduce the evaporative heat transfer. In addition, the alr-water interface area must be kept small for large water flow rates. To affect this over any given surface requires the channelling of water; a surface which has come concavity will favor this relation (see Figure 7), while surfaces which are flat or convex in nature will increase the avallable evaporative area. Being able to control the water flow pattern so that it wets only desired areas is an important design criterion. The packing plate must also serve as a heat exchanger; therefore, its thermal conductivity and surface properties are of major importance. As can be seen in Figure 1, the new wet-dry concept has heat transfer features similar to a fin tube arrangement. Acting as fins, the wetted plate surface (shaded) conducts the heat to its opposite side and toward the dry plate regions, where convection is possible with the cooler flowing air stream. Some energy transfer still occurs via the exposed alr-water Interface, but the mass transfer mechanism is greatly reduced by making this area smaller relative to the volume of water being considered. The purpose of the inftial experiments was to find which properties most influenced the water flow characteristics, and to determine how 


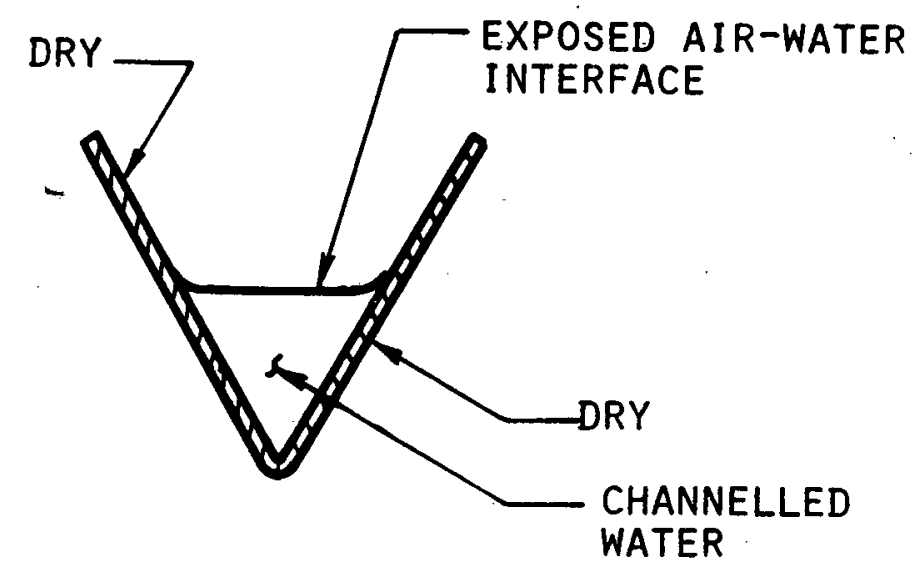

$\left.A_{1}\right)$ CHANNELLING OF A GIVEN VOLUME OF WATER PROVIDES AN "EXPOSER WET AREA/TOTAL AREA" RATIO OF MUCH LESS THAN $50 \%$

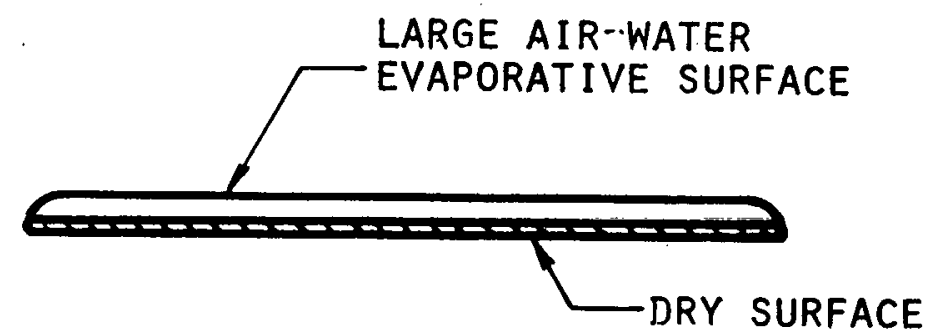

$B$, WETTED FLAT PLATES INDUCE EVAPORATION BY KEEPING THE EXPOSED WET AREA LARGE AND EQUAL TO THE DRY SURFACE AREA

FIGURE 7. WATER CHANNELLING CONCEPT 
surface condition and geometry could be altered to direct water flow to the best heat transfer and minimum mass transfer areas. After learning how to channel the flow, it was necessary again to study the plate design from the standpoint of heat transfer to design a suitable packing plate. Naturally, this required some parametric studies: allowing these area ratios to vary as water and air inlet conditions remained constant. Once the test plate design was completed it was analyzed with regard to practical manufacturability, cost, corrosion and maintenance.

A series of experiments were performed to study different water flow rates and geometric effects on small plate wetting patterns while temperorarily disregarding thermal properties of the material.

When exposed to cooling tower environments, packing plates corrode and collect scale and surface film with time. The extent to which the surface is changed (usually roughened) depends on many factors: e.g. water $\mathrm{pH}, \mathrm{plate}$ material and water/air operating temperatures. A rough surface is more easily wetted than a smoothly polished surface. Eventually, this would probably have an adverse effect on the function of the new plate design. If the water begins to spread from the channels by wetting roughened dry areas, a greater mass transfer area which increases evaporation is provided. To examine the severity of this effect, surface roughness tests were performed under the following conditions: 
1. Tap water was administered to the test plate by means of the distribution spray apparatus at a flow rate of $0.76 \mathrm{gpm} /$ linear foot of test plate.

2. The infitial test plates were flat and approximately one foot square.

3. Aluminum, plexi-glass, galvanized and ungalvanized sheet metal were used as test plate material, because each had a different inherent surface and each surface could be altered easily.

4. Plates with varying degrees of surface roughness were used to simulate packing sections with very smooth surfaces and with varying degrees of collected scale, film and rust.

5. One cup of non-sudsing detergent was added to the 25 gallon system as an alternate method to enhance possible surface wetting.

6. Vertical plates were mounted parallel to the spray pipe.

7. Spray jets were angled down at the plates at 45 degrees.

\subsection{DISCUSSION OF VISUAL OBSERVATIONS}

Very smooth flat surfaces approximated by wax polished plexi-glass and sheet steel allowed the low water flows to bead and to form individual rivulets straight down the plate with no noticeable variation for 
slight changes in plate angular ortentation from the vertical. This supports the concept of using non-wetting material strips to aid in channelling of flow. If, for example, teflon strips were placed along the flow edge of each channel, the flow would be prevented from spreading out of the channel to the dry fin-like surface. With continuous testing on the waxed plates the flow patterns became very irregular. Individual streams were constantly changing direction in the upper third of the plate. Some wetted more in the area where the jets contacted the plate, and others sporatically coalesced down the plate. The same observations were made of the untreated plates with their natural stock surface when they were tested. It was concluded that any coatings which may be used to reduce surface wetting must not lose their surface finish under normal operating wear, since partially worn effects induce unpredictable flow patterns. None of the plates tested thus far were capable of sustaining a completely wetted surface even when water was intentionally wiped across the entire plate by means of another plate or by hand. The other extreme, a completely rough surface, was considered; graining the surface with unfform fine groves, (number 60 emery paper), the plates could be wetted easily by the spray. It should be noted that when the grained plates were dried and then subjected to the flow, water occasionally would leave dry spots on the lower portion of the plate; but with time the flow would spread to cover the whole plate. However, when a grained flat plate 
was first dipped in water and then Immedlately put in the test stand, complete wetting took place. This rough condition approximates operating conditions when oxides have formed and have begun to corrode the surface. This test demonstrates that the design must be capable of wetting desired areas for both dry starts after a shut down, and wet starts.

The initial non-uniform flow over the dry rough surface and the transverse velocity perturbations must be controlled by some constraint. This tendency on flat plates or shallow wavy plate designs would result in total wetting and thereby defeat the channelling intention. As anticipated, the effect was more prominent when the grooves were perpendicular to the water flow. Teflon coatings or strips could control the flow but they would be an additional expense to fabricate and would also inhibit heat transfer by insulating portions of the conductive fin area. Therefore in succeeding tests a geometric flow guide was used.

Another observation of the early tests was the non-uniform flow of the water as it left the flat plates. The water flows from the plate in a few thick streams, which could hinder drain-off collection. This strong edge effect was used as a flow diverting technique in a test plate design (see Figure 14). Large holes were drilled in the upper portion of the plate creating a semi-circular edge for the water to follow; but, these proved ineffective. 
Surface tension measurements of the water before and after adding the detergent showed no noticeable change. It was concluded that the water being used was already considerably contaminated causing the most severe wetting conditions on the given plates (tap water 68.8 dynes $/ \mathrm{cm}$, test system water 43.0 dynes $/ \mathrm{cm})$.

\subsection{GEOMETRIC CONSTRAINTS}

Several different plate geometries were studied to find one which would control the water flow for all surface finishes.

A variety of sample plate configurations were fabricated out of sheet metal and plexi-glass as illustrated in Figure 8 through 16. Most of these plates were tested with smooth surfaces as well as the roughened surfaces. However, since the very smooth surface would not persist in actual cooling tower environment and the use of nonwetting material flow guides had been discarded, attention was focused on natural and roughened materials. In the following section, the motivation for each plate design will be discussed and the significance of each test on the final design will be pointed out.

Plate \#1: "Flat with a wax polish", Figure 8

The purpose of this test was to see how the flow would develop on smooth surfaces used as flow guides or test plates. Initially the flow was very regular. Each water jet formed an individual beaded rivulet down the plate. In time, however, the wax coating began to wear off and 


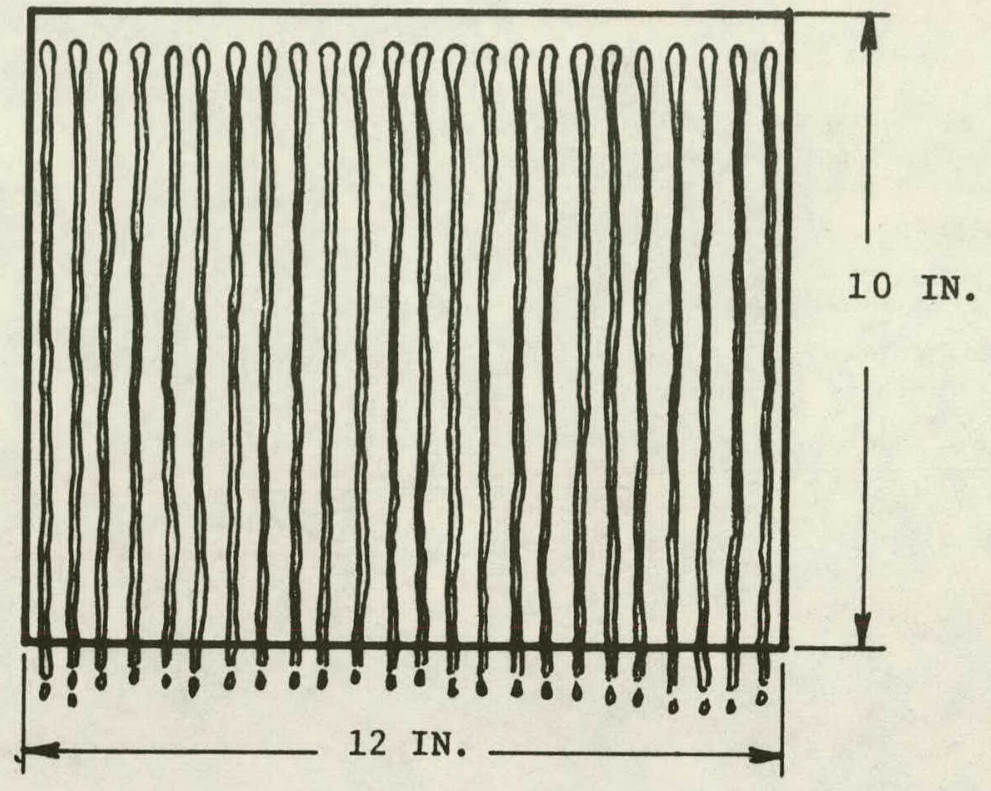

FIGURE 8. RIVULET WATER FLOW ON A FLAT SMOOTH PLATE

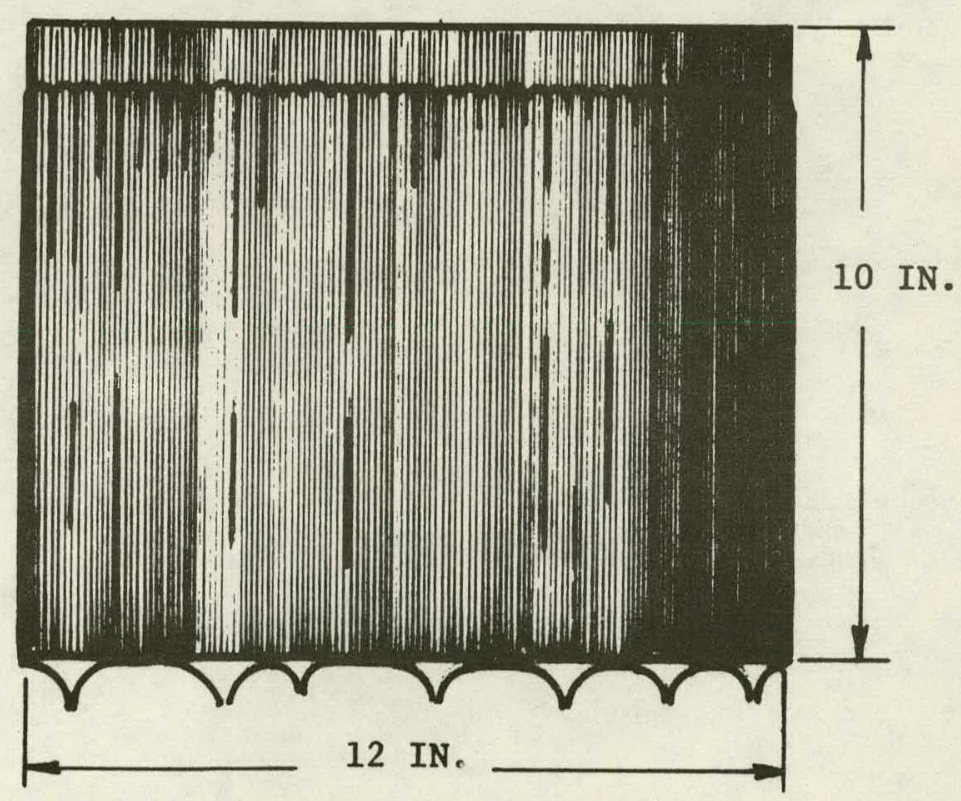

FIGURE 9. COMPLETE WETTING ON A ROUGH FLAT SURFACE 
the single rivulets became 1rregular, oscilating from side to side as they progressed down the plate and merging. A very smooth non-wetting surface can be employed between desired channeling areas to contain water only if these surfaces do not lose their finish and if their thermal properties do not inhibit convective heat transfer.

Plate\# 2: "Flat grained plate", Figure 9 Rust, film scale, and corrosion can increase wetting. This test simulated the roughened surface of a packing plate (by graining with number 60 emery paper) which had adversly changed through normal use. The sheet was wetted completely by the spray, and remained so unt11 water flow was shut off. This indicated the need for flow guides down the length of the plate to restrict the water to certain areas.

P1ate \# 3: "Multiple V-troughs", Figures 10 and 11 This concept was an enlargement upon the collection method used in callbrating the spray tube. It was considered as a possible design for distributing the sheet flow to desired channels and for maintaining channelled flow down the plate. The V-trough funnelled the jet spray together at the top of the test section; and the troughs were deep enough ( $5 / 8$ inches), to provide ample barriers for keeping 


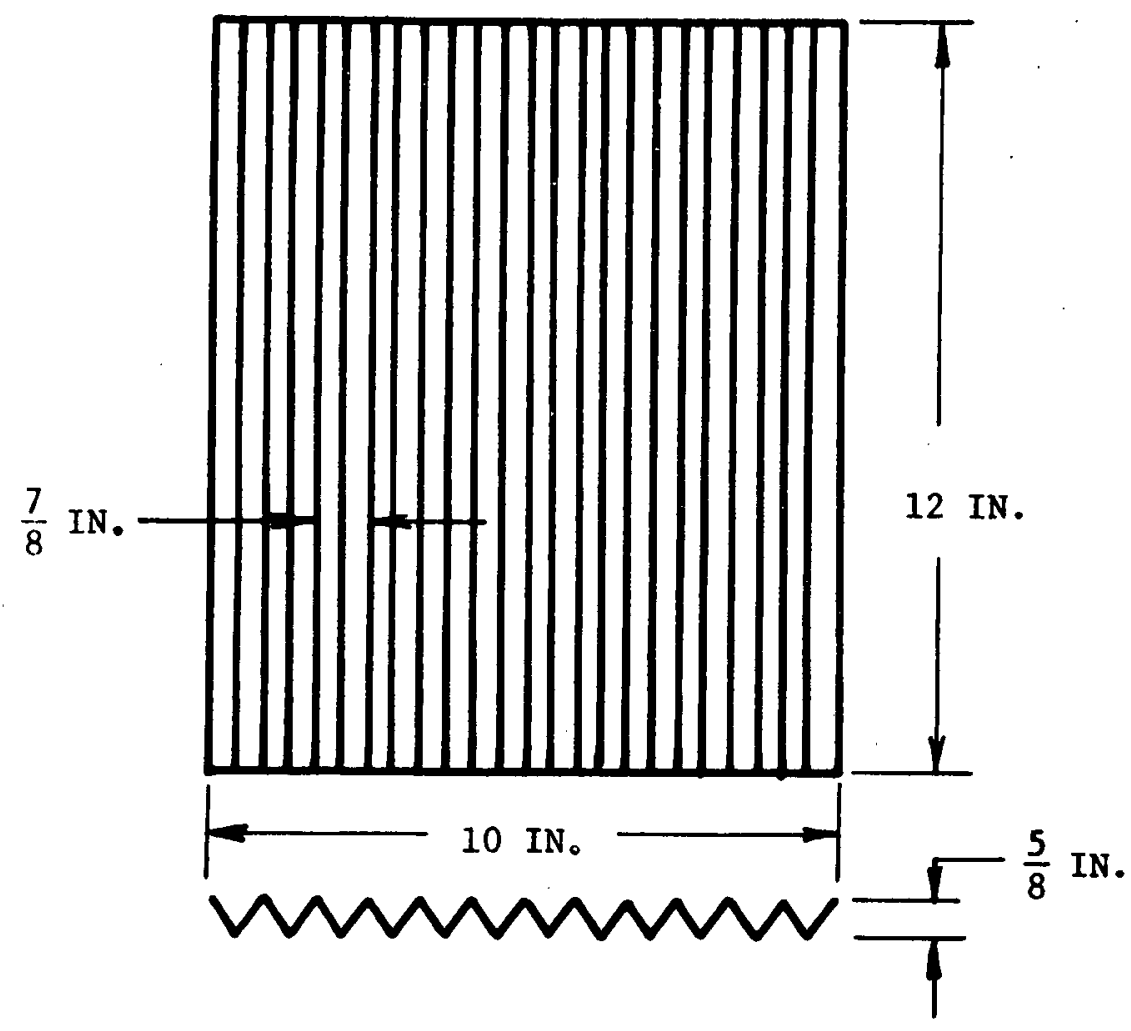

FIGURE 10, MULTIPLE V-TROUGHS

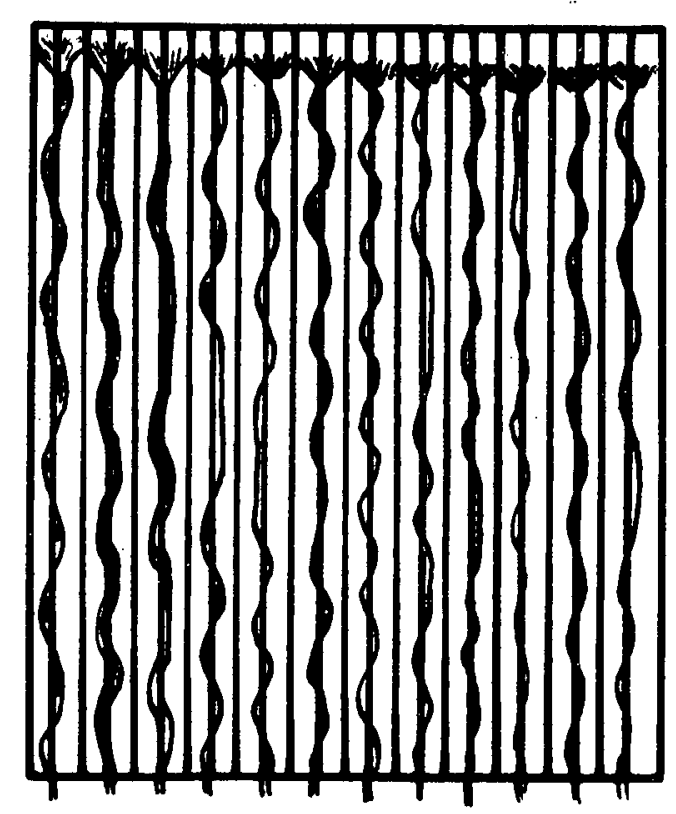

FIGURE 11. CYCLIC VARIATION OF V-TROUGHS FLOW (SMOOTH SURFACE) 
the flows separated. The relatively sharp bend forming the troughs alded in preventing random flow from leaving a channel, because the sharp corner would not support a continuous stream. While maintaining channelled flow the V-troughs also provided a means to control the air-water interfacia1 area in two ways: (1) by changing the included angle between the trough sides, which would reduce the alr-water interfacial area for a given flow or (2) by increasing the width of the sides of the troughs for a given angle and flow rate the dry surface area would increase while still maintaining the same airwater interfacial area. The design proved to work well for all surface conditions. Only slight cyclic variation of stream flow were shown for the "natural" condition, 1.e. the straight channelled flow was seen to alternate from one side of the groove to the other but always touched the base of the V-trough (see Figure 11). Even when the test plate (when waxed) was held at a small angle to the vertical (less than 10 degrees with the water side underneath), the flow remained channelled.

Plate \# 4: "Spaced channels", Figure 12 This test determined whether the flow would favor the channels enough to self distribute, leaving the flat areas dry. The results were not impressive. The flow was 


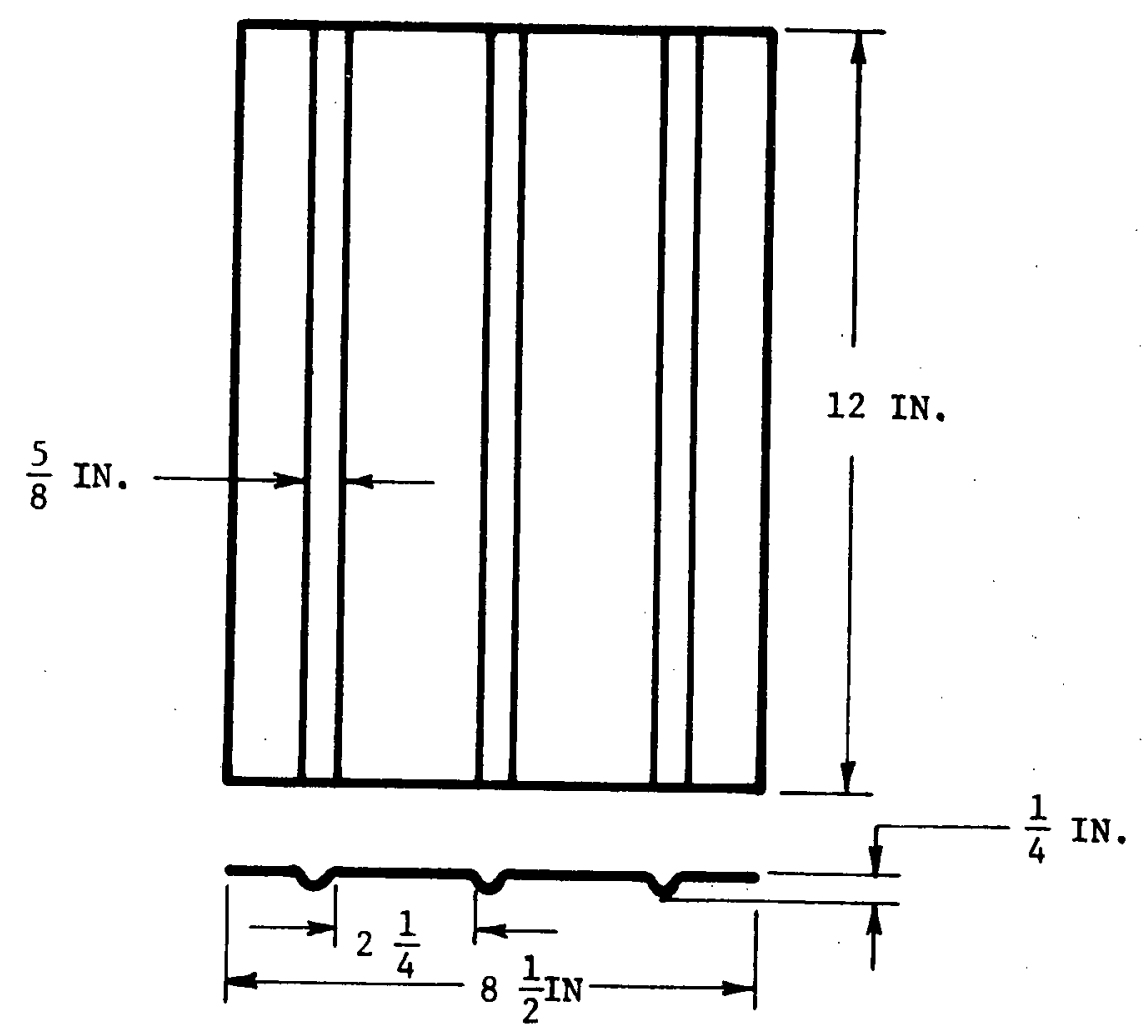

FIGURE 12. SPACED CHANNELS

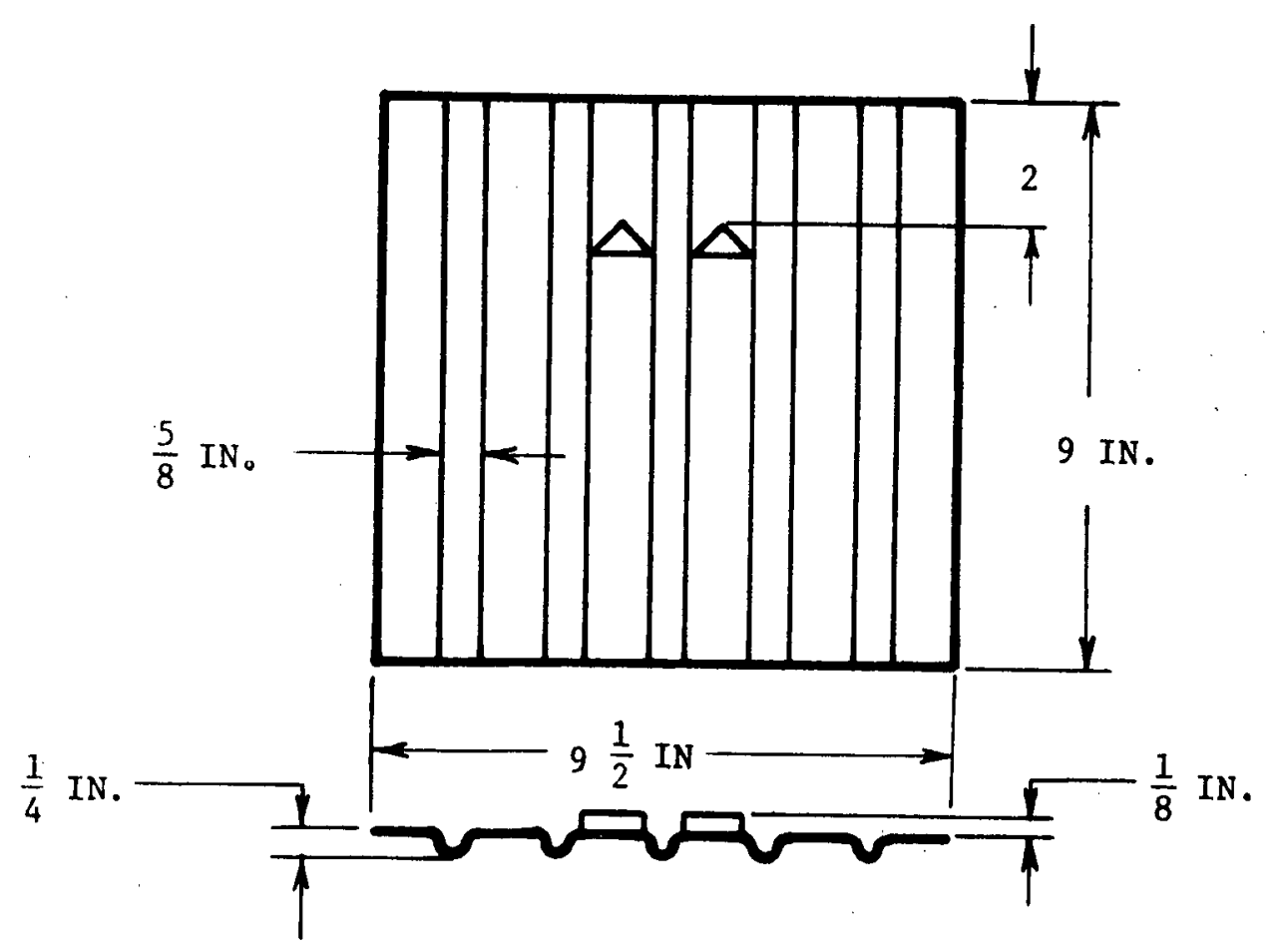

FIGURE 13. FLOW DIVERVERTS ON A SPACED CHANNEL PLATE 
irregular, and often the water which started in a given channel soon spilled out half way down the plate. This was partially due to the shallowness of the channe1s, as we11 as the wetting quality of the rough flat surface.

Plate \# 5: "Separated channels with plex1-glass flow diverters", Figure 13 Water flow diverters were affixed to the flat areas to help distribute the flow to the channels. The flow indeed was split and all the water directed to the adjacent channels but again one or two channels would lose water further down the plate. This may have been caused by the rounded edges produced by the rolling machine and the shallow channels. At this point it was proposed to add diverters at equal intervals down the plate.

Plate \# 6: "Channels with large holes to divert flow", Figure 14 Another flow diverting design made use of the surface tension at the plate edge. Plates were tested to see if this low cost augmentation would provide sufficient distribution of the spraying water to the channelled areas. This method did not work well. Not only was water lost through the holes, but the down-stream circular edge of the hole tended to draw water from the neighboring channels. 


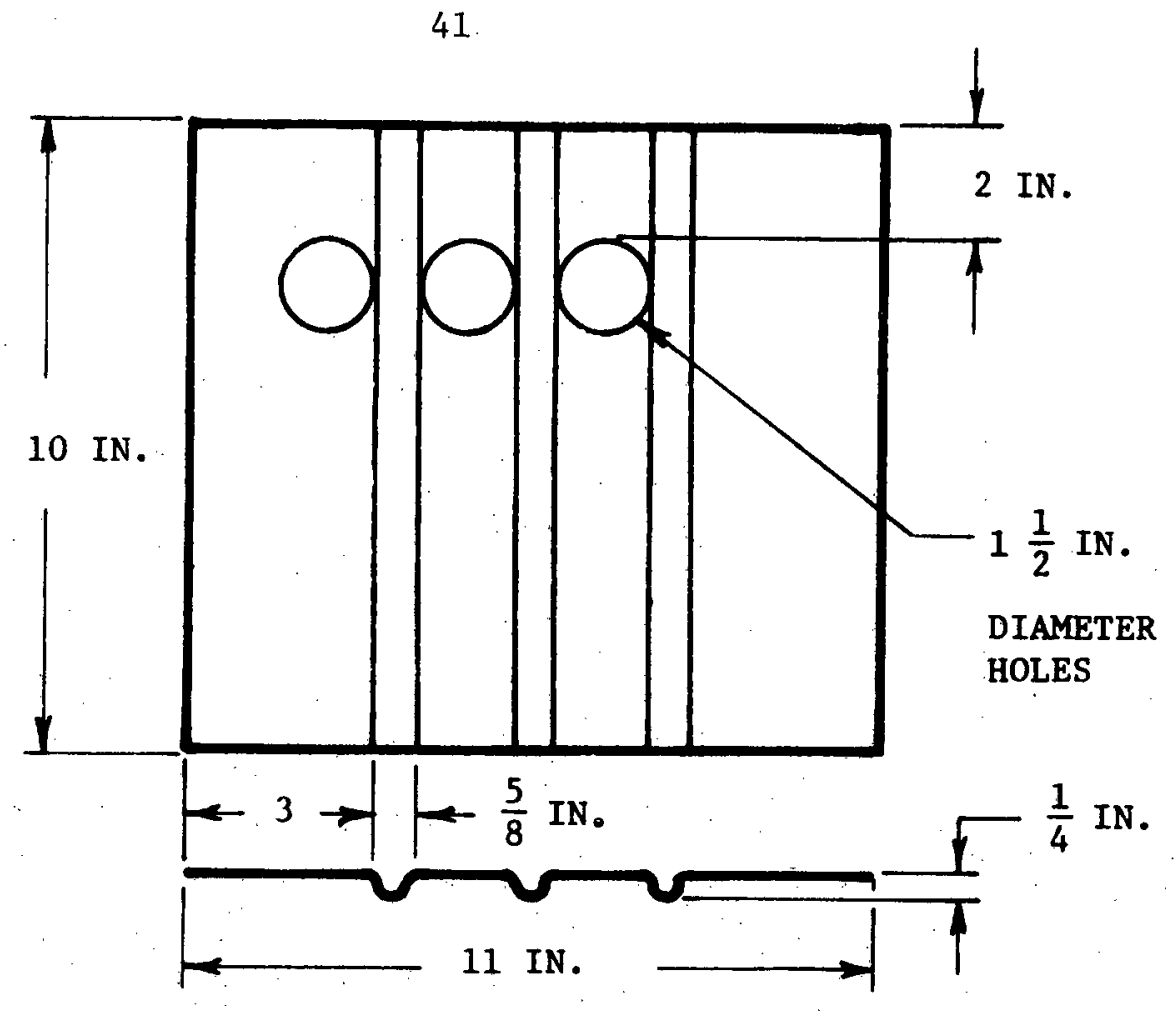

FIGURE 14. LARGE HOLES USED TO AID
CHANNELLED FLOW

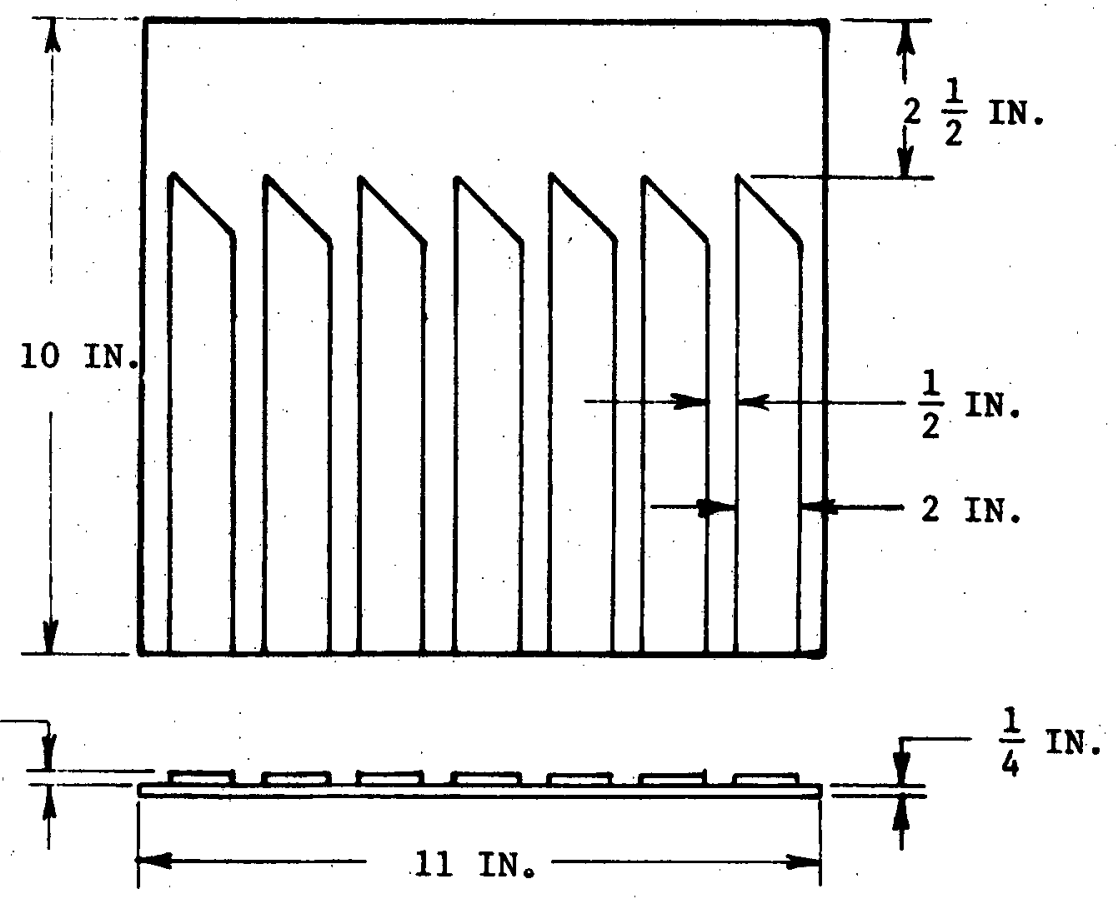

FIGURE 15, FLAT PLATE INLET WITH RAISED FLOW GUIDES 


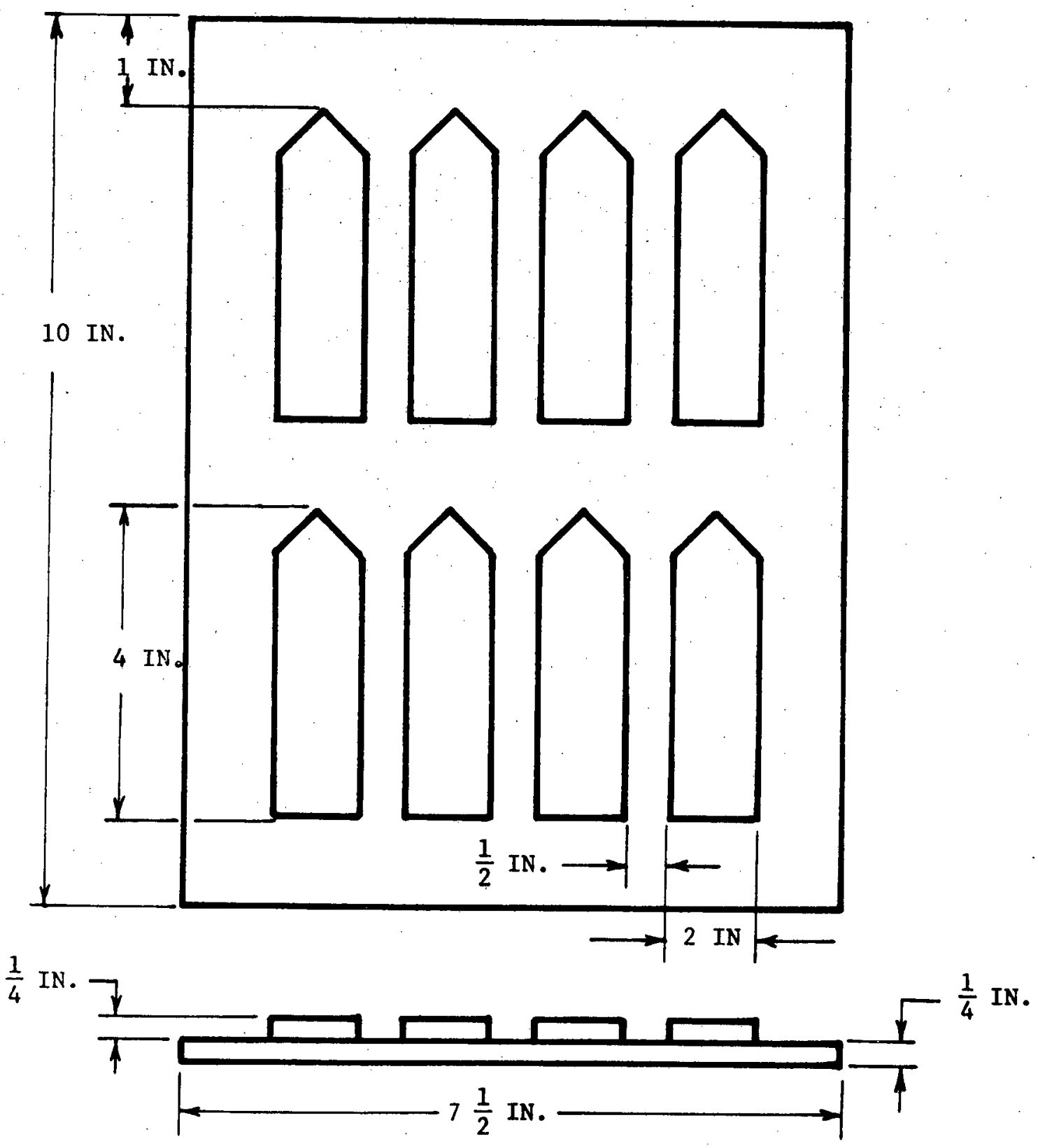

FIGURE 16, REPEATED RAISED FLOW GUIDES 
Plate \# 7: "Flat plate inlet with ralsed dividing plexi-glass guides", Figure 15

The reason for trying the plexi-glass configuration was to combine a distributing section with a channelled section. Visual observations of these test revealed that the $1 / 4$ inch divider was not high enough to prevent the accumulating flow from spllling over and running down onto the raised flat surfaces.

Plate \# 8: "Repeated raised dividers with arrow shaped flow spliters", Figure 16 Features of plates $\# 5$ and $\# 7$ were combined to solve the spill over problem at the flow distributing section, but this created the additional problem of the flow spreading between the raised sections.

\subsection{SUMMARY OF FLOW VISUALIZATION TESTS}

Of all the initial test plates examined the mult1ple V-troughs were the most effective for even distribution of flow to desired areas. This design was least effected by angular orientation of the jets to the troughs and of the plates to the vertical, and were even found to maintain flow in the inside corners for angles less than 10 degrees to the vertical with the water side down when smooth plates were used. Compared to the raised dividers, it had one distinct advantage; the design was simple to fabricate either on a small scale by using a standard sheet metal bending break or on a large scale by a mechanized stamping process. The channel sections of plate \# 5 offerred heat 
transfer characteristics similar to the V-troughs but involved the extra process of making and attaching the repeated flow diverters. Another important design feature of the V-trough was the ease at which the air-water to water-plate and dry plate area ratio could be changed by simply varying the angle or height of the troughs for a given flow rate. The fin efficlency of the V-troughs was calculated to be $79.6 \%$ (see Figure 22) and would be ample for heat transfer for the assumed initial conditions. Other designs were at this point discarded on the following premise: The wavy plate with shallow waves when rough became completely wet, and with sharp waves was not as effective at distributing channelled flow as V-troughs, as evidenced by the rounded edges of the channelled plate. The concepts which required teflon or the addition of flow guides did not demonstrate any outstanding features and entailed more manufacturing detail. It was concluded the V-troughs could provide a suitable surface for heat transfer tests. 


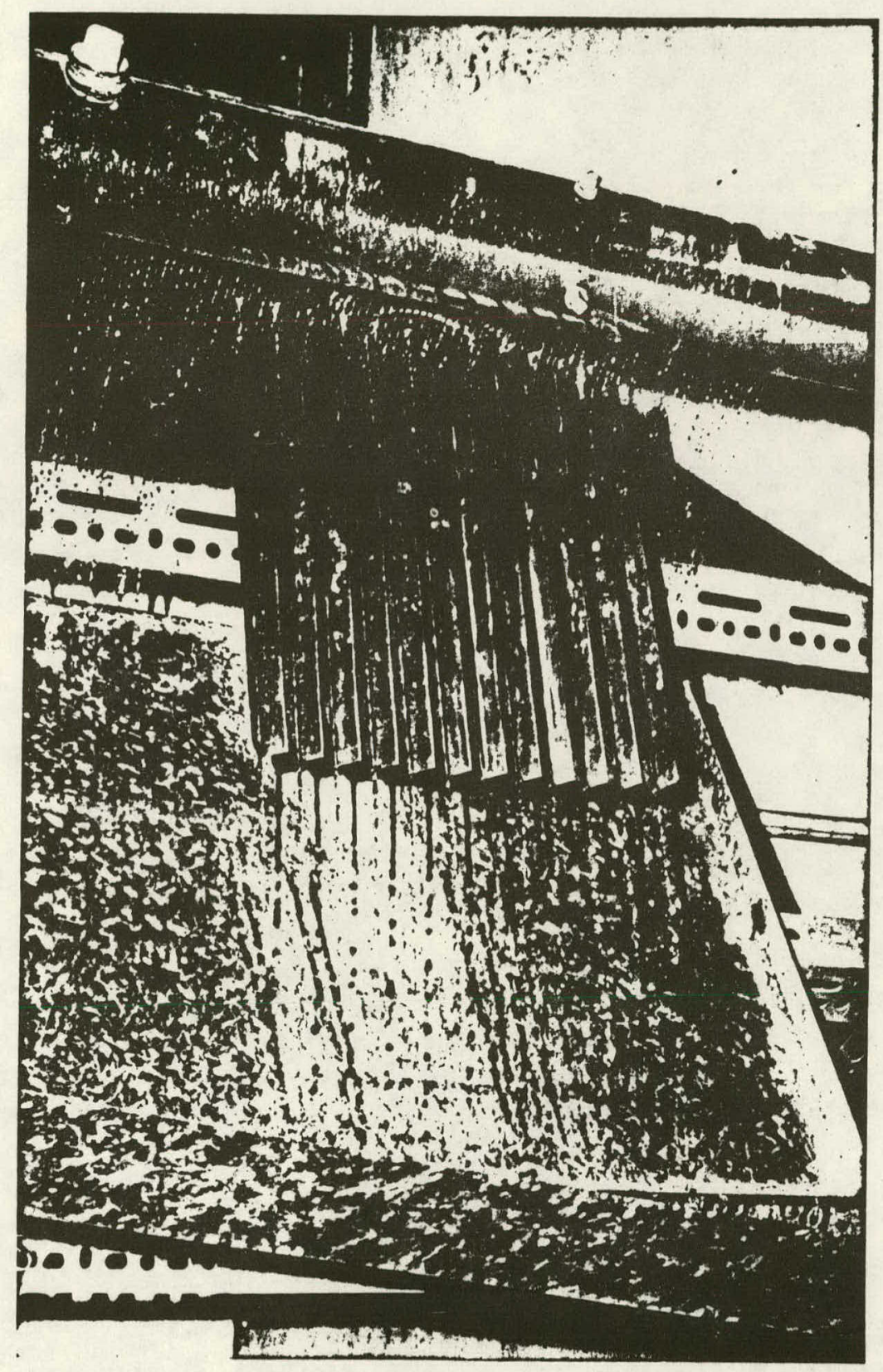

FIGURE 17. V-TROUGHS TEST PLATE CHANNEUING WATER FLOW 
CHAPTER FOUR

DESIGN OF AN ADVANCED DRY MODEL TOWER: HEAT TRANSFER

TEST APPARATUS

\subsection{HEAT TRANSFER TEST REQUIREMENTS}

The advanced dry concept requires a plate design which minimizes evaporation compared to convective heat transfer. The flow visualization tests showed that the V-troughs were able to maintain the water flow pattern necessary to minimize evaporation. They provided dry convective heat transfer surfaces alternated with open water channels. However, the heat transfer performance of the entire section must be measured to determine the operating characteristics of the new design. Also the amount of water evaporation to the air must be measured to determine whether the fog plume condition had been eliminated. An apparatus which would allow for these measurements, in many ways, resembled the conventional wet cooling towers.

The design of a fully instrumented controlled environment for testing the new packing concept emphasizes control of the boundary conditions at the top and bottom of the plate. These were used in the computer program which mathematically modelled the performance of the section design. Specifically this entailed: (1) maintaining "dry ambient air" at the bottom of the test plates, (2) preventing evaporation from the inlet water before it contacts the top of the packing plates. 
The system requirements for testing the new design dictated a design similar to a conventional wet cooling tower. For the test apparatus, a choice between forced draft and induced draft fans needed to be made. The forced draft type configuration has one significant advantage: the fans are not in the moist exit air stream, which reduces mechanical and electrical design problems. However, it does pose an additional problem, which in this particular case outweighs its other advantages: the need for a complicated transition section from the fan exhaust to the packing section to provide uniform air flow to the test section entrance. The induced draft system, which was selected, has the fan in the hot humid exhaust air but a uniform air inlet is easier to fabricate. Both of these concepts have three common disadvantages. First the inlet air has to travel through a minimum of two or three feet of water droplets falling from the packing section. Second the air is blowing across an area of water in the collection tank which increases the moisture in the air. Third the method of water distribution commonly used lets the water fall through a foot of exiting moist air before reaching the packing section. A feasible design would have to minimize the overall effects of these problems.

\subsection{DESIGN CRITERIA FOR THE ACTUAL SCALE MODEL}

Inlet conditions were specified according to those used in wet cooling towers. Approximate water and air flow rates were taken from 


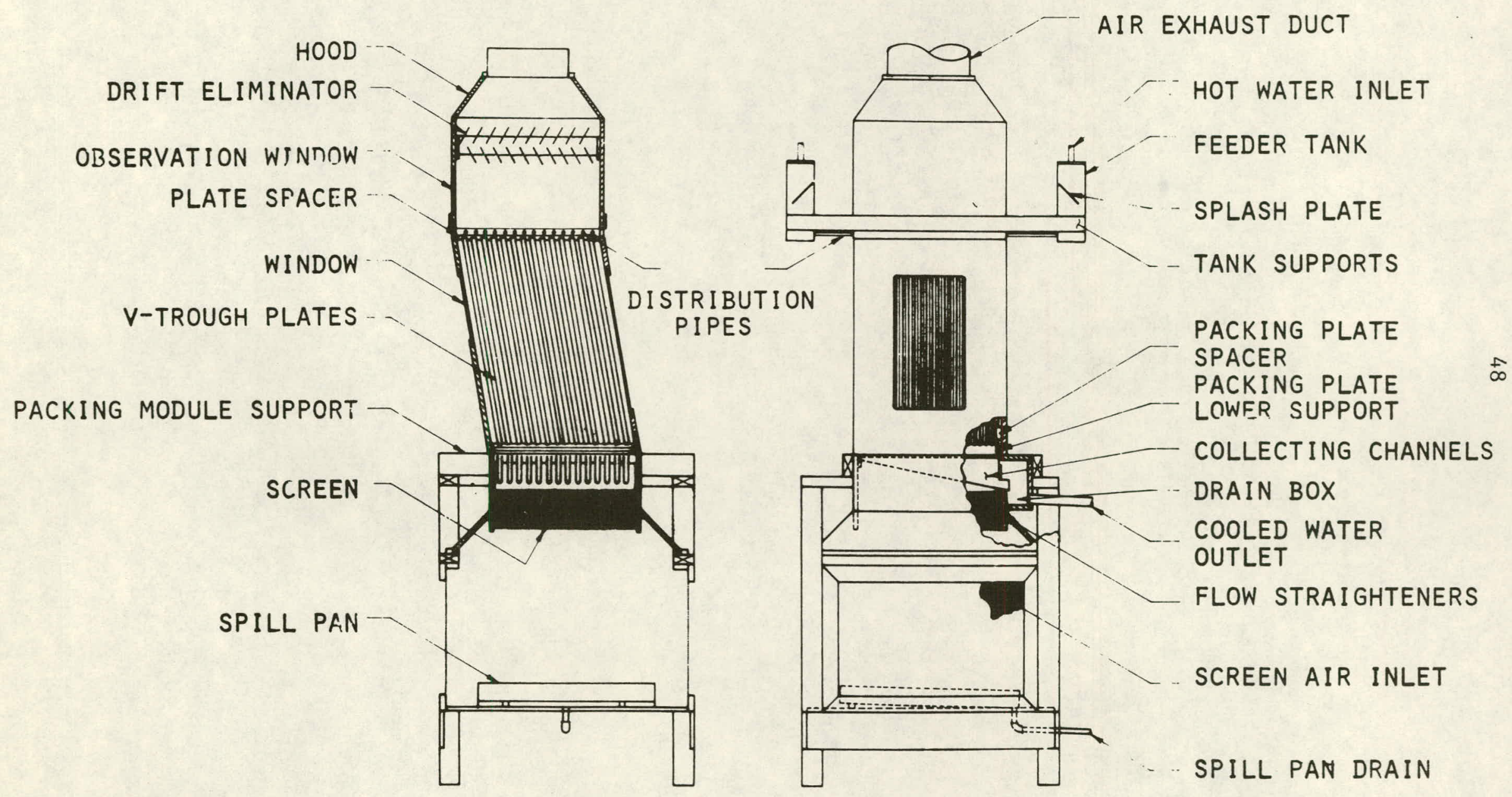

FIGURE 18. HEAT TRANSFER TEST APPARATUS ASSEMBLY 
those of conventional towers: water flow values of 2 to $18 \mathrm{gpm} / \mathrm{plan}$ foot square area, and air flow of 500 to $700 \mathrm{cfm} / \mathrm{plan}$ foot square area (2).

The overall size of the tower was limited by the laboratory area where it was to be built: celling clearance was 11 feet-4 inches and floor area was 6 feet by 6 feet including walk-around space. This restricted the size of the square air-inlet section. Making the air-inlet section 3 feet by 2 feet on all four sides, left one foot six inches all the way around the tower for work space. The square reducing section was not necessary but did offer less resistance to air flow. Use of the $61 / 4$ inch by $1 / 4$ inch diameter plastic drinking straws as air flow straighteners (see Figure 19) before the packing inlet section had been used successfully in the past by others to reduce the small eddie currents and to provide a uniform air velocity distribution to the packing inlet section.

The base pan (see Figure 18) was supported by $1 / 2$ inch plywood and stiffeners made out of galvanized sheetmetal, measuring 6 inch by 36 inch by 36 inch with a $3 / 4$ inch drain pipe soldered flush to the bottom. It was set on a slight pitch to collect sp 111 water from start up or faulty alignment between the distribution pipes and packing section or between the collection gutters and the packing section. 


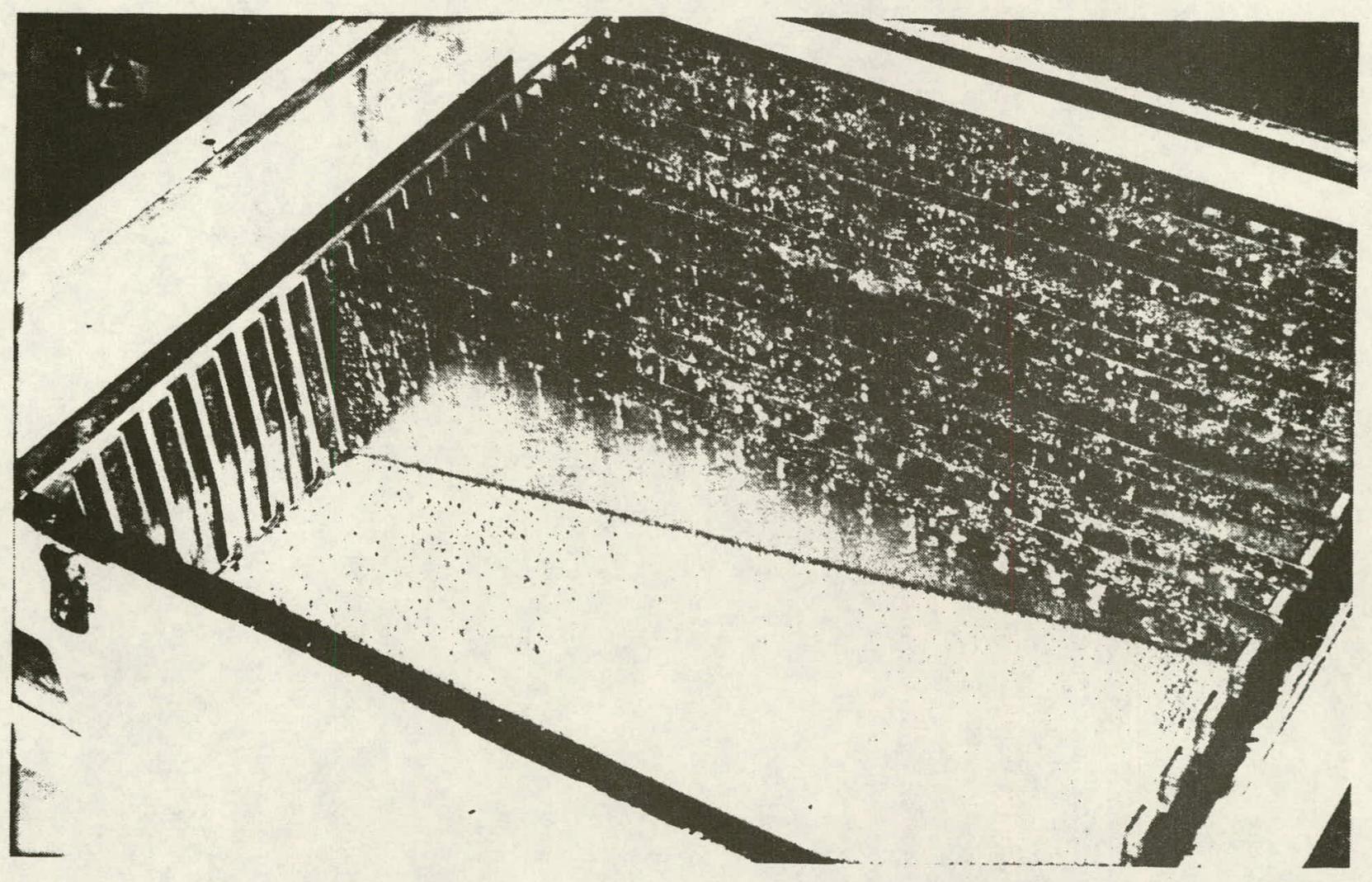

FIGURE 19. WATER COLIFCTING BOX

WITH FIVE WATER DRAIN OFF GUTTERS REMOVED TO SHOW STRAW FLOW STRAIGHTENERS 
The water collecting box (see Figure 19) was made of $3 / 4$ inch plywood. It contained the straw flow straighteners, and supported both the water collecting gutters and the side unit, the main water drail-off box. It also supported the upper portion of the tower; this was accomplished by the two cross member 2 by 4's which spanned the base frame.

The water collecting box drain was situated outside the main flow of the tower and was fed by 14 packing drain-off gutters. It, in turn, was drained by three $11 / 4$ inch diameter copper pipes into the two 20 gallon reserve tanks for recycling. It was made of galvanized sheet metal and was covered by a plexi-glass top, a window for observing water drain-off from each packing plate, which facilitated aligning and adjusting and the addition of thermocouple instrumentation.

The drain-off gutters were made of galvanized sheet metal, spanned the width of the packing section, and provided one of the essential control condition-features. They prevented the inlet air from contacting the exit water before it reached the packing plate. Their position was crucial to the packing section. The gutters must be parallel to the packing plates or some of the water drain-off will miss the gutters and fall into the inlet air stream.

The tower packing section was fabricated out of galvanized sheet metal 36 inches by 42 inches by 0.018 inches and formed on a standard sheetmetal break with alternate breaks of a 58.5 degree included angle. 
52

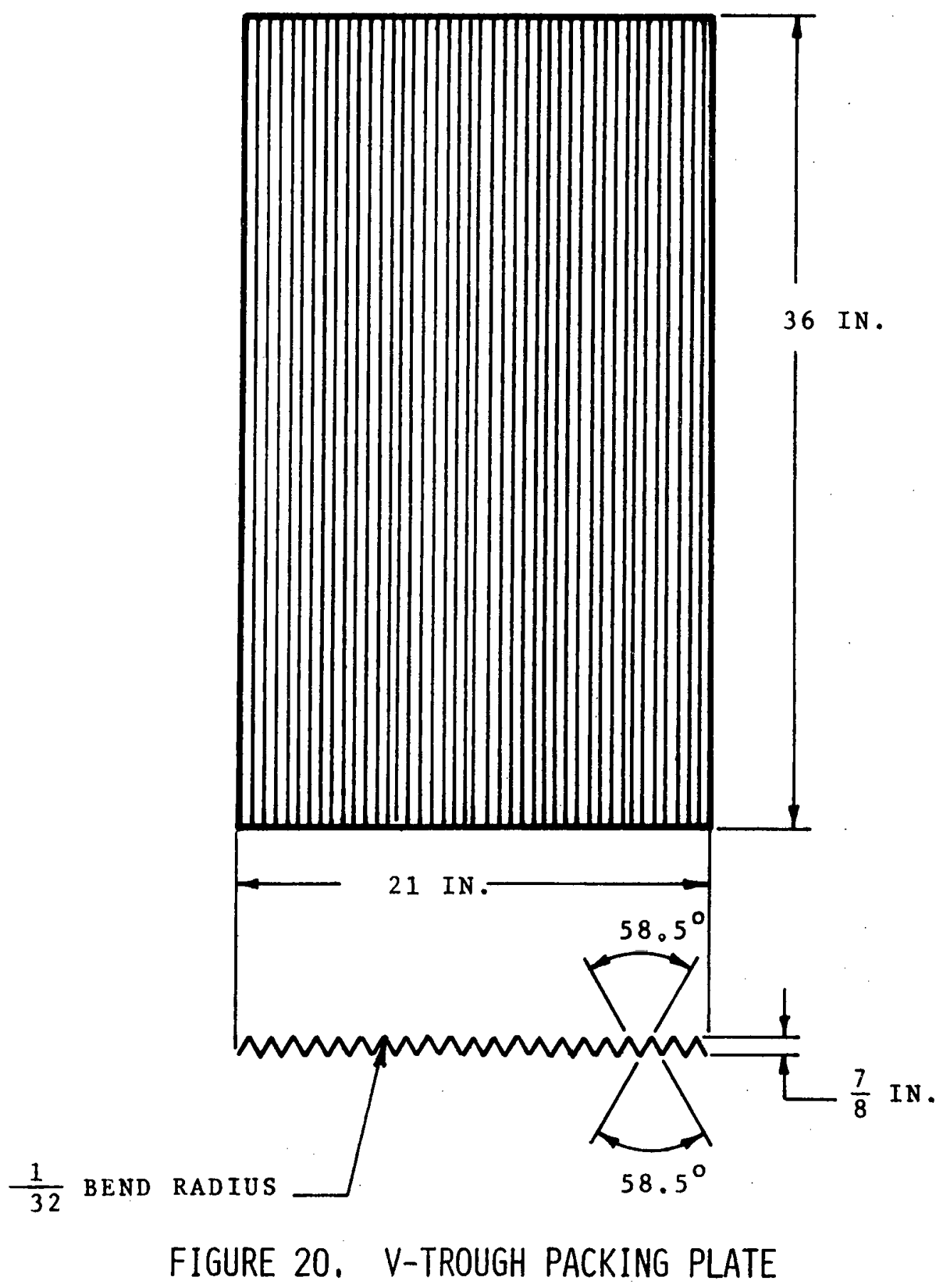


The troughs were approximately $7 / 8$ inches deep and 1 inch wide with 21 troughs to a plate (see Figure 20). A considerable amount of difficulty was encountered fabricating two identical plates; this has been attributed to the poor condition of the machines used. It was suggested that for production purposes this bending process be replaced by an automated stamping process. For the purposes of the test apparatus, the addition of measured stops and clamps proved sufficiently accurate. The packing section was composed of 14 plates spaced $11 / 2$ inches apart measuring from the trough of one to the trough of another. They were held in position by slots mounted on both inside walls of the tower. Across the top and bottom of the plates additional spacers, as depected in F1gure 21 , were used to maintain a uniform distance between plates, because individual plates possessed no rigidity in the horizontal direction.

An idealized approximation of the V-trough to fins was made, as shown in Figure 22. The calculated fin efficiency based on a convective heat transfer coefficient, $h$, of $5 \mathrm{BTU} /\left(\mathrm{Hr} \cdot \mathrm{Ft}^{2} \cdot{ }^{\mathrm{O}} \mathrm{F}\right)$ and the trough dimensions shown, was $79.6 \%$. Based on the results of the wetting characteristics test, a 10 degree angle was chosen for the slant of the packing section. It should be noted that the tower has been constructed in modular sections so that at any time a new section could be added or an old packing section deleted and replaced. Even though an angle of 10 degrees was used in this design, the distribution chamber 


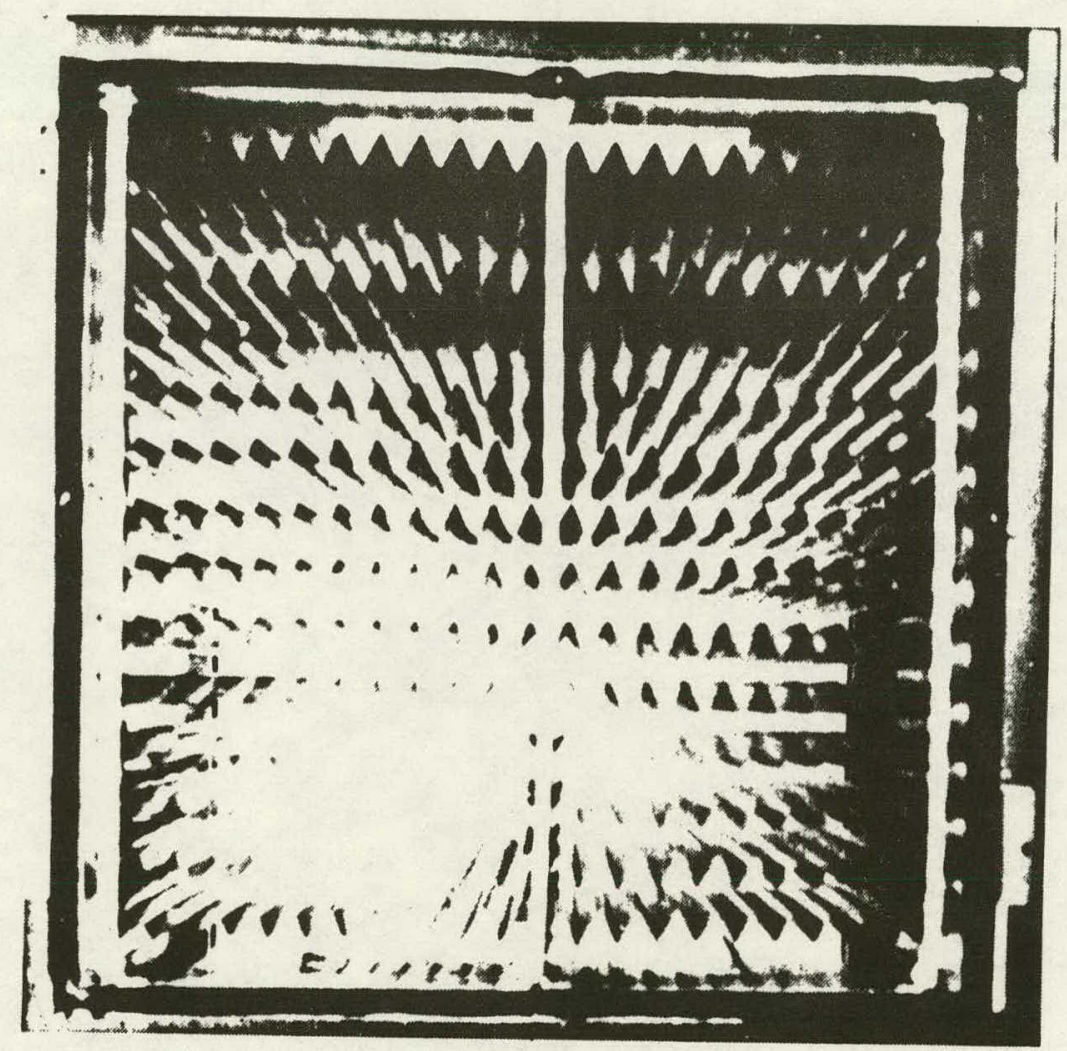

FIGURE 21. TOP VIEW OF V-TROUGH PACKING TEST SECTION 


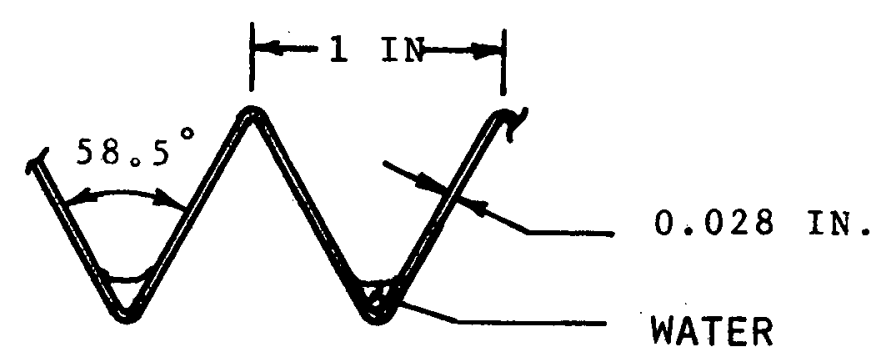

(A) PACKING PLATE CROSS-SECTION

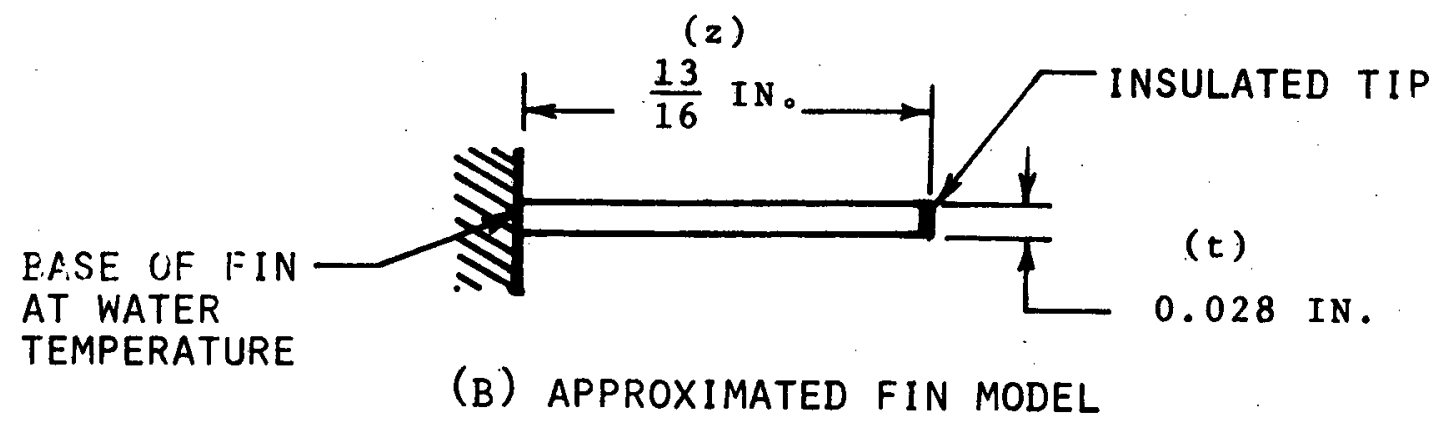

REFERENCE (4)

FIN EFFICIENCY, $\eta_{\mathrm{f}}=\frac{\text { ACTUAL HEAT TRANSFER }}{\text { HEAT WHICH WOULD BE TRANSFERRED }}$

IF ENTIRE FIN AREA WERE AT THE

BASE TEMPERATURE

$\eta_{f}=0.796$

FIGURE 22. MODEL OF PACKING SECTION AS A FIN 
and the collecting box both had a 2 foot by 2 foot cross-section and any 2 foot by 2 foot by 3 foot section could have been put between them.

The tower section holding the packing plates has windows on three of its sides to allow observation of wetting characteristics during operation.

The requirements for the water distribution apparatus were:

1. Should evenly distribute water over the entire crosssectional area of packing for purpose of testing any packing section.

2. Should prevent the inlet water from contacting the exit alr before reaching the packing plates.

3. Should be able to vary the operational flow rates between the predetermined values.

4. Should be able to maintain operation free of malfunction long enough for heat transfer test data to be collected.

5. Should be easily accessible for maintenance or replacement.

Here again, as with the packing spray tube, emphasis was upon methods which could be practically made. Many concepts were considered, but the use of pipes with a series of small holes was chosen because 1t minimized the distance that the distributed water had to travel through the exhaust air before contacting the packing plates. 
An alternate design with shower spray nozzles necessitates a one to two foot clearance above the packing surface for adequate shower spray coverage; this is in conflict with the conditions necessary for the exhaust air, and it confounds measurements with additional humidity. Also, the excessive moisture carried off is not conductive to prolonged fan operation.

Another concept using configurations similar to a 2 foot by 2 foot by $11 / 2$ foot tank with many water jet orifices fed by a constant head of water and separated by large air exhaust exhibits 3 distinct features (see Figure 23):

1. All jet holes can be manufactured to have the same angle

2. A constant head of water to each jet gives a uniform distribution to the entire packing area

3. The method allows the air to flow past the distribution system without contacting the inlet water.

However, this design required extensive machining and originally did not allow for a simple change of orifice size without the dismantling of the upper portion of the tower.

The concept of a horizontal water distribution pipe for each plate had already performed satisfactorily in the water visualization test apparatus. It would be a stralght forward machining process, and holes could easily be enlarged or added. However, the large pipe required to provide the flow could have hindered the exhaust air flow. It should be noted that all the methods described here are to optimize 

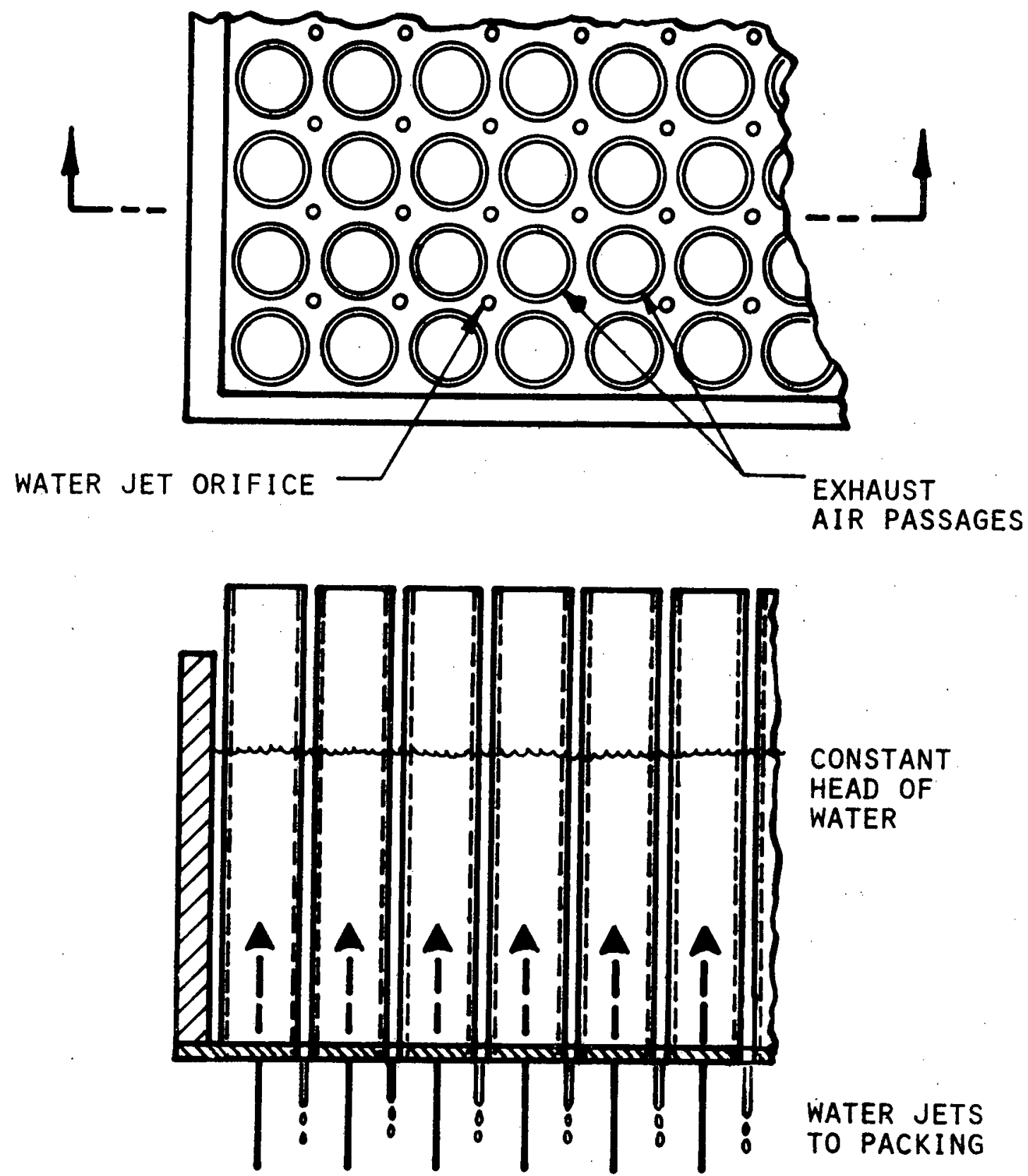

EXITING AIR

FROM PACKING

FIGURE 23. ALTERNATE WATER DISTRIBUTION DESIGN 
uniform distribution to the packing section so that the center plates could be instrumented with temperature sensitive devices uninfluenced by erractic neighboring conditions. Each of these methods would be too expensive for large scale application.

A study was conducted to find the minimum pipe size which would not have more than a $5 \%$ deviation of flow rate between the first hole and the last hole. It was found experimentally that for the specified flow rates a $1 / 2$ inch diameter pipe with twenty-one holes of 3/32 inch diameter spaced 1 inch on center would perform within the $5 \%$ flow deviation if the pipe was fed equally at both ends.

Each of the 14 pipes were spot-faced along one side just deep enough to provide a flat surface for the orifice (e.g., Figure 4). Then the 3/32 inch diameter holes were drilled, deburred on the inside with an emery plunger, and swabbed clean with cloth soaked in acetone.

A thin frame was constructed out of wood to space the pipes $11 / 2$ inches on center, identical to the packing plates spacing, and parallel to the plates (see Figures 24,25 ). The proper alignment for the pipes and the packing frame section was found by running water through the pipes and manually adjusting the pipe frame and pipe angular orfentation until all water flowed directly on to the packing plates. This frame was held in position with four two inch locating pins, one per side which allowed for fast removal. Figure 26 shows the relative juxtaposition of the frame, packing section, and the pipes with the water flow. The one inch length of completely dry plate area 


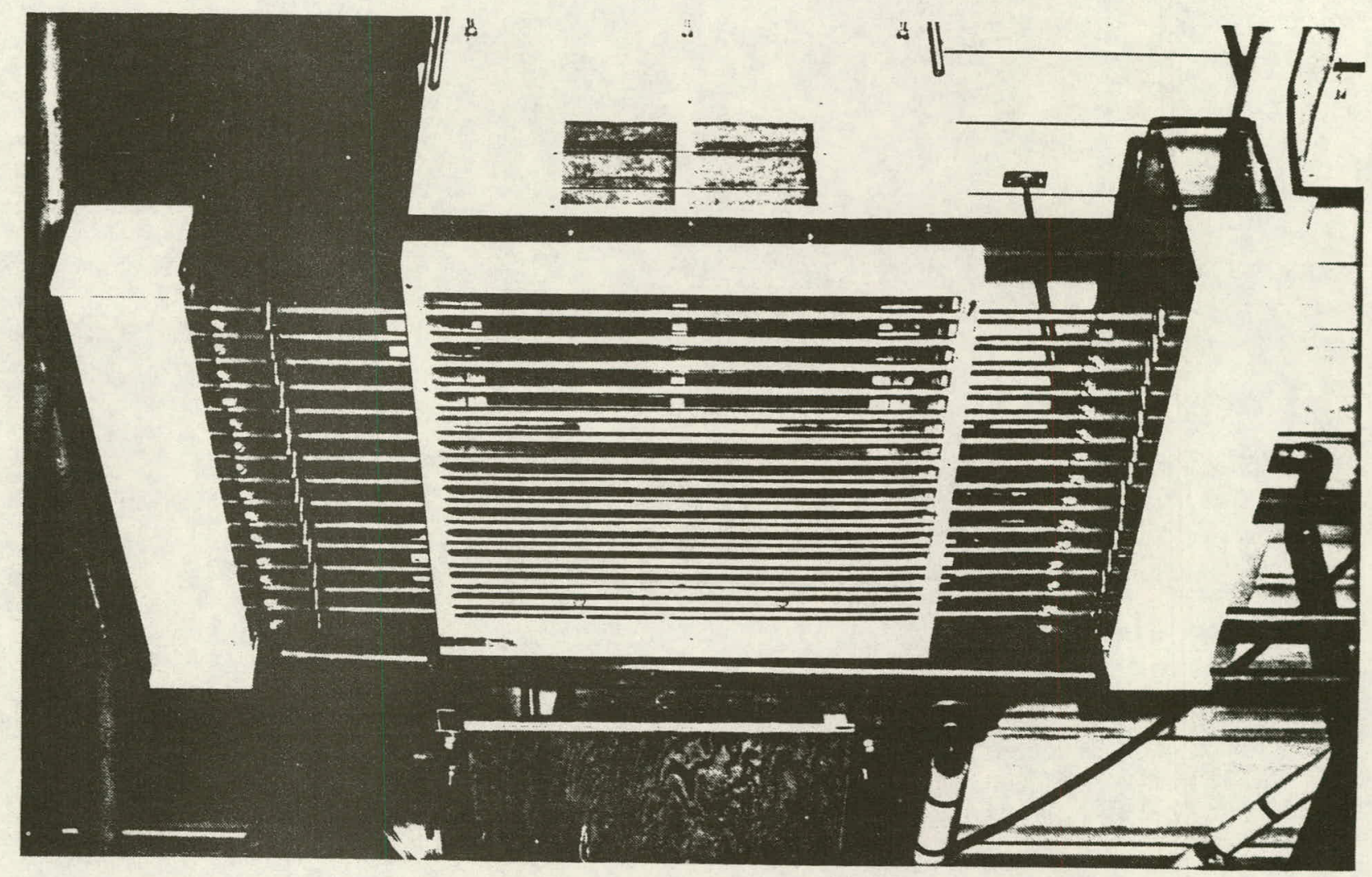

FIGURE 24. WATER DISTRIBUTION PIPES SEEN FROM BELOW (packing Section Removed) 

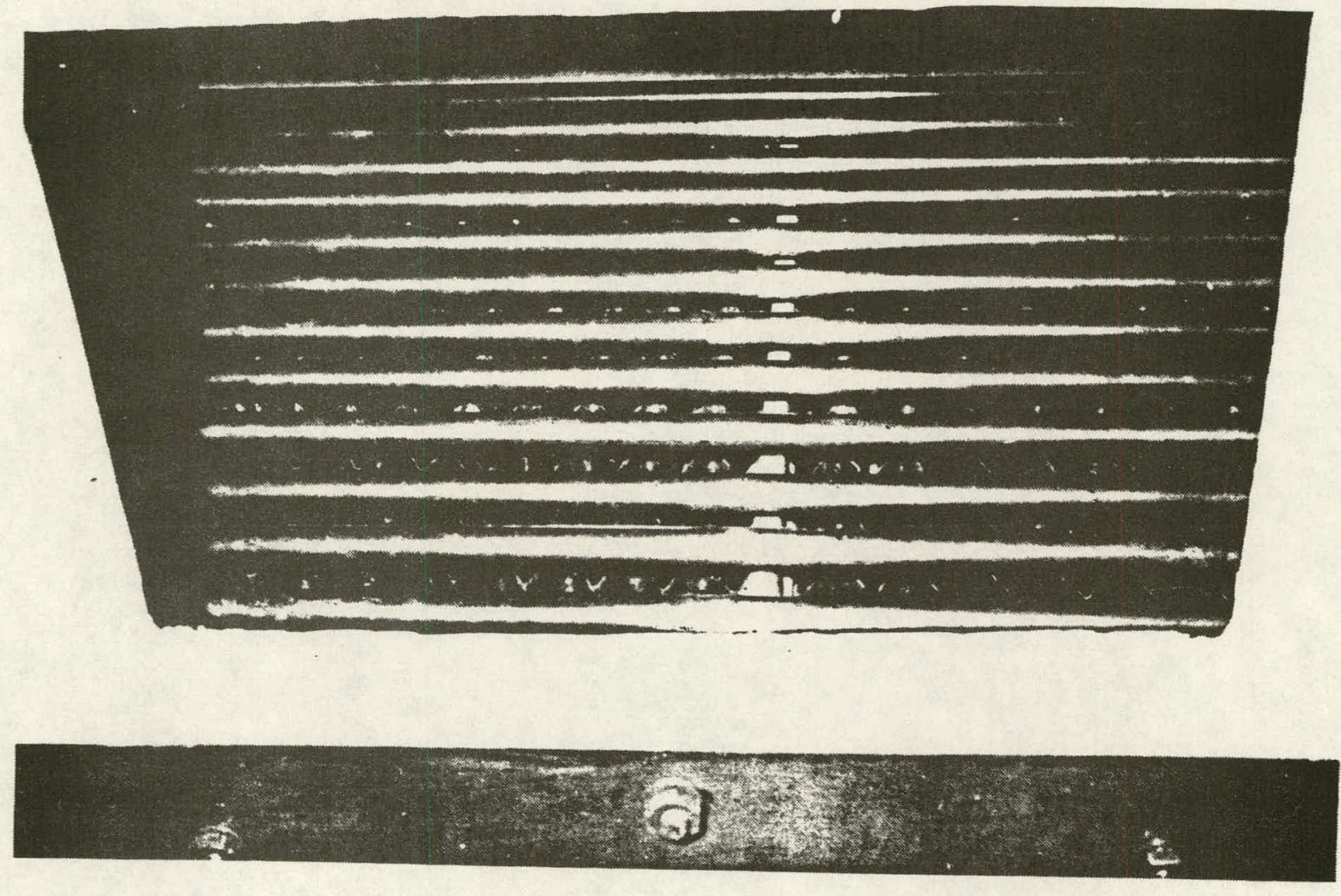

FIGURE 25, DISTRIBUTION PIPES AND V-TROUGH PACKING SECTION VIENED THROUGH THE DISTRIBUTION CHAMBER WINDOW 


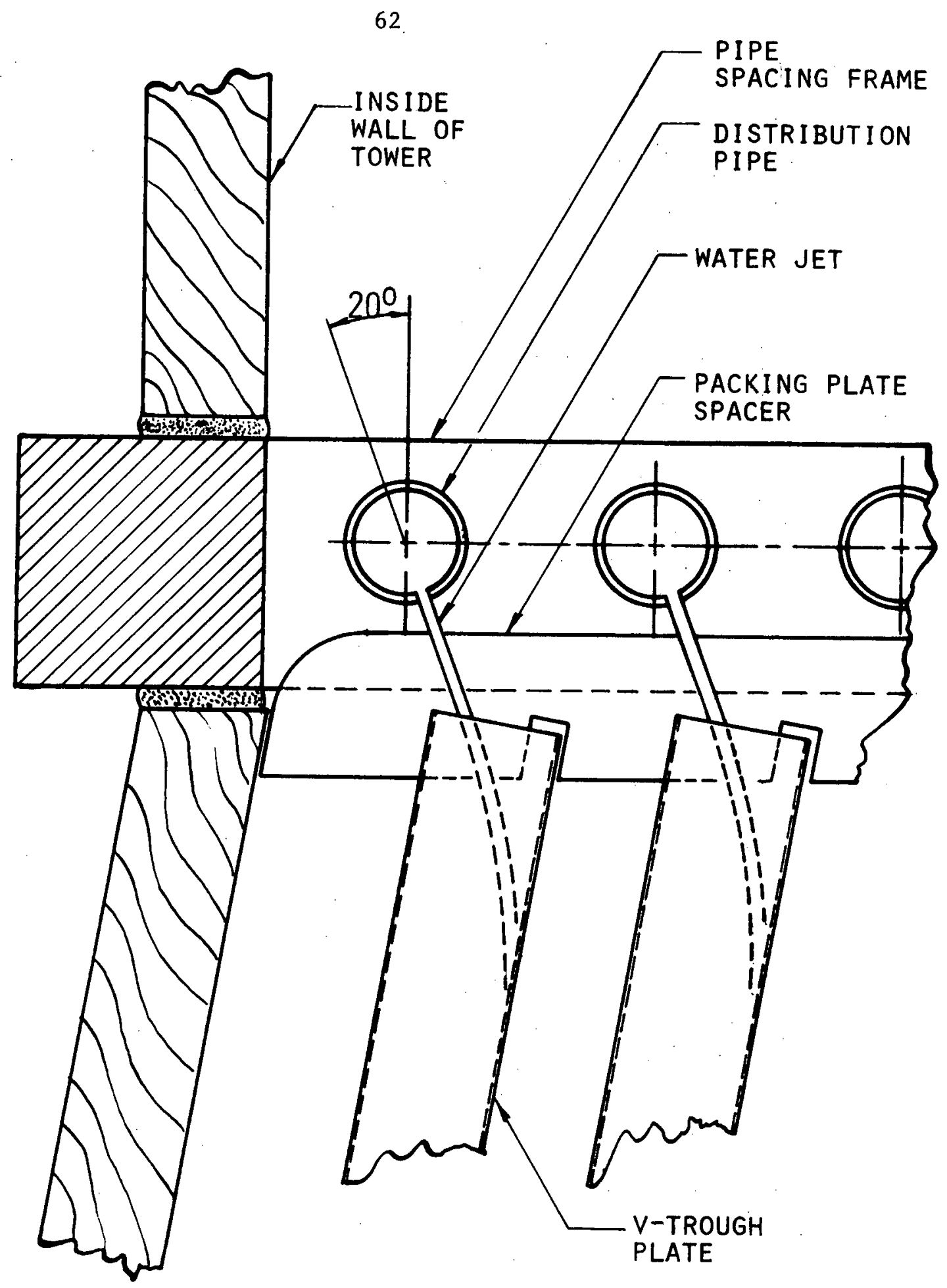

FIGURE 26. JUXTAPOSITION OF SPRAY PIPES, FRAME, SPACERS, AND V-TROUGH PLATES 
at the top of the packing section can accommodiate possible misalignment of the distribution pipes preventing water from accidentally spllling over the top of the plate and down the back of the trough, should a sudden change of flow rate occur. It can be seen in this idealization that the distance travelled by the water through the exhaust air is minimal; and the water remains a coherent stream.

The 14 pipes were fed by two plexi-glass tanks which would provide water head up to 11 inches. The flow ports were raised 1 inch off the bottom of the tank to minimize the possibility of sediment clogging the pipe orifices. Each tank received a supply of hot water from the heat exchanger via a rotometer and a valve arrangement which monitored the flow to each tank. The 14 pipes also served to equalize the head between the two tanks and alleviate the need for critical adjustment of the two rotometer valves.

The distribution chamber which is an open space above the packing section was designed to allow for experimentation with different types of water distribution systems at a later date. It provided room for observation through the two windows and thermocouple and humidity instrumentation. The upper part of the chamber contains a typical drift eliminator: a series of baffles to help prevent large moisture droplets, which had been carried up by the exhaust air, from escaping. 


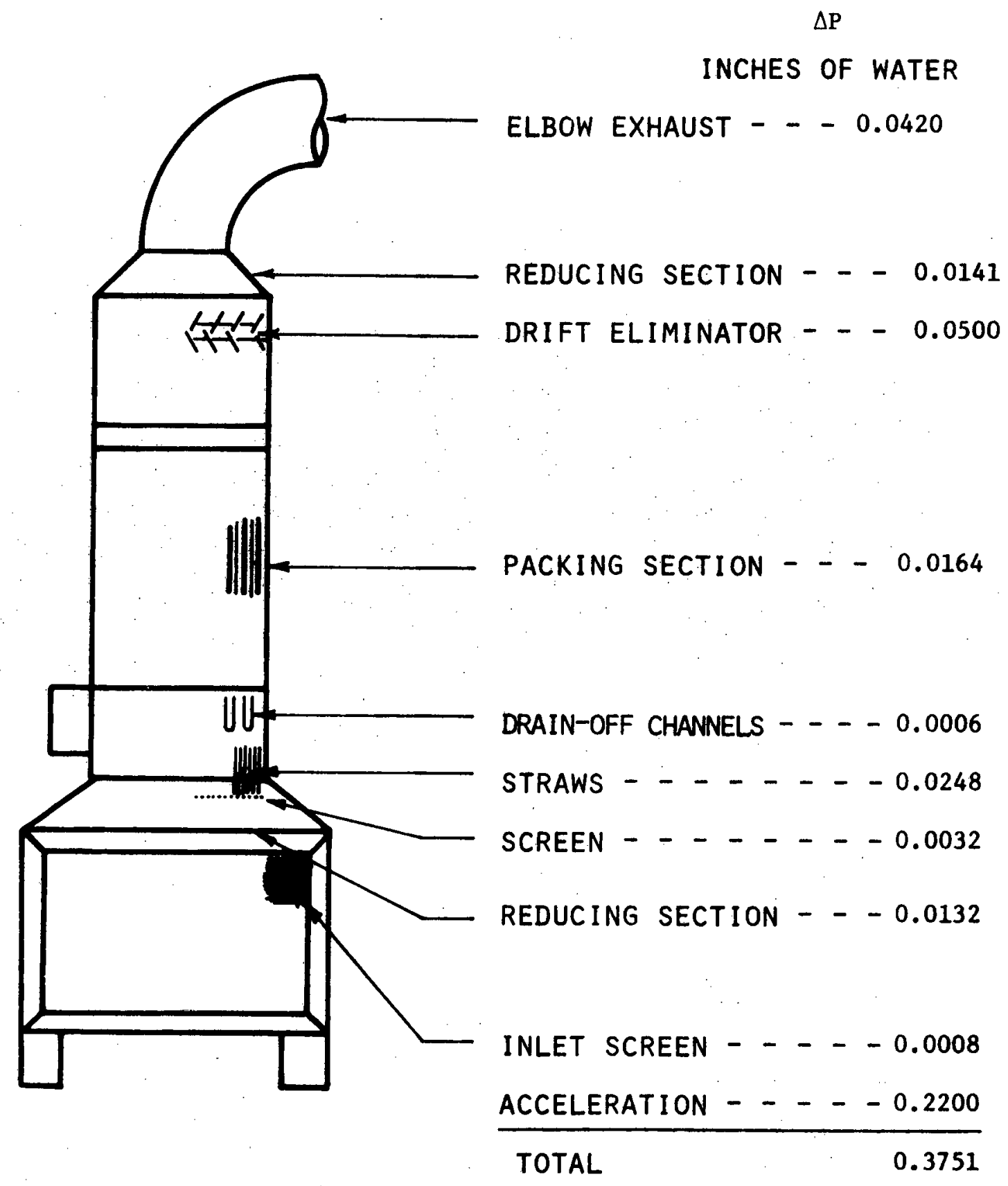

FIGURE 27. AIR FLOW PRESSURE DROP THROUGH THE MODEL TOWER 
To maintain operating conditions similar to those of existing wet towers, which use air flow rates of 500 or $700 \mathrm{cfm} / \mathrm{plan}$ foot square area, the designed tower of 4 square feet would require an air flow of approximately $2000 \mathrm{cfm}$. To obtain a fan and motor which could deliver this capacity, it is necessary to know the total head against which the fan will be working. An analysis of the entire tower pressure drop was performed and the results pictorially shown in Figure 27 . Reference to the exact method of analysis may be found in Appendix 4. It was concluded that the fan must be capable of delivering $2000 \mathrm{cfm}$ pressure drops less than 0.5 inches of water. It would require a pressure equivalent head of 0.22 inches of water just to accelerate the air from rest to 31 feet per second, which would be tha air exhaust velocity just before the fan, and an additional 0.16 inches of water to overcome friction.

\subsection{MODEL TOWER IN OPERATION}

The apparatus provided the specified environment for the packing plates. Inlet water temperature was easily varied from 100 degrees to 120 degrees Fahrenheit by a steam-water heat exchanger with considerable margin on either side. When these runs were made (July 1975) the air inlet temperature was 90 degrees and the humidity in the Experimental Projects Laboratory was $40 \%$. The fan works effortlessly, but measurements will be necessary to determine actual air flow velocities. The spray pipes have become misaligned with the water collecting gutter; but this is only slight and can be corrected. 
The V-troughs channel the flow as in the small section test experiments and only show unusual back wetting when a pipe becomes clogged.

After instrumentation is completed, the actual heat transfer data collecting experiment will be run. 


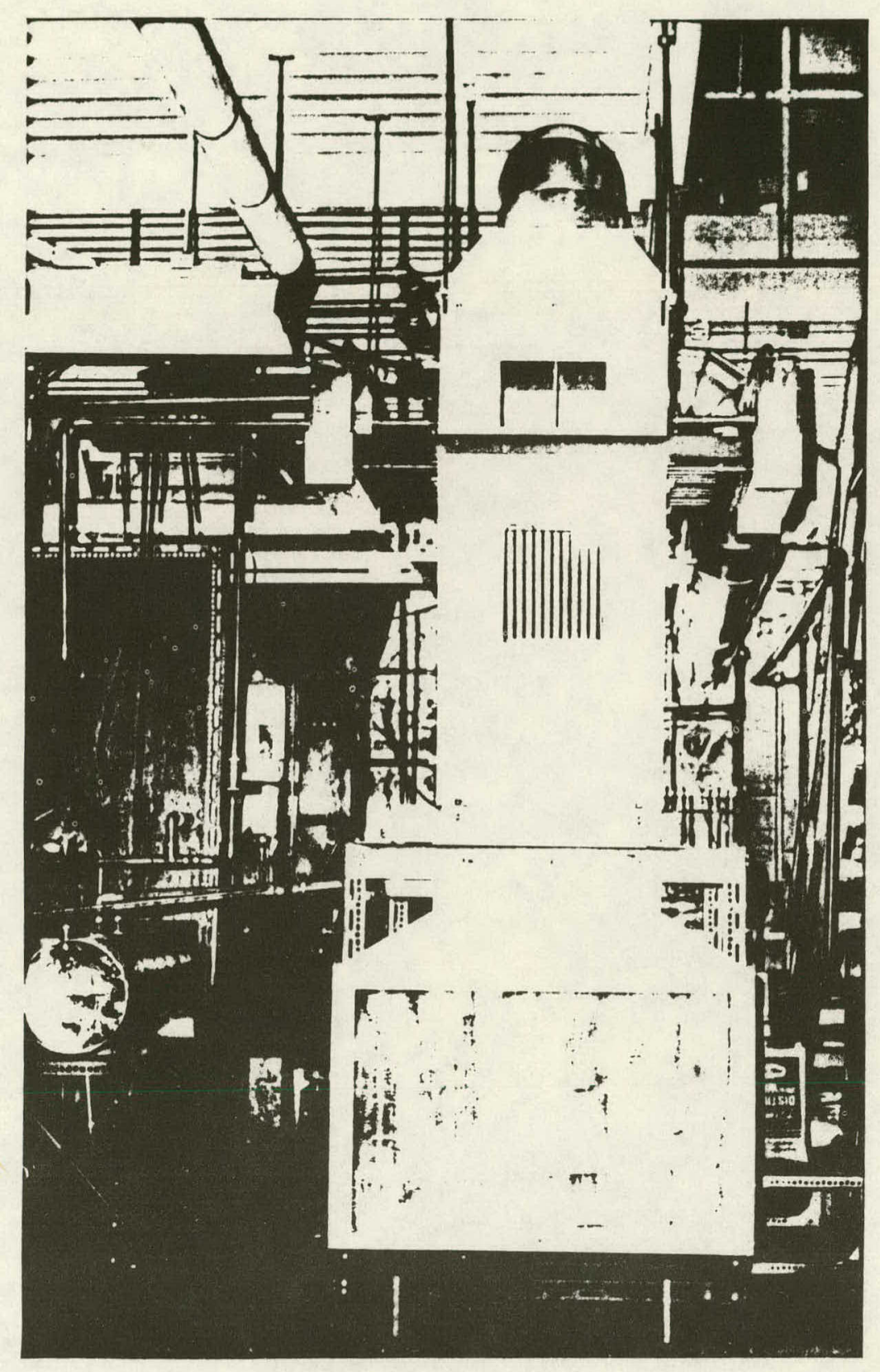

FIGURE 28, HEAT TRANSFER TEST APPARATUS 


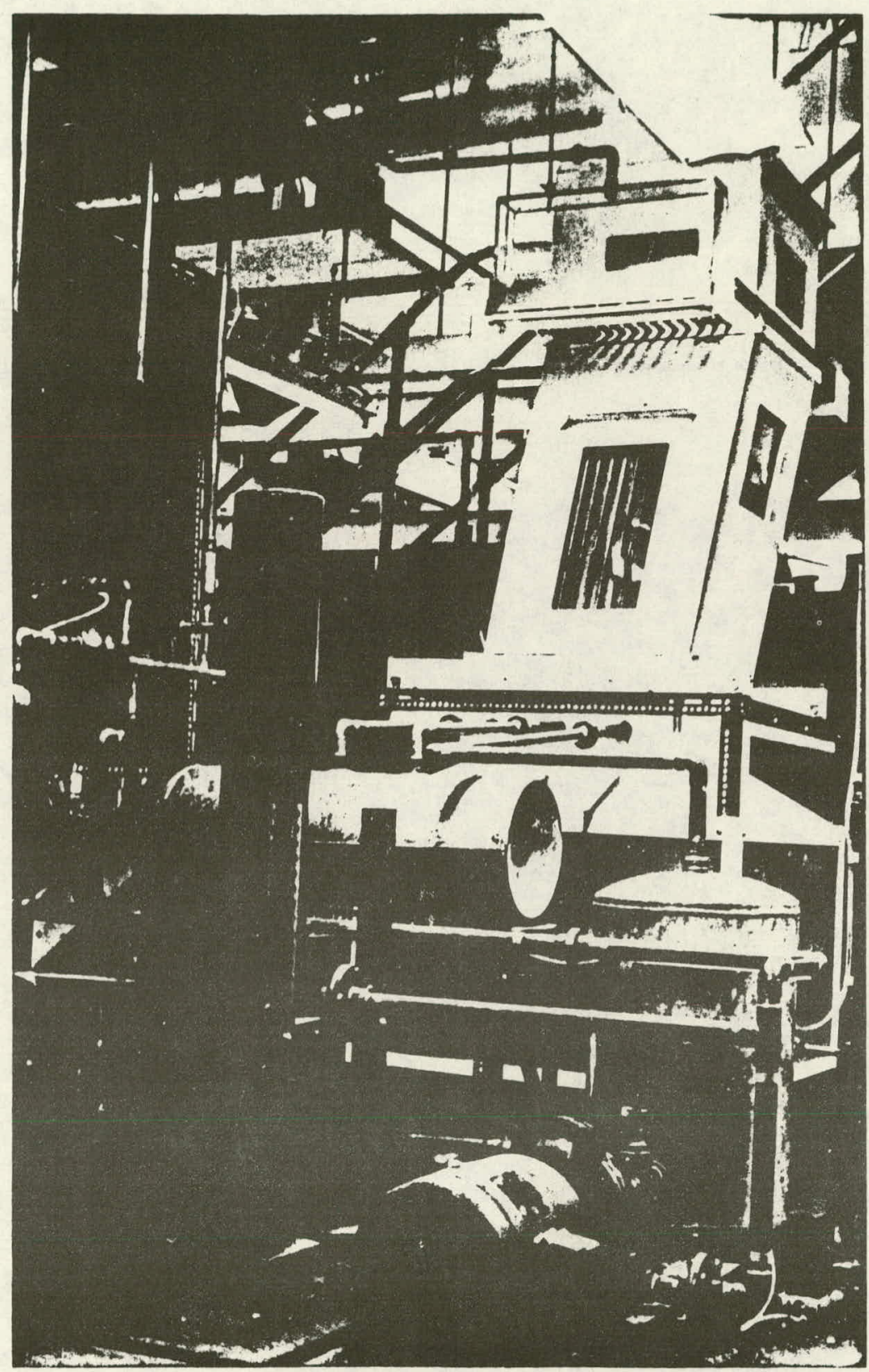

FIGURE 29. HEAT TRANSFER TEST APPARATUS

SHOWING THE TEN DEGREE SLANT OF THE PACKING SECTION WITH UTILITIES IN THE FOREGROUND 


\section{CHAPTER FIVE}

COMPUTER PROGRAM

\subsection{ANALYSIS}

The analytical portion of this project has involved the development of a computer program which will be used to simulate the performance of the wet-dry tower. It is intended that this program be used as a design tool for full scale towers. The present simulation is concerned with the V-trough packing section. However, only slight changes would be necessary to study other types of wet-dry packing sections. No analysis is made of heat transfer through a distribution system or water collection system. Only the packing section is studied. The small tower which has been built will be used to verify the program and to determine heat transfer coefficients or other parameters.

The basic equations were taken from a paper by G. Yadigaroglu [10] which was concerned with totally wet towers with flat plates. They were then modified to include heat transfer from the dry surface. The equations are listed in Figure 1. The solution involves choosing values for the temperatures, water flow rates, absolute humidity and heat transfer rates $\left(T_{\ell}, T, M_{\ell}, W, Q_{C L}, Q_{D P}, Q_{E L}\right)$ and solving for the incremental changes. These changes are then added to the initial values and the solution repeated in a marching out or Euler process along the packing section.

Other terms in the equations, such as specific heats, and heat transfer coefficients, are described by equations shown in the program listing. For all the equations in this section, the terms not defined in the text are given in Table 1. Dimensionless groups are given in the List of Principal Symbols. The expressions for the heat transfer coefficients $h$ and $h_{D P}$ are taken from the Dittus-Boelter relation used by Yadigarog1u [10]. 


$$
\mathrm{Nu}=0.022 \operatorname{Pr}^{0.6} \mathrm{Re}^{0.8}
$$

The mass transfer coefficient, $H_{D}$, is derived from the Chilton-Colburn analogy between heat and mass transfer:

$$
\frac{\mathrm{Nu}}{\operatorname{RePr}^{1 / 3}}=\frac{\mathrm{Sh}}{\operatorname{ReSc}^{1 / 3}}
$$

where Sh is the Sherwood number and Sc is the Schmidt number. This may be rewritten:

$$
h_{D}=\frac{h}{\rho_{\operatorname{mix}} C_{\text {mix }}}\left(\frac{P r}{S c}\right)^{2 / 3}
$$

$\rho_{\operatorname{mix}}$ and $\mathrm{C}_{\min }$ are the density and specific heat of its air water-vapor mixture. Yadigaroglu stated that these correlations are not the best for predicting cooling tower performance. Comparisons will be made with the model tower to check the accuracy of the program. The velocity used in calculating the Reynolds number for $h$ and $h_{D}$ is the relative velocity between the air stream and the water, while the velocity for $h_{D P}$ is simply the air stream velocity. The characteristic length used for both Reynolds numbers is the hydraulic diameter, DH, of the space between the packing plates: [5]

$$
\mathrm{DH}=4 \frac{\mathrm{A}}{\mathrm{P}}
$$

In this equation $\mathrm{A}$ and $\mathrm{P}$ are the area and perimeter of the space. The water velocity used is the average velocity calculated from the given geometry and wet to dry ratio. If it is specified that the tower is completely wet then the analysis is done for flat plates wetted by a film 
on both sides. In this case the velocity is given by [10]:

$$
v=\frac{\rho_{\ell} g \delta^{2} \sin \theta}{2 \mu_{\ell}} \quad \text { where } g \text { is }
$$

the gravitational acceleration and the film thickness $\delta$ is given by

$$
\sqrt[3]{\frac{3 \dot{\mathrm{m}}_{\ell} \mu_{\ell}}{\rho_{\ell}^{2} \mathrm{~B}_{\ell} g \sin \theta}}
$$

In both of these equations, $\rho_{\ell}$ and $\mu_{\ell}$ are the density and absolute viscosity of water.

The fin efficiency $\eta_{f}$ is taken from the equation:

$$
\eta_{\mathrm{f}}=\frac{\tanh ^{\sqrt{h \mathrm{PL}^{2} / \mathrm{KA}}}}{\sqrt{\mathrm{hPL}{ }^{2} / \mathrm{KA}}}
$$

where $P$ and $A$ are the perimeter and cross sectional area of the fin, $K$ is the thermal conductivity of the plate material and $L$ is the fin length, or half the distance between water channels. If the tower is assumed to be totally dry, then it is idealized as a heat exchanger with the water shielded from the air. In this case $\mu_{f}$ is set equal to one since the dry surface is at the water temperature. The expression for the thermal diffusivity of water vapor in air, $D_{v}$, was taken from the ASHRAE Handbook of Fundamentals [13] and that for the specific heat of water vapor from Wark [12]. The density of saturated water vapor $\rho_{v} v_{s a t}$ was obtained as a function of temperature by integration of the ClapeyronClausius equation. An additional correction factor was added to provide a better fit to tabulated data. Sutherland's formula was used to obtain 
the viscosity and conductivity of air as functions of temperature. Equations for the heats of vaporization, $h_{f g}$ and $h_{f g}{ }^{\circ}$, and the density and viscosity of water were found simply by fitting a curve to existing data.

As was stated earlier, the Euler method is used in the solution of the basic equations. Initial values are given at the bottom of the tower. However, since the tower is counterflow, only the air inlet conditions are known at the bottom. The water inlet conductions are given at the top. For this reason a guess of the water outlet conditions must be made and an iterative process is used to obtain the proper water inlet conditions.

\subsection{RESULTS}

The program was used to predict the performance of $V$-trough packing section under various operating condictions. The effect of different amounts of wet area is shown on Figure 31. It can be seen that increased water temperature drop is accompanied by increased outlet air humidity. In the program the assumption is made that the ratio of wet to total area is an independent variable, although it is a function of water flow rate and plate angle $\theta$. However, observation of the model tower has shown that the plate remains approximately $5 \%$ wet independent of the water flow rate with $\theta=10^{\circ}$. The values calculated for the $3 \%$ wet case are artificially high because the flow is forced through a hypothetically small area, resulting in high velocities and thus high heat transfer coefficients. Three percent is not a probably ratio for this type of packing sectionwith reasonable flow. Ratios higher than $5 \%$ can be obtained by changing the angle. 
Figure 32 shows the advantage of high air speeds. Heat transfer rates are increased and oultet humidity decreased. Figure 33 indicates that increases in the water flow rate have little effect on humidity but that the cooling range $\Delta \mathrm{T}$ is decreased.

The performance with various inlet conditions is shown in Table 2 . At high inlet humidities, fog plumes may still be formed by a wet-dry tower, but the severity and frequency will be reduced.

The results given have not yet been confirmed by actual runs of the tower. Tables 4,5 , and 6 show the results when different air inlet conditions' are used.

No provision is made for the presence of saturated air in the tower. Data included in Table 5 for the wet tower represents an artificial extreme for comparison to other data. Tables 7 and 8 show the effects of changing the heat transfer coefficient and step size, respectively, on the predicted performance. 


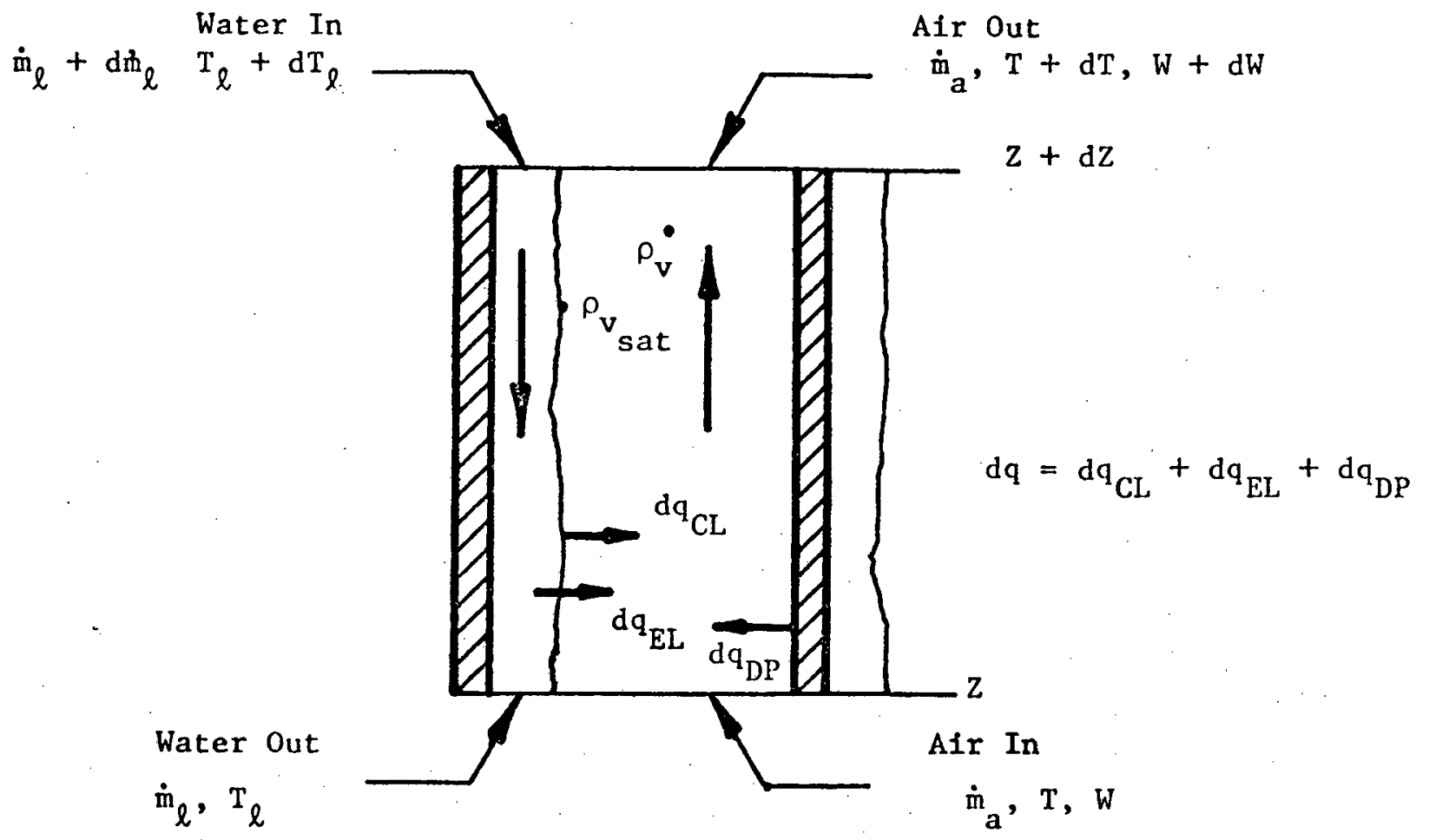

WATER HEAT BALANCE

$$
\left(\dot{\mathrm{m}}_{\ell}+\dot{\mathrm{d}}_{\ell}\right) \mathrm{c}_{\ell}\left(\mathrm{T}_{\ell}+\mathrm{d} \mathrm{T}_{\ell}-\mathrm{T}_{\mathrm{o}}\right)-\dot{\mathrm{m}}_{\ell} \mathrm{c}_{\ell}\left(\mathrm{T}_{\ell}-\mathrm{T}_{\mathrm{o}}\right)=\mathrm{dq}
$$

AIR HEAT BALANCE

$$
\begin{aligned}
& \dot{m}_{a} c_{a}\left(T-T_{o}\right)+w \dot{m}_{a}\left[c_{v}\left(T-T_{o}\right)+\dot{h}_{f g}\right]-\dot{m}_{a} c_{a}\left(T+d T-T_{o}\right) \\
& -(W+d W) \dot{m}_{a}\left[c_{v}\left(T+d T-T_{o}\right)+\dot{h}_{f g}\right]=-d q
\end{aligned}
$$

CONVECTIVE HEAT TRANSFER FROM WATER SURFACE

$$
\mathrm{dq}_{\mathrm{CL}}=\mathrm{h}\left(\mathrm{T}_{\ell}-\mathrm{T}\right) \mathrm{B}_{\ell} \mathrm{dZ}
$$

CONVECTIVE IHFAT TRANSFER FROI DRY SURFACE

$$
d q_{D P}=h_{D P}\left(T_{\ell}-T\right) B_{\ell} d Z+\eta_{f} h_{D P}\left(T_{\ell}-T\right) B_{D} d Z
$$

EVAPORATIVE HEAT TRANSFER

$$
{ }^{d q_{E L}}=\left[h_{f g}+c_{\ell}\left(\mathrm{T}_{\ell}-\mathrm{T}_{0}\right)\right] \dot{\mathrm{d}}_{\ell}
$$

MASS TRANSFER

$$
\dot{d m}_{\ell}=h_{D}\left[\rho_{v_{\text {sat }}}\left(\mathrm{T}_{\ell}\right)-\rho_{\mathrm{v}}(\mathrm{T})\right] \mathrm{B}_{\ell} \mathrm{d} Z
$$

Figure 30: Basic Equations 
Table 2: Nomenclature For Figure 30

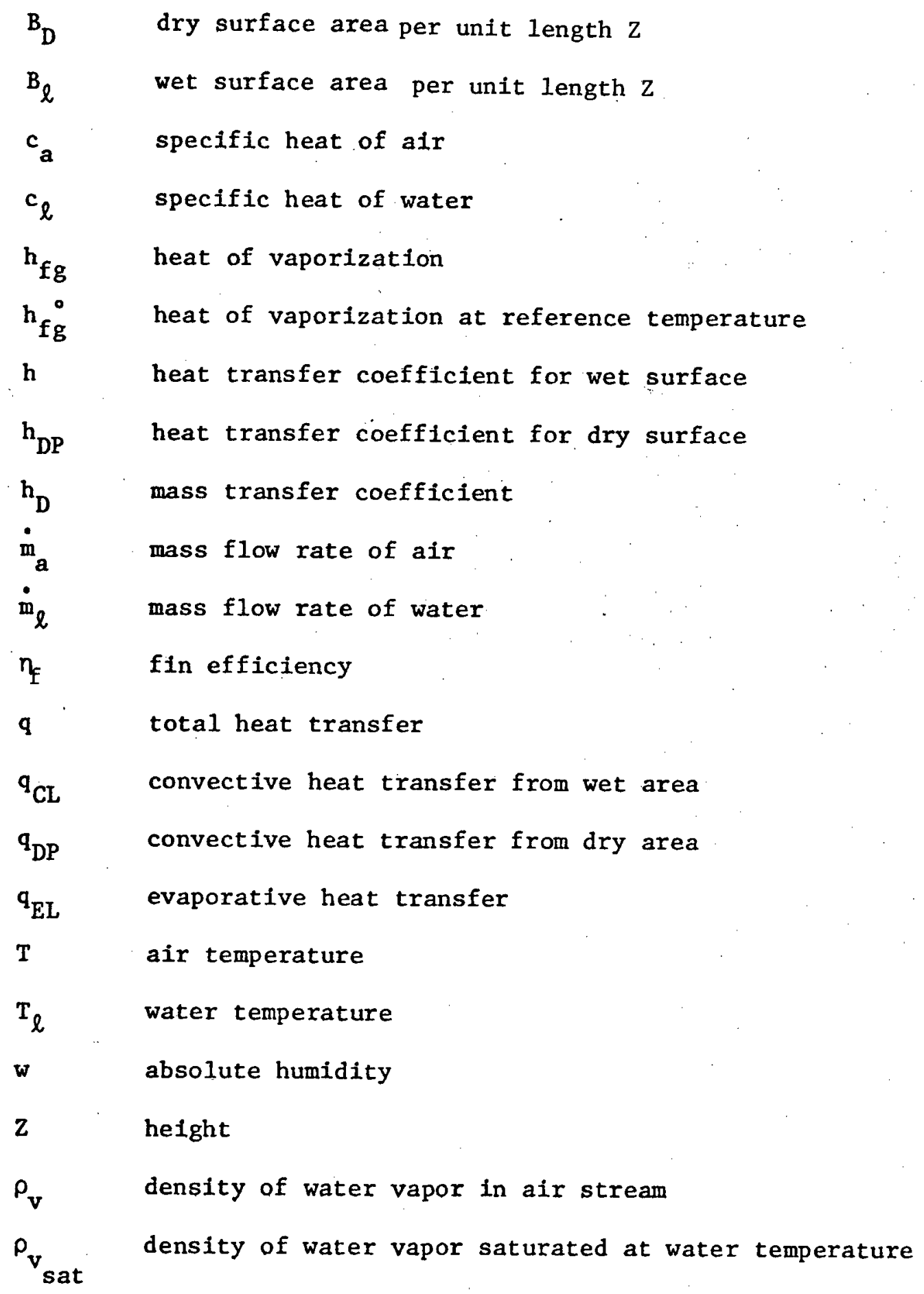


TABLE 3

Standard Inputs

$\begin{array}{ll}\text { Water Inlet Temperatre } & 120^{\circ} \mathrm{F} \\ \text { Water Inlet Flow Rate } & 20 \mathrm{GPM} \\ \text { Air Inlet Temperature } & 70^{\circ} \mathrm{F} \\ \text { Air Inlet Humidity } & 70 \% \\ \text { Approximate Air Velocity } & 7 \mathrm{ft} / \mathrm{sec} \\ \text { Wet to Total Area Ratio } & .05 \\ \text { Step Size } & .03 \mathrm{ft} \\ \text { Packing Width } & 2 \mathrm{ft} \\ \text { Packing Length } & 34 \mathrm{in} \\ \text { Number of Plates } & 14 \\ \text { Plate Spacing } & 1.5 \mathrm{in} \\ \text { Number of Troughs per Plate } & 21 \\ \text { Plate Angle From Vertical } & 10^{\circ} \\ \text { Plate Material } & \text { Steel }\end{array}$



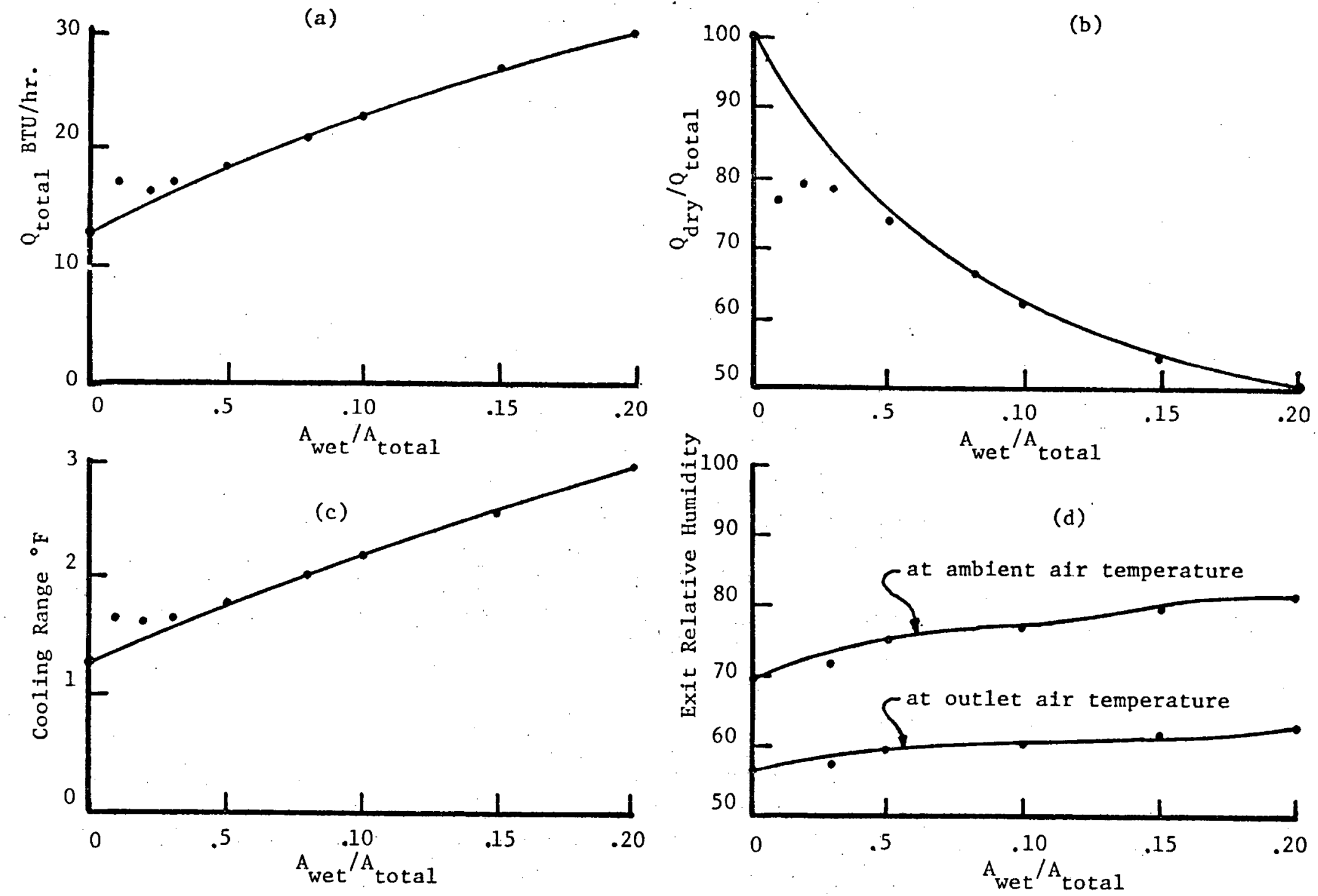

FIGURE $3 \mathbf{k}$ Wet to Total Area Ratio vs. Various Parameters

a. Total Heat Transfer b. Fraction Sensible Heat Transfer

c. Cooling Range d. Exit Humidity 

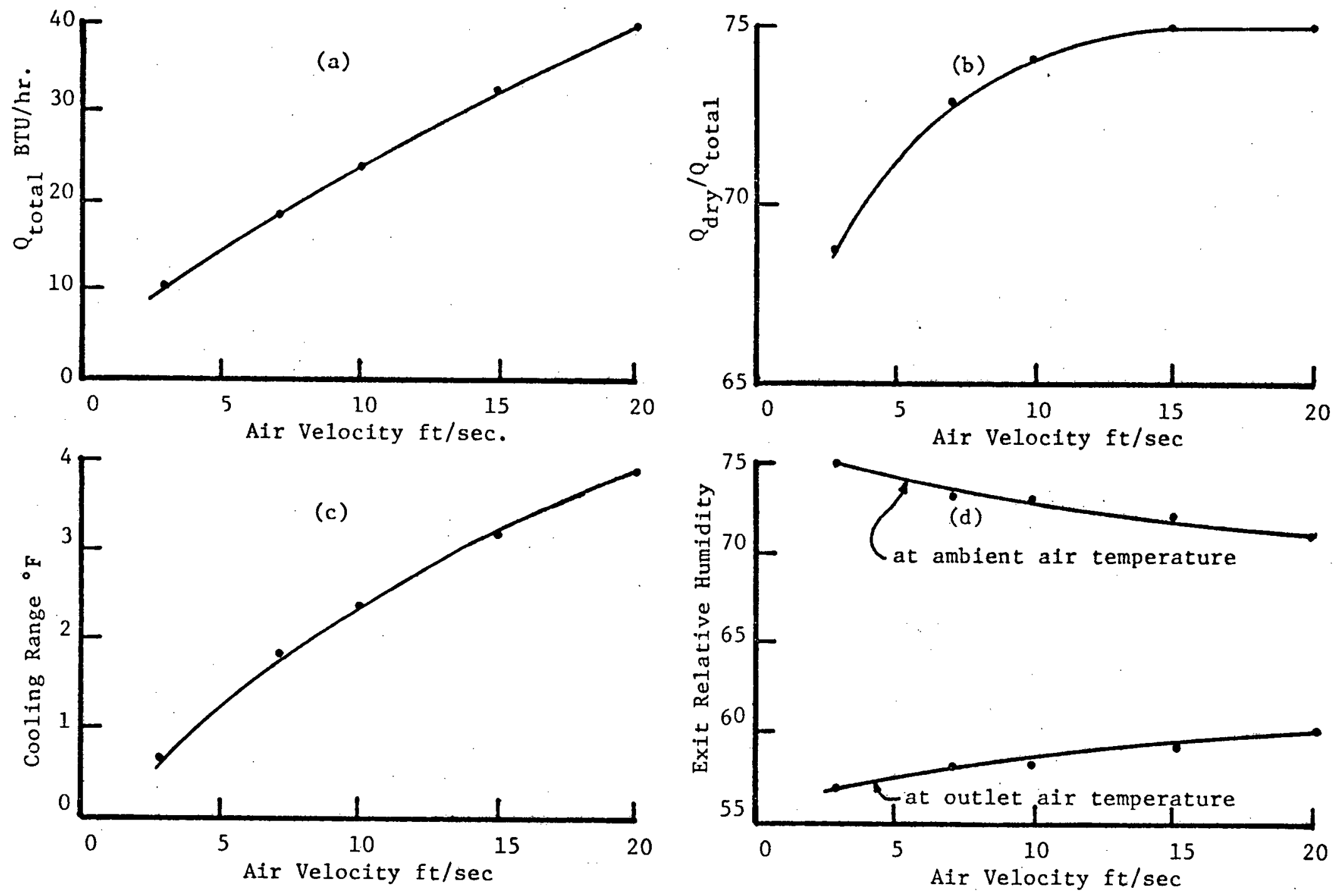

FIGURE 32: Approximate Air Velocity vs Various Parameters

a. Total Heat Transfer

b. Fraction Sensible Heat Transfer

b. Cooling Range

d. Exit Humidity 

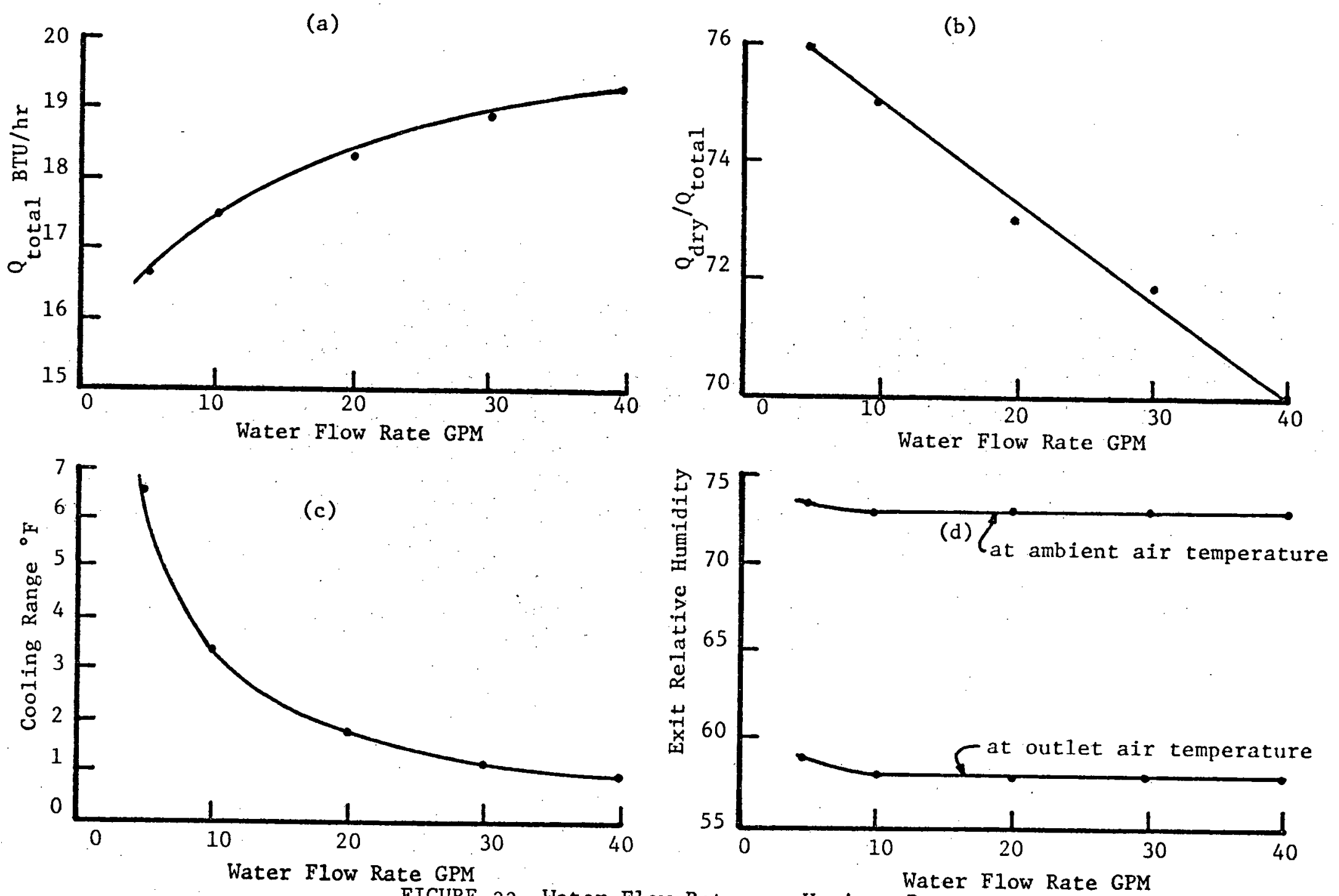

FIGURE 33: Water Flow Rate vs. Various Parameters

a. Total Heat Transfer b. Fraction Sensible Heat Transfer

c. Cooling Range d. Exit Humidity 
TABLE 4 Parameteric Study of A Dry Cooling Tower with Various Air Inlet Conditions

Inlet Air Temperature ${ }^{\circ} \mathrm{F}$

Inlet Air Humidity

Total Heat Transfer BTU/hr

Percent Sensible Heat Transfer BTU/hr

Cooling Range ${ }^{\circ} \mathrm{F}$

Outlet Humidity at Outlet Air Temperature

Outlet Humidity at Amblent Air Temperature

\begin{tabular}{|l|l|l|l|l|l|l|l}
\multicolumn{2}{|c|}{40} & \multicolumn{2}{|c|}{60} & \multicolumn{2}{c|}{80} & \multicolumn{2}{c|}{100} \\
\hline 30 & 90 & 30 & 90 & 30 & 90 & 30 & 60 \\
20507 & 20507 & 15485 & 15574 & 10405 & 10525 & 5253 & 5312 \\
100 & 100 & 100 & 100 & 100 & 100 & 100 & 100 \\
2.4 & 2.4 & 1.54 & 1.56 & 1.03 & 1.04 & .52 & .52 \\
20 & 59 & 22 & 68 & 25 & 75 & 28 & 55 \\
30 & 90 & 30 & 90 & 30 & 90 & 30 & 60
\end{tabular}

TABLE 5 Parametric Study of A 5\% wet Tower with Varfous Air Inlet Conditions

Inlet Air Temperatre ${ }^{\circ} \mathrm{F}$

Inlet Air Humidity

Total Heat Transfer BTU/hr

Percent Sensible Heat Transfer BTU/hr

Cooling Range ${ }^{\circ} \mathrm{F}$

Outlet Humidity at Outlet Air Temperature

Outlet Humidity at Ambient Air Temperature

\begin{tabular}{|l|l|l|l|l|l|l|l}
\multicolumn{2}{|c|}{40} & \multicolumn{2}{|c|}{60} & \multicolumn{2}{|c|}{80} & \multicolumn{2}{c|}{100} \\
\hline 30 & 90 & 30 & 90 & 30 & 90 & 30 & 60 \\
26665 & 26443 & 21409 & 20927 & 15986 & 15014 & 10315 & 9373 \\
79 & 80 & 74 & 76 & 67 & 72 & 52 & 58 \\
2.62 & 2.59 & 2.09 & 2.05 & 1.55 & 1.46 & .98 & .90 \\
27 & 65 & 24 & 71 & 29 & 77 & 29 & 56 \\
42 & 100 & 32 & 95 & 35 & 91 & 31 & 61
\end{tabular}

TABLE 6 Parametric Study of A Wet Tower with Various Air Inlet Conditions

Inlet Air Temperature ${ }^{\circ} \mathrm{F}$

Inlet Air Humidity

Total Heat Transfer BTU/hr

Percent Sensible Heat Transfer BTU/hr

Cooling Range ${ }^{\circ} \mathrm{F}$

Outlet Humidity at Outlet Air Temperature

Outlet Humidity at Ambient Air Temperature

\begin{tabular}{|l|l|l|l|l|l|l|l}
\multicolumn{2}{|c|}{40} & \multicolumn{2}{|c|}{60} & \multicolumn{2}{c|}{80} & \multicolumn{2}{c}{100} \\
\hline 30 & 90 & 30 & 90 & 30 & 90 & 30 & 60 \\
178923 & 172011 & 168350 & 153967 & 154712 & 126917 & 136342 & 110660 \\
.20 & .21 & .16 & .17 & .11 & .14 & .05 & .07 \\
16.98 & 16.33 & 15.91 & 14.58 & 14.55 & 11.03 & 12.75 & 10.33 \\
$*$ & $*$ & 97 & $*$ & 72 & $*$ & 58 & 75 \\
$*$ & $*$ & $*$ & $*$ & 100 & $*$ & 65 & 83
\end{tabular}

* Supersaturated condition. The heat transfer rates and cooling range are not true indicators of tower performance for this case. 
TABLE 7 The Effect on Performance of Multiplying the Heat Transfer Coefficient by Various Factors

$\begin{array}{ccc}\text { Factor } & \begin{array}{c}\text { Total Heat Transfer } \\ \text { BTU/hr }\end{array} & \begin{array}{c}\text { Cooling } \\ \text { Range }\end{array} \\ 1 & 18269 & 1.78 \\ 1.5 & 20985 & 2.04 \\ 2 & 23668 & 2.28 \\ 3 & 28933 & 2.77\end{array}$

TABLE 8 The Effect of Different Step Sizes on the Program Results

$\begin{array}{ccc}\begin{array}{c}\text { Step Size } \\ (\mathrm{ft})\end{array} & \begin{array}{c}\text { Total Heat Transfer } \\ \text { BTU/hr }\end{array} & \begin{array}{c}\text { Cooling } \\ \text { Range }{ }^{\circ} \mathrm{F}\end{array} \\ 0.3 & 19333 & 1.89 \\ 0.03 & 18269 & 1.78 \\ 0.003 & 17153 & 1.62\end{array}$


CHAPTER SIX

RESULTS AND CONCLUSION

\subsection{RESULTS}

The purpose of this year's work has been to develop a new dry cooling tower surface - a concept which would eliminate the excessive evaporative water loss of current wet cooling towers. The design was based on a low cost modification of existing film type packing sections. It minimized the amount of evaporation by limiting the air-water interfaclal area. The design resulted in a serles of long narrow open channels, in which the water was confined to flow, alternating with flat dry plate surface.

To determine the exact geometry of a section which would provide constant channelled flow, water wetting characteristics were studied on various plate designs. These tests were performed in a water flow visualization apparatus which was constructed to provide a constant and uniform spray of water to each test plate. The spray deviated in flow rate by less than $3 \%$ across the test section and the system provided a range of flow rates comparable to those used in conventional wet cooling towers.

Being able to control the water flow pattern so that it wets only desired areas was the important plate design criterion. Eight plate configurations were observed while in the test apparatus. Smooth non-wetting surfaces allowed the spray to form Individual rivulets and 
could be used to confine a flow. However, they would be an additional manufacturing expense, might wear off, and those with poor conductive properties would hinder heat transfer.

Roughened surfaces whether flat or gradually curved were found to wet completely. Since this surface condition was common after plates were exposed to cooling tower environments, geometric designs which would prevent water spreading were examined. Holes, ridges, and channels were formed in test plate sections. Surface tension effects on sharp edges and corners were observed and considered as possible flow diverters. Flat plates with large holes were not effective on the down stream side for maintaining channelled flow. Small ridges did not adequately divert the flow and allowed some transverse spreading. Large flow dividers did channel the flow but involved an added manufacturing process. Deep channels were effective in maintaining the channelled flow. A series of V-troughs provided a means to implement the deep channels inexpensively from a flat plate with the added feature of Initially self-distributing the sprayed water.

The simplicity of the V-trough design easily allows for varying the alr-water interfacial area to accommodate design flow rates. This is accomplished by changing the included angle of the trough and/or increasing the depth. 
To measure the effectiveness of the new design (heat transfer and evaporative rates), a heat transfer test appartus was constructed. It provided a controlled model environment similar to conventional wet cooling towers. A sample packing section of V-troughs measuring two feet by two feet by three feet was fabricated out of sheet metal to design specifications which would provide a fin efficiency of $79.6 \%$.

The heat transfer test system with the new dry surface packing section was completed. All ut1litles were connected and preliminary operational runs have been successfully made. A water recycling system provides conventional flow rates at required temperatures to the top of the test section with amblent induced draft air entering at the bottom. Mecury thermometer readings indicate a water temperature drop of $6^{\circ}$ across the test section. The water is being channelled by the V-troughs and is staying in the troughs for the entire length of each plate. Instrumentation will be required at this point to measure the amount of water lost through evaporation and also accurately determine the change In water temperature as it progresses down the plate.

\subsection{RECOMMENDATIONS}

Further instrumentation, 1.e., temperature sensing devices, humidity gauges and air flow meters will be necessary to enable the collection of performance data which can be directly compared to 
existing cooling towers. Air flow test will provide information regarding velocity distributions in the inlet section. Humidity measurements on the inlet and outlet air will indicate the amount of water loss due to evaporation, and the temperature readings will allow calculations for the packing section heat transfer efficiency. When all of this information has been correlated, the effectiveness of the improved advanced wet-dry cooling tower packing medium, V-trough, will be evaluated.

\subsection{CONCLUSION}

The V-trough design has provided a surface which exhibits the desired features of the new dry surface concept, open channelled water between fin-1ike dry surfaces. It can be fabricated at comparable cost to conventional film type packings and will reduce evaporation by limiting the air-water interfacial area. The effectiveness of this particular design to minimize water consumption while providing sufficient cooling will be determined with the future tests.

The computer program has shown that favorable heat transfer characteristics may be expected from this type of packing. The heat transfer rate will be larger than that for a dry tower, while the possibility of fog plume formation has been reduced. 


\section{REFERENCES}

1. Dynatech $R / D$ Company, A Survey of Alternate Methods for Cooling Condenser Discharge Water Large-Scale Heat Rejection Equipment, U.S. Government Printing Office, Washington, D.C., 1969.

2. Gurney, J.D., and Cotter, I.A., Cooling Towers, MaClaren and Sons LTD., London, 1966.

3. Dickey, J.B., Jr. and Eates, R.E., Managing Waste Heat with the Water Cooling Tower, Marley Company, Mission, Kansas, 1970.

4. Rohsenow, W.M., and Choi, H.Y., Heat, Mass and Momentum Transfer, Prentice-Hall, Inc., Englewood Cliffs, New Jersey, 1971.

5. Sabersky, R.H., Acosta, A.J., and Hauptmann, E.G., Fluid Flow, Second Edition, The Macmillan Company, New York, New York, 1971.

6. Baines and Peterson, "An Investigation of Flow Through Screens", Trans. ASME, Vol. 73, 1951, p. 471.

7. Shigley, J.E., Mechanical Engineering Design, McGraw-H111 Book Company, New York, 1963.

8. Marks, L. S., Standard Handbook for Mechanical Englneers, Seventh Edition, McGraw-Hill Book, New York, 1967 .

9. Kays, W.M. and London, A.L., Compact Heat Exchangers, Second Edition, McGraw-H111 Book Company, New York, 1964.

10. Yadigaroglu, G. and Pastor, E.J., "An Investigation of the Accuracy of the Merkel Equation for Evaporative Cooling Tower Calculations", AIAA Paper No. 74-756, ASME Paper No. 74-HT-59, 1974.

11. Kreith, F., Principles of Heat Transfer, Third Edition, Intext Educational Publishers, 1973.

12. Wark, K., Thermodynamics, Second Edition, McGraw-Hi11, Inc. 1971

13. ASHRAE Handbook of Fundamentals, 1972.

14. Zimmermann, 0. , and Lavine, I. Psychrometric Tables and Charts, Second Edition, Industrial Research Service, Inc. 1964. 


\section{APPENDIX 1.}

\section{Reference (6).}

The following section deals with the calculations of the volume flow rate which pertain to the design of the distribution pipe of the Flow Visualization test apparatus refer to Figure 4.

Consider only one of the jet holes, neglect friction in the one Inch pipe, three inch pipe and tank reservoir and using the steady state Bernoulli equation:

$$
\begin{aligned}
& \frac{V_{f}^{2}}{2}+\frac{P_{a}}{\rho_{w}}=\frac{V_{1}^{2}}{2}+\frac{P_{a}}{\rho_{w}}+g H \\
& P_{a}=\text { atmospheric pressure } \\
& \rho_{w}=\text { density of water } \\
& g=\text { acceleration of gravity } \\
& v_{1}=\text { Velocity of water level in reservolr, assumed to be zero }
\end{aligned}
$$

the ideal exit jet velocity, $v_{j}$, can be calculated. Due to friction through the orffice the actual exit velocity will be less than the ideal. Therefore:

$$
v_{j_{\text {act }}}=c_{v}\left(v_{j_{\text {Ideal }}}\right)=c_{v} \sqrt{2 g H}
$$

where $C_{v}$ is an experimental coefficient called the velocity coefficient and is less than one. The ideal volume flow rate is:

$$
Q_{\text {ideal }}=C_{c} A_{0} \sqrt{2 g H}
$$

where $C_{c}$ is the contraction coefficient of the area, $A_{0}$ of the 
(jet holes) exit stream and the actual volume flow rate becomes:

$$
Q_{\text {act. }}=C_{c} C_{v} A_{o} \sqrt{2 g H}
$$

The product of $\mathrm{C}_{c} \mathrm{C}_{v}$ is a maximum of 0.82 for thick walled orifices. Since $1 / 4$ inch wall plexi-glass was used for the distribution pipe, and the jet holes were assumed to be less than $1 / 8$ inch in diameter, the above value for $\mathrm{C}_{c} \mathrm{C}_{v}$ was used in the volume flow rate equation. After imposing the necessary conversion factors, the equation shown below gives the volume flow rate per hole as a function of the radius of the jet hole ( $R$ in inches) and the height of the water level above the hole ( $H$ in feet).

Volume Flow Rate Equation:

$$
\frac{\mathrm{gpm}}{\mathrm{Hole}}=(64.39) \quad \mathrm{R}^{2} \sqrt{\mathrm{H}}
$$

It was assumed that the smallest practical hole size which could be easily machined and provide unclogged water flow was 1/32 inch in diameter. To maintain structural integrity, the holes could not be placed closer together than one hole diameter. To prevent merging of starting streams, holes could not be closer than six diameters. Therefore the maximum number of 1/32 inch dlameter spray holes per foot is 75 holes. 
APPENDIX 2.

\section{PRESSURE DROP IN THE DISTRIBUTION PIPE}

If the pressure is constant down the length of the distribution pipe then the flow through each jet will be the same. This section shows the calculation of the pressure change down the length of the pipe due to friction and change in momentum. Since this quantity was small in comparison to the pressure drop across an individual jet it was concluded that the flow through all jets would be uniform as a first approximation.

Length of Pipe, L $=1 \mathrm{Ft}$.

Average Pipe Flow Rate, $Q=2 \mathrm{gpm}$

Pipe Inside diameter, $d=3$ inches

Average pipe velocity, $V=0.679 \mathrm{Ft} / \mathrm{sec}$.

Kinematic viscosity, $v=0.044 \frac{\mathrm{Ft}^{2}}{\mathrm{hr}}$, water at $60^{\circ} \mathrm{F}$

Reynolds number, $\operatorname{Re}=\frac{\mathrm{Vd}}{\mathrm{V}}=15,729$.

Friction factor, $f=0.017$

Pressure drop due to friction is

$$
\begin{aligned}
\Delta \mathrm{p}_{\mathrm{f}} & =\frac{\mathrm{L} \mathrm{v}^{2}}{\mathrm{~d}} \rho \\
\Delta \mathrm{p}_{\mathrm{f}} & =0.0306 \frac{1 \mathrm{bf}}{\mathrm{ft}^{2}}
\end{aligned}
$$


The pressure change due to the deacceleration of the pipe flow is:

$$
\begin{aligned}
\frac{\Delta \mathrm{P}_{\mathrm{m}}}{\rho} & =\frac{\mathrm{V}^{2}}{2} \\
& =0.45 \frac{1 \mathrm{bf}}{\mathrm{Ft}^{2}}
\end{aligned}
$$

Knowing the exit water jet velocity the pressure drop across the jet orifice may be calculated from the following equation:

$$
\begin{aligned}
P_{p}-P_{a} & =\rho_{w}\left(\frac{v_{j}^{2}-v_{p}^{2}}{2}\right) \\
& =116.64 \frac{1 b f}{F^{2}}
\end{aligned}
$$




\section{APPENDIX 3.}

\section{FIN EFFICIENCY CALCULATION FOR V-TROUGH PLATES}

\section{Reference (4).}

See Figure 22.

Fin Efficiency equation:

$$
n_{f}=\frac{\text { Tauh } m L}{m L}
$$

L, length of fin considered - - - I inch

$h$, convective heat transfer coefficient - - $5 \frac{B t u}{h r-f t^{2}-{ }^{\circ}}$

$k$, thermal conductivity of sheet metal $25 \frac{\mathrm{Btu}}{\mathrm{hr}-\mathrm{ft}-{ }^{\circ} \mathrm{F}}$

$z$, width of fin - - - - - $13 / 16$ inch

$t$, thickness of fin $--\cdots+--0.028$ inch

$$
\begin{aligned}
& m=\sqrt{\frac{h(z z+z t)}{k z t}} \\
& m L=0.8988 \\
& n_{f}=0.796
\end{aligned}
$$


APPENDIX 4.

CALCULATIONS OF THE TOTAL AIR FLOW PRESSURE DROP THROUGH

THE HEAT TRANSFER TEST APPARATUS

A.4.1 PRESSURE DROP ACROSS THE SCREEN INLET

VOLUME FLOW RATE OF "DRY" AIR REQUIRED

THROUGH THE PACKING SECTION - - - - - - $2000 \mathrm{cfm}$

POROSITY $=\frac{\text { OPEN FLOW AREA }}{\text { TOTAL AREA }}$

SOLIDITY RATIO = $1-$ POROSITY

TOTAL AREA OF SCREEN INLET - - - - $24 \mathrm{ft}^{2}$

SCREEN MESH - - - $\ldots \ldots$ - $\ldots$ - 40 wires/in

WIRE DIAMETER - - - - - - - 0.007 in

POROSITY $\simeq 0.44 \quad$ SOLIDITY RATO $=0.56$

FROM Reference 6, with $S=0.56$ :

$$
\frac{\Delta P}{\rho \frac{V_{0}^{2}}{2}} \simeq 2.0 \quad \text { (ROUND WIRES) }
$$

$V_{0}$ (velocity of alr going through the screen) was approximated by assuming it was some average value over the entire inlet section and then using the continuity requirement through the packing section, 1.e.,

$$
\begin{aligned}
& \rho_{0} A_{0} V_{0}=\rho_{2} A_{2} V_{2} \quad\left(\rho_{0} \simeq \rho_{2}\right) \\
& \therefore \quad v_{0}=\left(\frac{2000 \mathrm{ft}^{3}}{m i n}\right) / 24 \mathrm{ft}^{2}
\end{aligned}
$$




$$
v_{0} \simeq 1.39 \frac{\mathrm{ft}}{\mathrm{sec}}
$$

and from equation A.4.1.1:

$$
\Delta \mathrm{p}=0.00084 \text { in } \mathrm{H}_{2} \mathrm{O}
$$

\section{A.4.2 PRESSURE DROP ACROSS THE FIRST REDUCING SECTION}

Reference (4):

First assuming the most abrupt reducing section, calculate

$\mathrm{K}_{\mathrm{c}}$ from equation $(4.30 \mathrm{~b}$, ref. 4$)$

$$
\begin{gathered}
K_{c}=\left[1-\left(A_{1} / A_{o}\right)^{2}\left(C_{c}^{2} / B_{o}\right)-2 C_{c}+2\left(C_{c}^{2} / B_{1}\right.\right. \\
\left.-1+\left(\frac{A_{1}}{A_{o}}\right)\right] / C_{c}^{2}
\end{gathered}
$$

$\beta=0.5$ For a parabolic velocity distribution

$\beta=1.0$ For a uniform velocity distribution

$C_{c}$ is found from Ref. 4 after calculating the ratio $A_{1} / A_{0}$

$$
\frac{A_{1}}{A_{0}} \simeq \frac{(2)(2)}{(3)(3)} \simeq .444
$$

Therefore $c_{c}=0.63$

$$
\begin{aligned}
& \mathrm{K}_{\mathrm{c}_{\text {slug }}}=\frac{1-(0.444)^{2}\left(0.63^{2} / 1\right)-2(0.63)+2\left(0.63^{2} / 1\right)}{0.63^{2}} \\
& {[-1]+(.444)^{2}} \\
& K_{c}=0.346 \text { for slug flow } \quad K_{c} \text { sharp }=.0575 \\
& K_{c_{\text {Tapered }}}=\frac{1}{6} \mathrm{~K}_{c}
\end{aligned}
$$




$$
\begin{aligned}
& \mathrm{K}_{\mathrm{C}_{\text {Tapered }}}=.0575 \\
& \frac{P_{0}-P_{1}}{\rho_{01}}+\frac{v_{0}^{2}-v_{1}^{2}}{2}=k_{c} \frac{v_{1}^{2}}{2} \\
& V_{0}=3.70 \mathrm{ft} / \mathrm{sec} \\
& v_{1}=8.333 \mathrm{ft} / \mathrm{sec} \\
& \rho_{01}=0.7631 \mathrm{bm} / \mathrm{ft}^{3} \\
& \Delta \mathrm{P}_{2}=0.0132 \text { in } \mathrm{H}_{2} \mathrm{O}
\end{aligned}
$$

\section{A.4.3 PRESSURE DROP ACROSS SCREEN MESH HOLDING STRAW FLOW STRAIGHTENERS}

Same procedure as in Appendix 4.1 but for different air velocities and wire sizes.

$$
\begin{aligned}
& \text { MESH }-\cdots-\cdots+-16 \text { wire } / \mathrm{in} \\
& \text { WIRE DIAMETER }--0.011 \text { in } \\
& \text { POROSITY }-0.321 \text {, SOLIDITY RATIO }=0.679 \\
& V_{0}=8.33 \mathrm{ft} / \mathrm{sec}
\end{aligned}
$$

From Ref. 6

$$
\begin{aligned}
& \frac{\Delta \mathrm{P}}{\frac{1}{2} \rho \mathrm{V}_{0}^{2}} \simeq 5.1 \\
& \Delta \mathrm{P}=0.0032 \text { in } \mathrm{H}_{2} \mathrm{O}
\end{aligned}
$$




\section{A.4.4 PRESSURE DROP THROUGH THE STRAW FLOW STRAIGHTENERS}

To find the average velocity through the straw section, the continuity equation was used with a reduced flow area which was calculated.

The inlet area was $2 \mathrm{ft} \times 2 \mathrm{ft}$ but the section was reduced in area by all the straw walls. The 6 in. straws were $1 / 4$ diameter with a wall thickness of 0.006 inches

$$
\frac{16 \text { straw }}{\text { in. }}+16 \times \pi\left(\frac{1}{4}\right) \times 0.006=0.075 \mathrm{in}^{2}
$$

Solid area of straw walls $=0.075 \mathrm{in}^{2}$ per square inch of flow straightening section. Therefore for the entire $4 \mathrm{ft}^{2}$ section there would be:

$$
\frac{0.075 \mathrm{in}^{2}}{1 \mathrm{in}^{2}} \times 24^{2} \mathrm{in}^{2}=43.42 \mathrm{ln}^{2} \text { solid }
$$

Cross-sectional area of the flow straightening section is $A_{1}=576 \mathrm{in}^{2}$ Reduced flow area becomes $(576-43.42) \mathrm{in}^{2}$. Average velocity of air through each straw 1s:

$$
\begin{aligned}
& V_{2}=\frac{A_{1}}{A_{2}} \quad V_{1}=\left(\frac{576}{576-43.42}\right) 8.33 \\
& V_{2}=9.009 \mathrm{ft} / \mathrm{sec} \\
& \operatorname{Re}_{d}=\frac{V d}{\nu} \\
& \nu=0.56 \mathrm{ft}^{2} / \mathrm{hr} \text { at } 60^{\circ} \mathrm{F} \\
& \operatorname{Re}_{d}=1207
\end{aligned}
$$


Friction coefficient for the pipe flow is (5):

$$
\begin{aligned}
\mathrm{f} & =0.056 \\
\Delta \mathrm{p} & =0.0248 \text { in. } \mathrm{H}_{2} \mathrm{O}
\end{aligned}
$$


A.4.5 PRESSURE DROP ACROSS THE WATER COLLECTING CHANNELS

Reference (9):

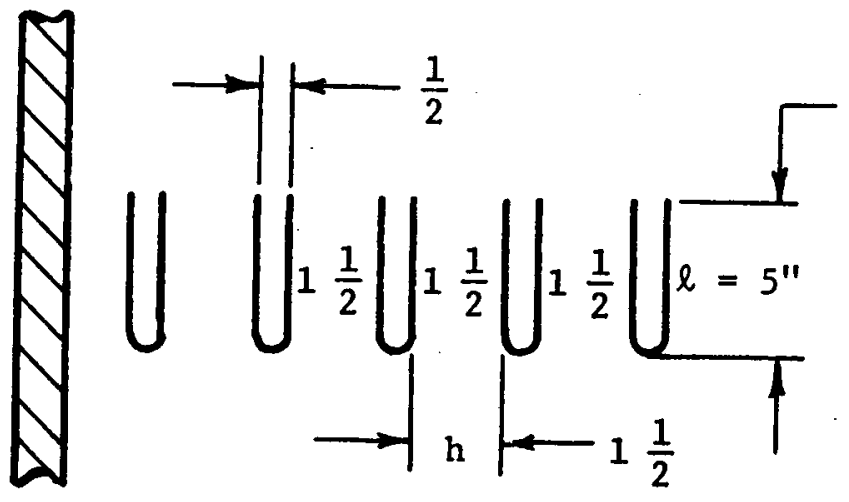

FIGURE 34. Drain Off Channel Configuration for Pressure Drop Analysis (15 channels)

$$
\Delta p=12 \frac{\mu l}{h^{2}} v
$$

Frontal Area - . - $180 \mathrm{in}^{2}$

$$
\begin{aligned}
& V=12.1 \mathrm{ft} / \mathrm{sec} \\
& \mu=0.043 \frac{1 \mathrm{bm}}{\mathrm{hr} . \mathrm{ft}}
\end{aligned}
$$

$$
\therefore \Delta \mathrm{p}=0.00062 \text { in. } \mathrm{H}_{2} \mathrm{O}
$$




\section{A.4.6 PRESSURE DROP ACROSS THE PACKING TEST SECTION}

Reference (5).

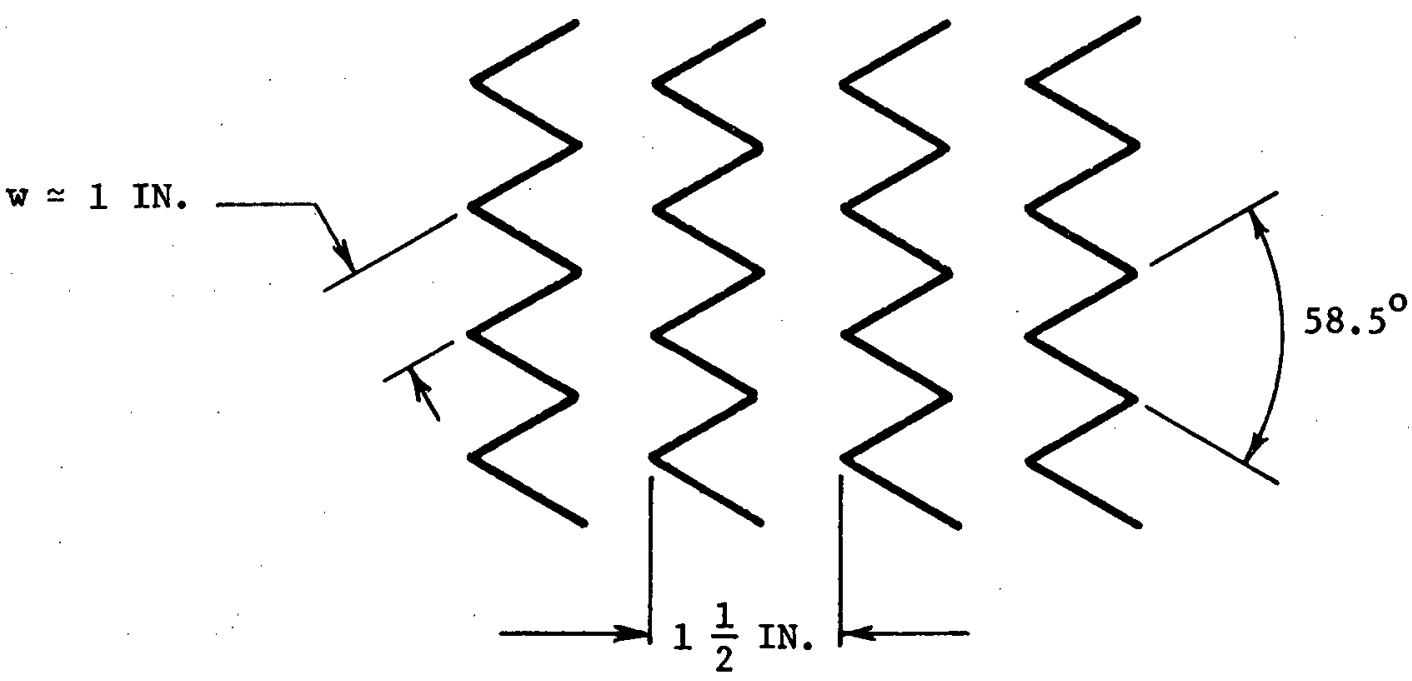

FIGURE 35. PARTIAL END VIEW OF PACKING TEST SECTION FOR PRESSURE DROP ANALYSIS

FLOW BETWEEN ANY TWO PLATES - - - - - $125 \mathrm{cfm}$

FLOW AREA BETWEEN PLATES - - - - - $42 \mathrm{in}^{2}$

AVERAGE VELOCITY - $-\ldots \ldots$ - $-\ldots 15 \mathrm{ft} / \mathrm{sec}$

Reynold Number $=\underline{v_{\text {ave }} w}=3830.3$

$v$

Effective diameter $=d_{e}=4 \frac{(1+1.75)}{2+3.50}=1.273$ in.

Material galvanized steel $: \frac{e_{s}}{d}=0.005$ 
From Reference (5):

$$
f=0.05=h_{f} \frac{1}{\frac{l}{d} \frac{v^{2}}{2 g}}
$$

where:

$$
\begin{aligned}
& \frac{\Delta \mathrm{P}}{\rho \mathrm{g}}=\mathrm{h}_{\mathrm{f}} \\
& \frac{\Delta \mathrm{P}}{\rho \mathrm{g}}=1.12 \mathrm{ft} \\
& \Delta \mathrm{p}=0.016 .4 \text { in. } \mathrm{H}_{2} 0
\end{aligned}
$$

\section{A.4.7 PRESSURE DROP ACROSS THE DRIFT ELIMINATOR}

Referring to Reference (2).

The largest pressure drop for a conventional drift eliminator is 3.1 velocity heads. For the heat transfer test apparatus this becomes:

$$
\Delta \mathrm{p}=(3.1) \rho \frac{\mathrm{v}^{2}}{2}
$$

With the velocity through the 2 foot by 2 foot section being $8.33 \mathrm{ft} / \mathrm{sec}$ and $\rho=0.07631 \mathrm{bm} / \mathrm{ft}^{3}$

$$
\Delta p=0.05 \text { in. } H_{2} 0
$$




\section{A.4.8 PRESSURE DROP THROUGH THE EXHAUST DUCT ELBOW \\ Reference (8).}

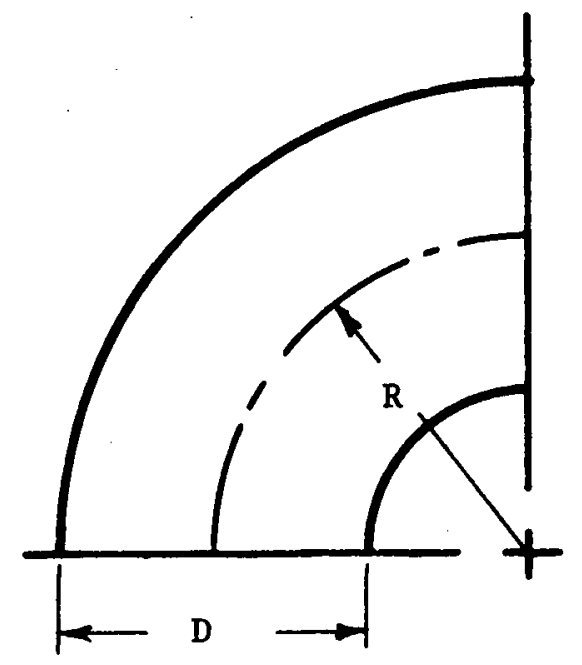

$\mathrm{R}=24 \mathrm{IN}$.

$\mathrm{D}=14 \mathrm{IN}$.

FIGURE 36. ELBOW EXHAUST DUCT DETAIL

$$
\begin{aligned}
& \frac{R}{D}=\frac{3}{2} \\
& V=\frac{Q_{\text {Tower }}}{A_{\text {duct }}} \\
& V=1871 \mathrm{ft} / \mathrm{min}
\end{aligned}
$$

From Reference (8) a ratio $\left(\frac{R}{D}\right)$ of $\frac{3}{2}$ implies an equivalent length of duct equal to 12 diameters of straight pipe with:

.35 in. $\mathrm{H}_{2} \mathrm{O}$ drop for $100 \mathrm{ft}$ of straight pipe $\Delta \mathrm{p}=0.042$ in. $\mathrm{H}_{2} \mathrm{O}$ 


\section{A.4.9 PRESSURE DROP IN ACCELERATING THE AIR FROM REST TO THE}

EXHAUST VELOCITY OF $31.2 \mathrm{ft} / \mathrm{sec}$.

Reference (5) steady state Bernoulli equation:

$$
\begin{aligned}
& \frac{P_{1}}{\rho}+\frac{v_{1}{ }^{2}}{2}=\frac{P_{2}}{\rho}+\frac{v_{2}}{2} \\
& v_{1}=0 \\
& \frac{P_{1}-P_{2}}{\rho}=\frac{v_{2}^{2}}{2} \\
& P_{1}-P_{2}=\rho \frac{v_{2}^{2}}{2}=0.22 \text { in. } H_{2} 0
\end{aligned}
$$

* Temporarily assuming $\rho$ is a constant. 
APPENDIX 5.

PLUMBING SYSTEM COMPONENTS FOR THE HEAT TRANSFER TEST APPARATUS

See Figure 33. below.

1. Water Flow Rate Regulating Valves

2. Rotometers

3. Feeder Tanks for Distribution Pipes

4. Packing Section

5. Water Collection Drain

6. Spil1 Pan

7. Water Collection Tanks

8. Recirculating Pump

9. Pressure Gage

10. By-Pass Valve

11. Water Filter

12. Main Shut Down Valve

13. Steam-Water Heat Exchanger

14. Steam Pressure Gage

15. Steam Pressure Reducing Valve 


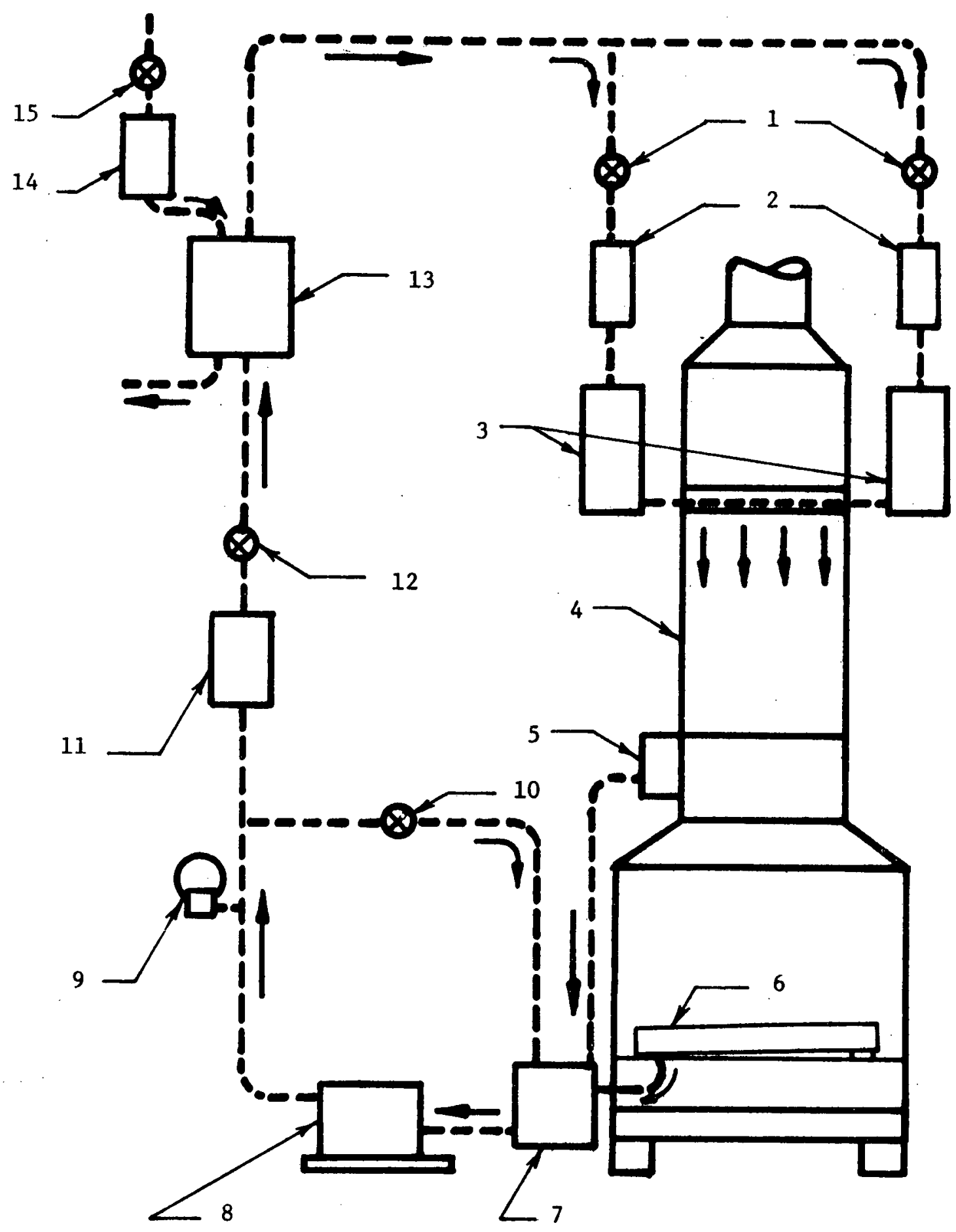

FIGURE 37. PLUMBING SCHEMATIC OF HEAT TRANSFER TEST APPARATUS 


\section{APPENDIX 6.}

\section{COMPUTER LISTING}

REAL K,KF,L,MA,MIIA, MUL, UV, NG,NHL, NIJ, ML., 'LIN, MLOUT

DIMENSTO: RT TOOP, RMLISTAI

$\Rightarrow \quad N A M E L I S T, M A, M L I N, K, T L I V, T Y N, W I N, D L, B, T O, L, N P L, S P, T H E T A, T F, K P$, * RATTO,NG, PACKWI 


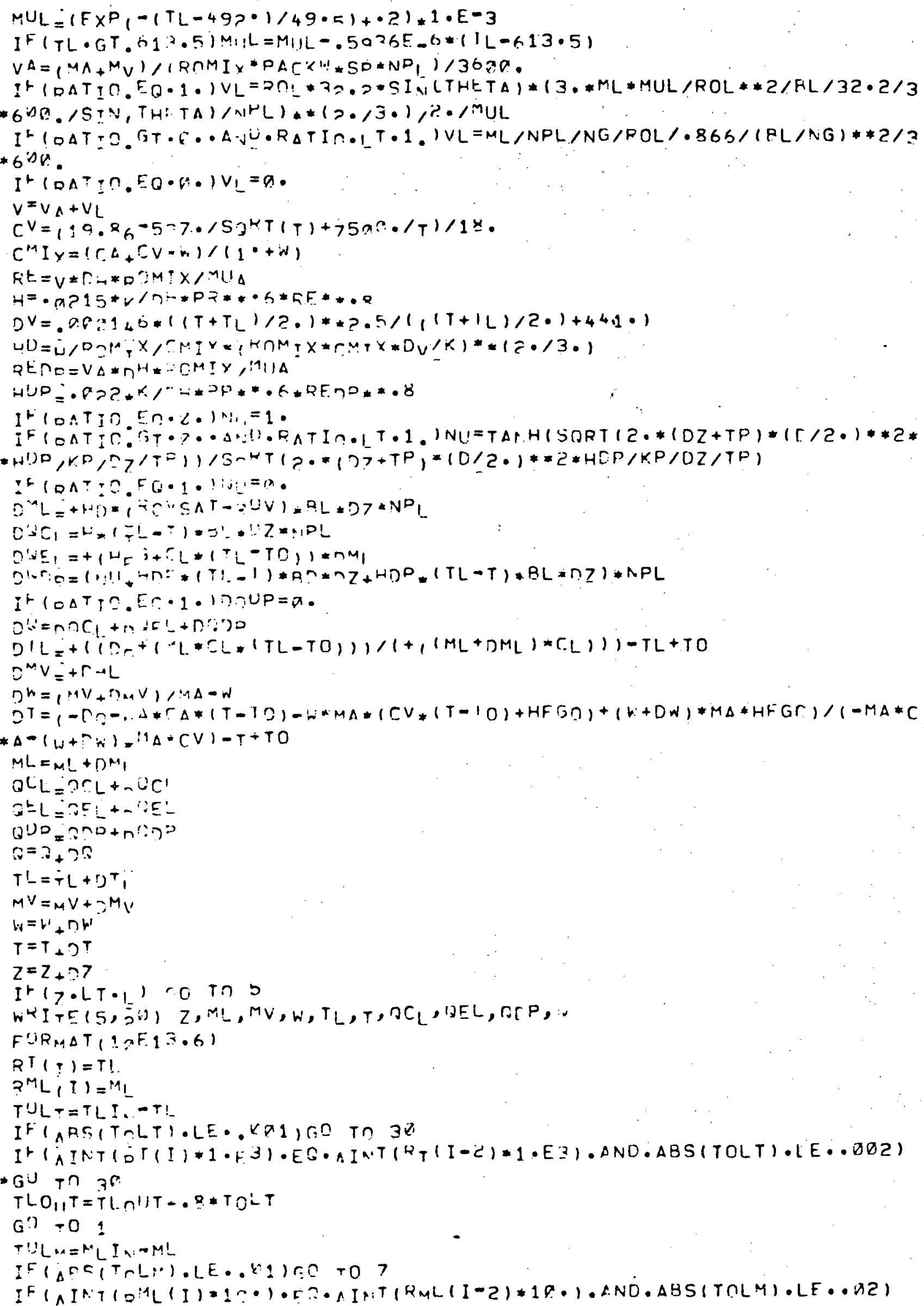


* GO †ि 7

$M I O_{1}, T=M L n ! J T+.8 * T \cap L M$

GU in

so CONTINIIE SIOO

EvD 


\section{List of Variables}

B

BD

BL

CA

CL

CMIX

CV

D

$\mathrm{DH}$

DMI

DMV

DQ

DQCL

DQDP

DQEL

DT

DTL

DV

DW

DZ

H

HD
Total Surface Area of a Plate Per Foot of Height

Total Width of Dry Portion of a Plate

Total Width of Wet Portion of a Plate

Specific Heat at Constant Pressure for Air

Specific Heat at Constant Pressure for Liquid Water

Specific Heat at Constant Pressure for Air and Water Mixture

Specific Heat at Constant Pressure for Water Vapor

Distance Between Water Channels in the Packing

Hydraulic Diameter of the Space Between Packing Plates

Change in Water Flow Rate

Change in Vapor Flow Rate

Change in Heat Transfer Rate

Change in Convective Heat Transfer from Water Surface

Change in Convective Heat Transfer from Dry Surface

Change in Evaporative lleat Transfer

Change in Air-Vapor Temperature

Change in Water Temperature

Diffusion Coefficient for Water Vapor in Air

Change in Absolute Humidity

Change in Distance through the Packing

Convective Heat Transfer Coefficient from Liquid Water to Air

Mass Transfer Coefficient for Water in Air $f t$.

ft.

ft.

$\mathrm{BTU} / 1 \mathrm{bm}{ }^{\circ} \mathrm{R}$

$\mathrm{BTU} / 1 \mathrm{bm}{ }^{\circ} \mathrm{R}$

$\mathrm{BTU} / 1 \mathrm{bm}{ }^{\circ} \mathrm{R}$

$\mathrm{BTU} / 1 \mathrm{bm}{ }^{\circ} \mathrm{R}$

ft.

$f t$.

$1 \mathrm{bm} / \mathrm{hr}$.

$1 \mathrm{bm} / \mathrm{hr}$.

$\mathrm{BTU} / \mathrm{hr}$.

${ }^{\circ} \mathrm{R}$

${ }^{\circ} \mathrm{R}$

$\mathrm{BTU} / \mathrm{Hr}$.

${ }^{\circ} R$
${ }^{\circ} R$
$f t / h r$.
$1 b m / 1 b m$
$f t$.
$B T U / h r . f t^{2}{ }^{2} \mathrm{R}$.
$\mathrm{ft} / \mathrm{hr}$.




\begin{tabular}{|c|c|c|}
\hline HDP & $\begin{array}{l}\text { Convective Heat Transfer Coefficient from Dry } \\
\text { Surface to Air }\end{array}$ & $\mathrm{BTU} / \mathrm{hr}, \mathrm{ft}^{2}{ }^{\circ} \mathrm{R}$ \\
\hline HFG & Heat of Vaporization for Water & $\mathrm{BTU} / 1 \mathrm{bm}$ \\
\hline HFGO & Heat of Vaporization for Water at TO & $\mathrm{BTU} / 1 \mathrm{bm}$ \\
\hline I & Counter for Number of Iterations & \\
\hline $\mathbf{K}$ & $\begin{array}{l}\text { Thermal Conductivity of Alr (used for Air- } \\
\text { Vapor Mixture) }\end{array}$ & $\mathrm{BTU} / \mathrm{hr}$. ft ${ }^{\circ} \mathrm{R}$ \\
\hline $\mathbf{K P}$ & Thermal Conductivity of the Plates & $\mathrm{BTU} / \mathrm{hr} . \mathrm{ft}{ }^{\circ} \mathrm{R}$ \\
\hline $\mathbf{L}$ & Total Height of Packing & ft. \\
\hline MA & Mass Flow Rate of Air & $1 \mathrm{bm} / \mathrm{hr}$. \\
\hline ML & Mass Flow Rate of Water & $1 \mathrm{bm} / \mathrm{hr}$. \\
\hline MIIN & Mass Flow Rate of Water at Inlet & $1 \mathrm{bm} / \mathrm{hr}$ \\
\hline MLOUT & Mass Flow Rate of Water at Outlet & $1 \mathrm{bm} / \mathrm{hr}$. \\
\hline MUA & $\begin{array}{l}\text { Absolute Viscosity of Air (Used for } \\
\text { Alr-Vapor Mixture) }\end{array}$ & $1 \mathrm{bm} / \mathrm{ft} . \mathrm{sec}$. \\
\hline MUL & Absolute Viscosity of Liquid Water & $1 \mathrm{bm} / \mathrm{ft} . \mathrm{sec}$ \\
\hline MV & Mass Flow Rate of Vapor & $1 \mathrm{bm} / \mathrm{hr}$ \\
\hline NG & Number of Channels on Each Packing Plate & \\
\hline NPL & Number of Plates in the Packing & \\
\hline NU & Fin Efficiency Between the Channels & \\
\hline $\mathbf{P}$ & Total Pressure of the Air-Vapor Mixture & $1 \mathrm{bf} / \mathrm{ft} \mathrm{t}^{2}$ \\
\hline PA & Partial Pressure of the Air & $1 \mathrm{bf} / \mathrm{ft}^{2}$ \\
\hline PACKW & Actual Width of Packing & ft. \\
\hline PR & $\begin{array}{l}\text { Prandtl Number for Afr (used for Alr-Water } \\
\text { Mixture) }\end{array}$ & ! \\
\hline PV & Partial Pressure of Water Vapor & $1 \mathrm{bf} / \mathrm{ft}^{2}$ \\
\hline PVSAT & Partial Pressure of Water Vapor at Saturation & $1 \mathrm{bf} / \mathrm{ft} \mathrm{t}^{2}$ \\
\hline$Q$ & Total Heat Transfer Rate & $\mathrm{BTU} / \mathrm{hr}$ \\
\hline
\end{tabular}


QCL Convective Heat Transfer from Water Surface

$\mathrm{BTU} / \mathrm{hr}$,

QDP Convective Heat Transfer from Dry Surface

$\mathrm{BTT} / \mathrm{hr}$.

QEL Evaporative Heat Transfer

BTU/hr .

RA Gas Constant for Air

ft. $1 b f / 1 b m{ }^{\circ} R$

RATIO Fraction of Packing Surface Which is Wet

RE Reynold's Number for Air Over Water With Counter F1ow

REDP Reynold's Number for Air Over Dry Surface

RML Array which Records the Values of ML After

Each Iteration

ROA Density of Air

RDL Density of Water

$1 \mathrm{bm} / \mathrm{ft}^{3}$

ROMIX Density of Air-Vapor Mixture

$1 \mathrm{bm} / \mathrm{ft}^{3}$

ROV Density of Water Vapor

$1 \mathrm{bm} / \mathrm{ft} \mathrm{t}^{3}$

ROVSAT Density of Water Vapor at Saturation

$1 \mathrm{bm} / \mathrm{ft}^{3}$

RT

Array which Records the Values of TL After

Each Iteration

RV Gas Constant for Water Vapor

ft. $1 b f / 1 b m{ }^{\circ} R$

SP Spacing Between Packing Plates

ft.

T Temperature of Air-Vapor Mixture

${ }^{\circ} \mathrm{R}$

THETA Angle Between the Plates and Vertical

radians

TIN Temperature of Air at Inlet

${ }^{\circ} \mathbf{R}$

TI Temperature of Water

${ }^{\circ} \mathbf{R}$

TLIN Temperature of Water at Iniet

${ }^{\circ} \mathbf{R}$

ThOUT Temperature of Water at Out let

${ }^{\circ} \mathbf{R}$

To Reference Temperature

${ }^{\circ} R$

TOLM Parameter Used to Check Convergence of TL 


$\begin{array}{llc}\text { TOLT } & \text { Parameter Used to Check Convergence of ML } \\ \text { TP } & \text { Thickness of the Plates } & \mathrm{ft}, \\ \text { V } & \text { Velocity of Air Relative to Water } \\ \text { VA } & \text { Air Velocity } & \mathrm{ft} / \mathrm{sec} . \\ \text { VL } & \text { Water Velocity } / \mathrm{sec} . \\ \text { W } & \text { Absolute Humidity of the Air } & \mathrm{ft} . / \mathrm{sec} . \\ \text { WIN } & \text { Absolute Humidity of the Air at Inlet } & 1 \mathrm{bm} / 1 \mathrm{bm} \\ \text { Z } & \text { Distance from Air Inlet } & 1 \mathrm{bm} / \mathrm{lbm}\end{array}$

